\author{
Universidade de São Paulo \\ Instituto de Física
}

\title{
Múons no experimento COSINE-100: seleção dos eventos, monitoramento do detector e modulação anual
}

\section{Ricardo Laranjeira Couto Pitta}

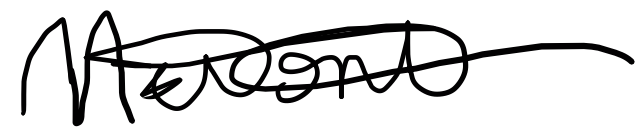

Orientador: Prof. Dr. Nelson Carlin Filho

Dissertação de mestrado apresentada ao Instituto de Física da Universidade de São Paulo, como requisito parcial para a obtenção do título de Mestre em Ciências.

Banca Examinadora:

Prof. Dr. Nelson Carlin Filho

Prof. Dra. Sandra dos Santos Padula

Prof. Dr. Sergei Anatolyevich Paschuk 
FICHA CATALOGRÁFICA

Preparada pelo Serviço de Biblioteca e Informação do Instituto de Física da Universidade de São Paulo

Pitta, Ricardo Laranjeira Couto

Múons no experimento COSINE-100: seleção dos eventos, monitoramento do detector e modulação anual. São Paulo, 2021.

Dissertação (Mestrado) - Universidade de São Paulo, Instituto de Física, Depto. de Física Nuclear.

Orientador: Prof. Dr. Nelson Carlin Filho

Área de Concentração: Física de Partículas e Campos

Unitermos: 1. Matéria escura; 2. Detector de múons; 3. COSINE-100. 
University of São Paulo

Physics Institute

\title{
Muons in the COSINE-100 experiment: events selection, detector monitoring and annual modulation
}

\author{
Ricardo Laranjeira Couto Pitta
}

Supervisor: Prof. Dr. Nelson Carlin Filho

Examining Committee:

Prof. Dr. Nelson Carlin Filho

Prof. Dra. Sandra dos Santos Padula

Prof. Dr. Sergei Anatolyevich Paschuk

Dissertation submitted to the Physics Institute of the University of São Paulo in partial fulfillment of the requirements for the degree of Master of Science. 





\section{Agradecimentos}

Agradeço por todo suporte de minha família, principalmente de minha mãe Antônia Milva que sempre me apoiou e sem a qual não estaria aqui hoje.

Agradeço ao apoio de meus amigos e colegas, professores do Instituto de Física que permitiram uma boa formação.

Agradeço ao meu orientador, Prof. Dr Nelson Carlin, por me acolher no grupo de pesquisa de matéria escura e me apoiar durante o percurso da duração do mestrado. Agradeço também aos outros participantes do grupo de pesquisa, em especial o Bruno Manzato e o Luís França, também orientados pelo Nelson Carlin, pelas discussões referentes às análises do experimento COSINE-100.

Agradeço aos colaboradores do COSINE-100, em especial ao Dr. Chang Hyon Ha e Dr. Hyun Su Lee pela confiança e recepção à colaboração, bem como a Hafizh Prihtiadi, que com muita paciência me ensinou como fazer as análises e estudos referentes aos múons do COSINE-100.

Agradeço também a todos para qual essa dissertação possa ser útil no futuro. Você que está lendo, obrigado!

Agradeço à CAPES, pelo auxílio financeiro, processo 88882.332865/2019-01, sem o qual essa dissertação não poderia ter sido realizada: O presente trabalho foi realizado com apoio da Coordenação de Aperfeiçoamento de Pessoal de Nível Superior - Brasil (CAPES) Código de Financiamento 001. 

O sonho das pessoas nunca tem fim!

Marshall D. Teach 


\section{Resumo}

Pouco se sabe sobre a natureza da matéria escura. A sua existência é conhecida devido a evidências gravitacionais e muitos modelos teóricos sugerem a existência de partículas com propriedades esperadas para as partículas de matéria escura. Há um esforço global para a detecção dessas partículas e um dos experimentos observa sinais atribuídos à modulação anual da taxa de eventos de matéria escura desde a década de 1990: o experimento DAMA/LIBRA utiliza cristais de $\mathrm{NaI}(\mathrm{Tl})$, porém, nenhum experimento observou o mesmo tipo de sinal. O COSINE-100 é um esforço conjunto dos experimentos KIMS e DM-Ice, e com o uso do mesmo material do DAMA/LIBRA, tenta reproduzir ou refutar o sinal observado. $\mathrm{O}$ experimento iniciou sua operação em 2016 no laboratório subterrâneo de Yangyang (Y2L), na Coreia do Sul. Para garantir a qualidade dos dados, os fundos provenientes de decaimentos de radionuclídeos dos materiais e eventos gerados por raios cósmicos devem ser estudados. Os múons são uma importante fonte de fundos, pois induzem eventos nos cristais na região de interesse para busca de matéria escura. Além disso, durante o ano, o fluxo de múons sofre uma modulação anual. Esse trabalho se concentra no estudo de eventos gerados por múons e por isso, essa dissertação apresenta uma breve descrição do experimento COSINE-100, em específico os painéis plásticos utilizados para detecção de múons, procedimentos do monitoramento da estabilidade desses detectores e a correção de ganho, bem como resultados do fluxo diário de múons, sua modulação anual e sua correlação com a modulação da temperatura atmosférica.

Palavras-chave: Matéria Escura; detector de múons; COSINE-100; 



\section{Abstract}

Little is known about the nature of dark matter. Its existence is well known due to gravitational evidence and many theoretical models suggest the existence of new particles with properies expected for dark matter particles. There is a global effort to detect these particles and one of the experiments observes signals attributed to the annual modulation rate of dark matter events since the 1990s: the DAMA / LIBRA, experiment uses NaI (Tl) crystals, however, no experiment has observed the same type of signal. COSINE-100 is a joint effort of the KIMS and DM-Ice experiments, and with the use of the same target material as DAMA / LIBRA, tries to reproduce or refute the observed signal. The experiment started operating in 2016 at the underground laboratory in Yangyang (Y2L), South Korea. To guarantee the quality of the data, the background signals from radionuclide decays of the materials and events generated by cosmic rays must be studied. Muons are an important source of background, as they induce events in the crystals in the region of interest to search for dark matter. In addition, during the year, the muons flux undergoes an annual modulation. This work focuses on the study of events generated by muons and, therefore, this dissertation presents a brief description of the COSINE-100 experiment, specifically the plastic panels used to detect muons, procedures for monitoring the stability of these detectors and their gain corretion, as well as results of daily muon flux, its annual modulation and its correlation with atmospheric temperature modulation.

Keywords: Dark Matter; Muons' detector; COSINE-100. 



\section{Lista de Figuras}

2.1 Curva de rotação da Galáxia NGC 6503. A linha tracejada indicada como gás representa a contribuição de poeira e gases no meio estelar. A linha tracejada do disco representa a contribuição dos componentes visíveis. A linha tracejada

Halo apresenta a curva de velocidades atribuída à matéria faltante para obtenção da linha que melhor ajusta os dados experimentais . . . . . . . . . . . 6

2.2 Modelo Padrão de partículas. . . . . . . . . . . . . . . 8

2.3 Localização aproximada dos experimentos de detecção direta de matéria escura. 12

2.4 Limites superiores para a seção de choque de interação WIMP-núcleo em fun-

\begin{tabular}{|c|}
\hline ção da massa do WIMP para diversos experimentos. É também mostrado o \\
\hline
\end{tabular}

2.5 A imagem esquematiza o vento de WIMPs ao qual o Sol e a Terra estão sujeitos,

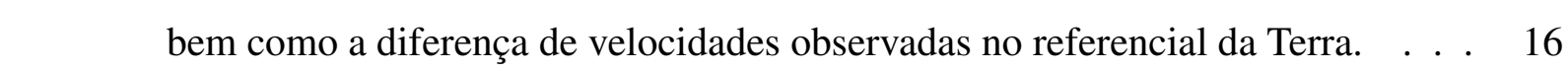

2.6 Taxa residual de eventos de cintilação únicos com energia entre 2 a $6 \mathrm{keV}$ medidos durante a fase 1 e fase 2 do experimento DAMA/LIBRA em função do tempo. A função ajustada é $A \cos \frac{2 \pi\left(t-t_{0}\right)}{T}$, onde A é a amplitude igual 0.0095(8) $\mathrm{cpd} / \mathrm{kg} / \mathrm{keV}$, T o período igual 1 ano e $t_{0}$ a fase da modulação, igual a 152.5 dias (2 de junho). . . . . . . . . . . . . . . . . . 17

2.7 Comparação entre os dados obtidos pelo DAMA/LIBRA e um modelo que

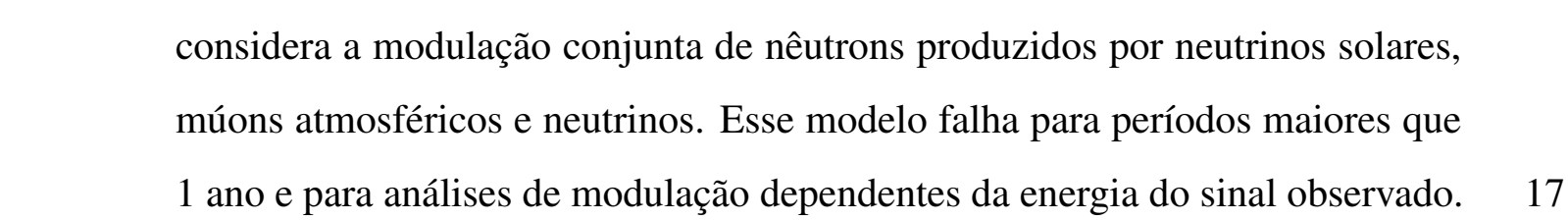

2.8 Limites de exclusão de seção de choque para interações WIMP-nucleon independentes de spin para os dados dos primeiros 59.5 dias do experimento COSINE-100. Esses limites excluem a região de sinais observados pelo DAMA/LIBRA. $\square \ldots \ldots \ldots \ldots \ldots \ldots \ldots \ldots \ldots \ldots$ 
2.9 Amplitude da modulação em função da energia para dados de 1.7 anos do COSINE-100. As barras de erro horizontais representam a largura do bin de energia usado na análise. Barras de erro verticais representam $1 \sigma$ da amplitude de modulação. Os pontos azuis e verdes representam as fases 1 e 2 do experimento DAMA/LIBRA. . . . . . . . . . . . . . . . . . . . . . . . . 19

2.10 Amplitude da modulação em função da energia para dados de 1.5 anos do ANAIS-112. As barras de erro horizontais representam a largura do bin de energia usado na análise. Barras de erro verticais representam $1 \sigma$ da amplitude de modulação. Os pontos em azul representam os dados da fase 2 do experimento DAMA/LIBRA. . . . . . . . . . . . . . . . . . . 20

3.1 Localização do laboratório Y2L . . . . . . . . . . . . . . . . 21

3.2 Componentes do experimento COSINE-100 montados. . . . . . . . . . . . . 22

3.3 Planta de Y2L, com identificação dos túneis A5 e A6. . . . . . . . . . . . . . 22

3.4 Componentes da blindagem do COSINE-100. . . . . . . . . . . . . . 23

3.5 Foto do detector com a parte frontal aberta, mostrando os componentes de seu

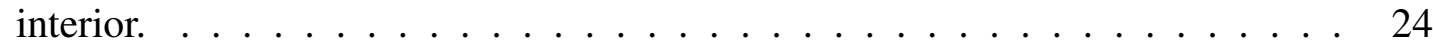

3.6 Diagrama do arranjo dos cristais. A mesa de acrílico suporta o conjunto de cristais, rotulados de C1 a C8. Os orifícios para calibração, bem como as dimensões da mesa, em mm, são indicados. . . . . . . . . . . . . . . . . . . . . 26

3.7 Foto mostrando os cristais. Cada cristal tem 2 PMTs acopladas em cada uma de suas extremidades. São encapsulados em cobre e por um filme reflexivo de politetrafluoretileno (PFTE). . . . . . . . . . . . . . . . . . 26

3.8 Configuração para obtenção da eficiência da detecção de múons pelos painéis plásticos utilizados. . . . . . . . . . . . . . . . . . . . 28

3.9 Fluxograma do COSINE-100. Os sinais das fotomultiplicadoras são enviados a dois tipos de digitizers, administrados pelo TCB. A informação digitalizada é salva no computador do DAQ. São usados 32 canais do FADC e 60 do M64ADC. A visualização e armazenamento dos dados são realizadas com o InfluxDB e Grafana. . . . . . . . . . . . . . . . . . . . . . . . . . 29 
3.10 Sequência de trigger do M64ADC. Os eventos são considerados coincidentes

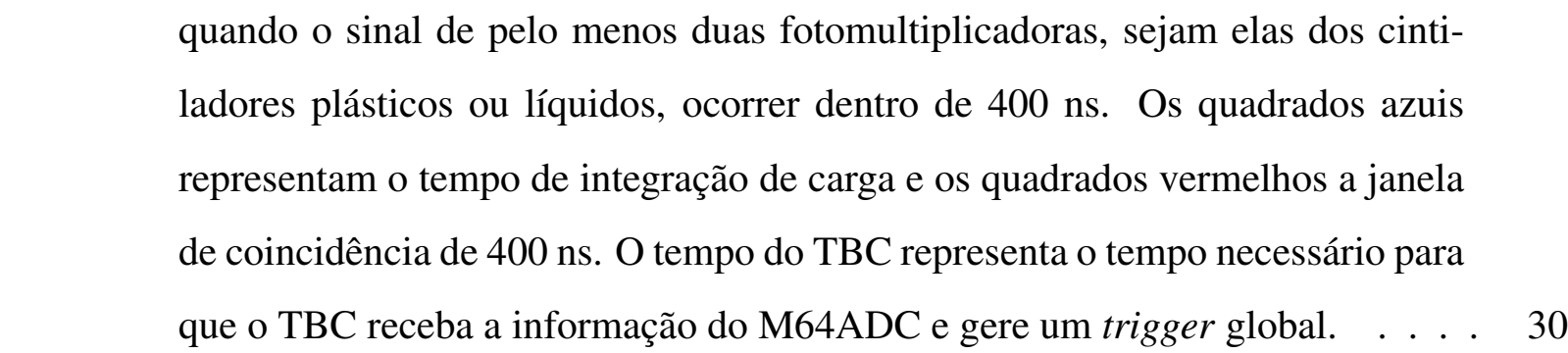

3.11 Algoritmo para gravação passiva. As caixas azuis representam o tempo de integração de carga e as caixas vermelhas a janela de coincidência de tempo de 200 ns. Em azul escuro, a representação do tempo necessário para que o TCB interprete as informações dos módulos e gere os triggers globais. Caso as condições sejam satisfeitas, todos os dados são coletados ao mesmo tempo. . . . . . . . . 32

3.12 Exemplo de visualização das variáveis monitoradas pelo Grafana. Podemos ver o status dos módulos de aquisição de dados, trigger rate dos ADCs e atual run e subrun de tomada de dados. . . . . . . . . . . . . . . . . . . . . . . . . . . 33

3.13 Exemplo de visualização das variáveis monitoradas pelo Grafana. A imagem mostra o status da temperatura em vários locais do detector, umidade, tensão de saída dos pré-amplificadores e variação da tensão e corrente das fotomultiplicadoras acoplada nos cristais. . . . . . . . . . . . . . . . . . . . 34

3.14 Exemplo de variáveis monitoradas. A referência, em vermelho, é retirada de dados validados. Em azul são apresentados os dados tomados em 2 horas. No exemplo, a energia de eventos únicos com seleção bdt nos cristais 1, 2, 3 e 4. 35

3.15 Monitoramento da taxa de eventos observada nos cristais e no sistema do M64ADC. 35

3.16 Monitoramento da carga do cintilador líquido, assimetria da carga do cintilador líquido e múons/2horas. . . . . . . . . . . . . . . . . . . . . . . . . . 36

4.1 Total de carga integrada pelos painéis do topo antes da aplicação de thresholds e triggers. Em vermelho, a carga integrada por todos os painéis do topo. Em azul, a carga integrada por apenas uma das fotomultiplicadoras do topo. . . . . 39

4.2 exemplo de múon atravessando os detectores. . . . . . . . . . . . . . . . 40

4.3 Histograma 2D dos eventos por carga no ADC para os painéis do topo (eixo Y) e painéis de baixo (eixo $\mathrm{X}) . \ldots \ldots$. . . . . . . . . . . . . 40

4.4 Espectro de carga dos painéis do topo. Em vermelho, toda carga coletada, em azul, carga referente aos múons. 
4.5 diferença de tempo de eventos simultâneos entre os painéis do topo e de baixo com carga inferior ao threshold de carga. . . . . . . . . . . . . . . . . . . 42

4.6 diferença de tempo de eventos simultâneos entre os painéis do topo e de baixo com carga superior ao threshold de carga. Em vermelho, região limitada em 5 $\sigma$ para excluir contaminação dos fundos. . . . . . . . . . . . . . . . . . 43

4.7 Comparação entre espectros de carga de uma das fotomultiplicados na tomada de dados de referência (em preto) e no período entre setembro e novembro de 2019 (vermelho), antes da correção do ganho. . . . . . . . . . . . . . . . 44

4.8 Espectro de carga de possíveis eventos de múons de uma das fotomultiplicadoras de um dos painéis do lado esquerdo com o ajuste de uma função gaussiana para obtenção do valor mais provável. O algoritmo do ROOT obtém um valor aproximado de pico, sinalizado pelo triângulo vermelho, para uso como valor inicial do ajuste da função. . . . . . . . . . . . . . . . . . . . . . . 45

4.9 Espectro de carga de possíveis eventos de múons de uma das fotomultiplicadoras de um dos painéis do topo com o ajuste de uma função Landau para obtenção do valor mais provável. O algoritmo do ROOT obtém um valor aproximado de

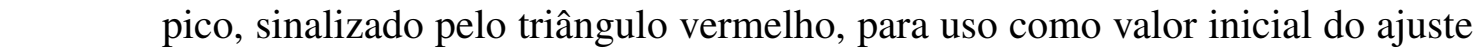
da função. . . . . . . . . . . . . . . . . . . . . . 45

4.10 Exemplo de evolução temporal do valor mais provável da carga para uma das fotomultiplicadoras estudadas. Acima, valores sem a correção de ganho e abaixo, valores obtidos após a aplicação do fator de correção de ganho. As linhas apresentam o ajuste linear aplicado ao valor mais provável. As linhas vermelhas apresentam o valor mais provável da carga dos primeiros 60 dias de aquisição de dados do COSINE-100, utilizados como referência. . . . . . . . . . . . . . 46

4.11 Comparação dos espectros de carga de uma das fotomultiplicados na tomada de dados de referência (em preto) e de Setembro a Novembro de 2019 (vermelho) após a correção do ganho.

4.12 Variação do valor mais provável do ganho das fotomultiplicadoras antes da correção de ganho. . . . . . . . . . . . . . . . . . . . . . . . 47

4.13 Variação do valor mais provável do ganho das fotomultiplicadoras depois da correção de ganho . . . . . . . . . . . . . . . . . . . . . . . . . . . . 48 
4.14 Fluxo de múons no experimento COSINE-100. Cada ponto representa um dia. A linha vermelha apresenta um ajuste linear para obtenção do fluxo médio diário de múons. Esse ajuste apresenta a qualidade de ajuste $\chi^{2} / N D F$ de $1364 / 1233 \approx 1.1$, indicando que os dados estão de acordo com o modelo pro-

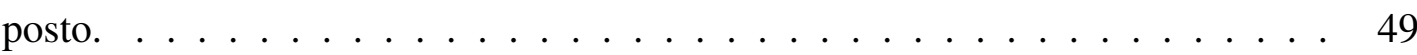

4.15 Fluxo de múons com sinais coincidentes nos painéis do topo e de baixo no experimento COSINE-100. Cada ponto representa a contagem média de múons diários para 4 dias. A linha vermelha apresenta o ajuste à modulação. . . . . . 51

4.16 Em vermelho, o valor médio da temperatura para cada altitude/nível de pressão atmosférica. Em azul, as ponderações normalizadas $W_{\pi}+W_{\kappa}$ utilizadas para determinação da temperatura efetiva. . . . . . . . . . . . . . . . 55

4.17 Temperatura efetiva da atmosfera acima do laboratório Y2L no período de 23 de \begin{tabular}{|c|c|c|}
\hline setembro de 2016 a 22 de setembro de 2020 calculada com a equação & 4.6 . Cada
\end{tabular} ponto apresenta a temperatura média de 4 dias. A linha vermelha apresenta a função ajustada. . . . . . . . . . . . . . . . . . 56

$4.18 \Delta I_{\mu} / I_{\mu}^{0}$ por $\Delta T_{e f f} / T_{e f f}^{0}$. Cada um dos pontos representa os dados médios de 4

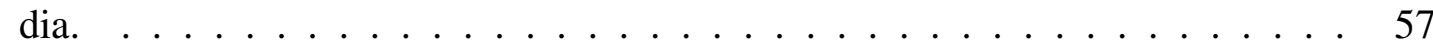

4.19 Medida de valores de $\alpha_{T}$ em função da profundidade equivalente de vários experimentos. A linha vermelha apresenta a predição teórica para produção de múons por píons e káons com razão de káons/píons listada na Tabela 4.5 | A linha preta apresenta a predição teórica no caso em que ocorre apenas decaimento de múons por píons. . . . . . . . . . . . . . . . . . . . . . . 58 


\section{Lista de Tabelas}

2.1 Comparação de resultados de amplitudes e fase entre experimentos de cristais de NaI. As duas primeiras linhas apresentam o ajuste dos dados com a fase da modulação como parâmetro livre. Os dados do COSINE-100 (Sem LS) apresentam os parâmetros obtidos sem a remoção de eventos pelo veto do cintilador líquido $(\mathrm{LS}) . \ldots \ldots \ldots \ldots \ldots$. . . . . . . . . . . . . . . . 18

3.1 Painéis plásticos do experimento COSINE-100. . . . . . . . . . . . . . . 27

4.1 Valores de carga para seleção de múons para cada painel do detector de múons e cintilador líquido. . . . . . . . . . . . . . . . . . . . . 41

4.2 Fluxo diário de múons no laboratório Y2L . . . . . . . . . . . . . . . 50

4.3 modulação de múons no laboratório Y2L. . . . . . . . . . . . . . . . . 52

4.4 Variação da amplitude de modulação e fase observada em diversos experimentos. 52

4.5 Valores dos parâmetros utilizados para determinação da temperatura efetiva $T_{\text {eff. }}$. 54

4.6 modulação da temperatura efetiva acima laboratório Y2L. . . . . . . . . . . . 56 


\section{Sumário}

\begin{tabular}{lll}
\hline 1 & Introdução & 1
\end{tabular}

2 Matéria escura - Visão geral

2.1 Deteç̧ão da matéria escura $\ldots \ldots \ldots \ldots$. . . . . . . . . . 9

2.1 .1 Detecção direta . . . . . . . . . . . . . . . . . . . 13

2.1 .2 Modulação anual . . . . . . . . . . . . . . . . . 15

\begin{tabular}{|lll}
\hline 3 & Experimento COSINE-100 & 21
\end{tabular}

3.1 Componentes do experimento $\ldots \ldots \ldots \ldots \ldots \ldots \ldots$

3.1 .1 Painéis de cintiladores plásticos . . . . . . . . . . . . 24

3.1 .2 Armação de chumbo . . . . . . . . . . . . . . . . . . . . 24

3.1 .3 Caixa de cobre . . . . . . . . . . . . . . . . 24

3.1 .4 Cintilador líquido . . . . . . . . . . . . . . . 25

$3.1 .5 \quad$ Cristais de $\mathrm{NaI}(\mathrm{Tl})$. . . . . . . . . . . . . . 25

3.2 Sistema de veto do cintilador líquido . . . . . . . . . . . . . . . 26

3.3 Detectores de múons $\ldots \ldots \ldots \ldots$. . . . . . . . . . . . . . 27

3.4 Sistema de aquisição de dados (DAQ) $\ldots \ldots \ldots \ldots$. . . . . . . . 28

$3.4 .1 \quad$ Módulos M64ADC $\ldots \ldots \ldots$. . . . . . . . . . . . . . . . . . . . . . . . . 29

3.4 .2 Módulos FADC . . . . . . . . . . . . . . . . . . . . . 30

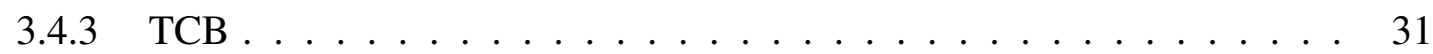

3.4 .4 Monitoramento lento . . . . . . . . . . . . . . 32

3.4 .5 Monitoramento da qualidade dos dados . . . . . . . . . . . . . . 34

4 Análise dos eventos gerados por múons

4.1 Múons . . . . . . . . . . . . . . . . . . . . . . . . . . 38

4.2 Caracterização dos sinais de múons $\ldots \ldots$. . . . . . . . . . . . . . . 39

$4.2 .1 \quad$ Correção de ganho . . . . . . . . . . . . . . . . . . . 43

4.3 Fluxo de múons . . . . . . . . . . . . . . . . . . . . . . . . . . . . . . . . 48

4.4 Modulação anual de múons e temperatura atmosférica . . . . . . . . . . . . . . 50 
5 Considerações finais 59 


\section{Capítulo 1}

\section{Introdução}

Pouco se sabe sobre a natureza da matéria escura [1,2]. A sua existência é conhecida devido a evidências gravitacionais e muitos modelos teóricos sugerem a existência de partículas com propriedades esperadas para as partículas de matéria escura.

A matéria escura, em teoria, pode ser detectada de forma direta, quando interage com o material do detector [3], de forma indireta [4], quando a interação entre partículas de matéria escura produzem partículas do modelo padrão e por meio de produção em colisores [5], onde sua presença seria observada como energia faltante nos resultados finais.

Apesar das várias formas possíveis de detecção, apenas um experimento apresentou observações positivas 1 . Esse experimento, o DAMA/LIBRA [6], utiliza detecção direta e está situado no Laboratório Nacional de Gran Sasso, Itália. Ele utiliza cristais de Iodeto de Sódio $\mathrm{NaI}(\mathrm{Tl})$ como detector principal. A detecção é baseada na interação dos cristais com o vento de WIMPs (Weakly Interacting Massive Particles). O sistema solar se move no halo de matéria escura de nossa galáxia. Devido ao movimento de translação da Terra em torno do Sol, há uma variação anual na velocidade relativa da Terra com relação ao halo de matéria escura. $\mathrm{O}$ experimento observa uma modulação no sinal do detector que seria decorrente da interação dos núcleos do cristal com WIMPs, principais candidatos a partículas de matéria escura.

DAMA/LIBRA vem reportando observação de sinais desde a década de 1990, porém, todos os outros experimentos até o momento excluem a região do sinal observado. Esses experimentos, utilizam outros materiais para detecção da matéria escura, como gases nobres (XENON1T [7]), detectores de estado sólido (CoGeNT [8]), e detectores criogênicos (CRESST [9]). Dada a divergência de resultados observados por diferentes detectores, um detector que utilize o mesmo material do DAMA/LIBRA é essencial para confirmar os seus resultados.

O experimento COSINE-100 [10], do qual nosso grupo faz parte, nasce do esforço con-

\footnotetext{
${ }^{1}$ Outros experimentos, como a primeira fase do CRESST, CoGenT e CDMS observaram sinais atribuídos a matéria escura. Atualizações nesses experimentos melhoraram a seleção de eventos e atualmente os mesmos apresentam apenas um limite superior compatível com outros experimentos
} 
junto entre as colaborações do DM-Ice e KIMS para a busca por interações de matéria escura utilizando detectores de cristais de $\mathrm{NaI}(\mathrm{Tl})$ e começou sua tomada de dados em 2016. KIMS (Korea Invisible Mass Search) foi um experimento à base de cristais de Iodeto de Césio (Csi(Tl)), localizado no laboratório subterrâneo Yangyang (Y2L), e O DM-Ice é um experimento à base de cristais de $\mathrm{NaI}(\mathrm{Tl})$ localizado no Polo Sul. A utilização do mesmo material pode ser a chave para confirmar ou refutar os resultados do DAMA/LIBRA. Os primeiros resultados do COSINE-100, publicados pela Nature [10], não apresentaram sinais atribuídos a WIMPs na região dos sinais do DAMA/LIBRA e em análises posteriores foram obtidos resultados de modulação anual que concordam tanto com o DAMA/LIBRA quanto com a hipótese nula [11]. Outro experimento também baseado em detecção com cristais de $\mathrm{NaI}(\mathrm{Tl})$, o ANAIS, também obteve resultados nulos [12]. As análises ainda estão em andamento e a tomada de dados continua.

A qualidade dos resultados observados depende do tratamento correto dos fundos presentes nos cristais. Ruídos da eletrônica, decaimentos de componentes radioativos da estrutura e eventos gerados por raios cósmicos sãos os principais fundos existentes em experimentos de busca por matéria escura.

Quando os raios cósmicos interagem com a atmosfera criam uma miríade de partículas, entre elas os múons. Os múons energéticos podem chegar aos detectores dos experimentos, bem como espalhar nêutrons e induzir outros fenômenos que produzem sinais nos detectores na região de interesse de buscas pela matéria escura. A quantidade de múons que chega aos detectores também possui uma modulação, uma vez que há uma relação entre a altura da atmosfera e as estações do ano. Hoje é sabido que apenas múons e eventos relacionados não produzem interações suficientes para explicar os resultados do DAMA/LIBRA, sendo a modulação dos múons, nêutrons e neutrinos solares uma das primeiras explicações alternativas à modulação observada [13]. Assim, o monitoramento dos detectores e estudo de eventos relacionados a múons são importantes para suprimir suas contribuições das análises.

O COSINE-100 possui 37 painéis de cintiladores plásticos distribuídos em volta dos cristais, possibilitando a detecção de múons em um ângulo sólido de $4 \pi$. Isso nos permite monitorar o fluxo diário de múons no detector, observar a modulação anual dos múons causada pela variação da temperatura da atmosfera e verificar a correlação desses dados. Os eventos classificados como múons podem ser removidos das análises dos dados dos cristais para garantir que qualquer sinal atribuído aos WIMPs observado pelo experimento COSINE-100 não ocorra 
por conta das interações com múons. Dessa forma, o monitoramento dos múons, em especial o seu fluxo diário e sua modulação anual, e a estabilidade dos detectores são essenciais para o bom funcionamento do experimento: qualquer evento atribuído à matéria escura deve ocorrer em um único sinal.

Quando o experimento registra sinais coincidentes $2^{2}$ entre um ou mais cristais e um múon classificado pelos detectores plásticos, esse evento é registrado como evento múltiplo e descartado das análises de busca por matéria escura. É nesses aspectos que o trabalho apresentado se concentra.

Essa dissertação traz uma breve introdução à matéria escura, formas de detecção, componentes do COSINE-100 e foca no detector de múons. Aqui são apresentadas as técnicas para discriminação de eventos gerados por múons, os procedimentos referentes ao monitoramento e correção do ganho das fotomultiplicadoras dos painéis plásticos do detector de múons, tarefa de responsabilidade do grupo da Universidade de São Paulo e resultados do fluxo e modulação anual de múons observados desde o inicio da tomada de dados do experimento, bem como sua correlação com a temperatura atmosférica.

\footnotetext{
${ }^{2}$ dentro do intervalo de tempo estipulado
} 


\section{Capítulo 2}

\section{Matéria escura - Visão geral}

Desde a publicação de "Philosophiae Naturalis Principia Mathematica" de Isaac Newton, as anomalias no movimento de corpos celestes poderiam indicar duas condições: a existência de um objeto não visível que interage gravitacionalmente ou a existência de falhas nas teorias utilizadas.

U. Le Verrier e John Couch Adams são um exemplo bem sucedido da primeira condição. Ao estudarem anomalias no movimento de Urano que poderiam ser explicadas por perturbações gravitacionais de outro corpo celeste, sugeriram a existência de outro planeta, que mais tarde seria descoberto e nomeado Netuno.

Já a busca pelo planeta Vulcan, que explicaria as anomalias no movimento de Mercúrio nunca foi bem sucedida. Esse é um exemplo da segunda condição, para a qual uma teoria mais abrangente e refinada da gravidade, a Relatividade Geral, foi capaz de explicar essa anomalia observada.

Nesse contexto, as principais evidências da existência de matéria escura vêm de observações astrofísicas realizadas em diversas escalas, de galáxias a todo o universo observável. Esses resultados de observações distintas apontam, de forma independente, para a existência de matéria escura.

O primeiro uso do termo Matéria Escura no sentido moderno foi usado por F. Zwicky, em 1933, quando estudava a dispersão de velocidades de galáxias no aglomerado de Coma [14].

Zwicky se utilizou do teorema do virial para determinar o limite superior da massa do aglomerado:

$$
\frac{1}{2} \sum_{i} \frac{d^{2} M_{i} r_{i}^{2}}{d t^{2}}=\sum_{i} \vec{r}_{i} \vec{F}_{i}+2 K_{i}
$$

onde $M_{i}$ é a massa de cada galáxia no aglomerado, $r_{i}$ a distância até o centro de massa da galáxia, $F_{i}$ a força que resultante em cada galáxia, $\operatorname{Vir}=\sum_{i} \vec{r}_{i} \vec{F}_{i}$ o virial do aglomerado e $K_{t}$ 
a energia cinética total do aglomerado. Considerando o aglomerado estacionário, o momento de inércia polar $\Theta=\sum_{i} M_{i} r_{i}^{2}$ varia de forma que médias temporais são constantes. Tomando o valor da média temporal de 2.1

$$
\overline{V i r}=-2 \overline{K_{T}}
$$

Considerando então o potencial gravitacional como responsável pelas interações entre as galáxias e a média temporal da energia cinética total do aglomerado, a equação (2.2) pode ser escrita como:

$$
-\bar{U}=-2 \overline{K_{T}}=\sum_{i} M_{i} \overline{v_{i}^{2}}
$$

Tomando como hipótese que a distribuição de massa do aglomerado $M_{\text {total }}$ está distribuída em uma esfera de raio $R_{t o t a l}$ de forma que que podemos escrever $U=-G_{N} \frac{3 M_{\text {total }}^{2}}{5 R_{\text {total }}} \operatorname{com} G_{N}$ a constante gravitacional de Newton e realizando uma média sobre as velocidades médias das galáxias, podemos escrever $\overline{K_{T}}$ como $\sum_{i} M_{i} \overline{v_{i}^{2}}=M_{\text {total }} \overline{\overline{v^{2}}}$,sendo $\overline{\overline{v^{2}}}$ a média das médias das velocidades ao quadrado. Sendo assim, obtemos de 2.3 .

$$
M_{\text {total }}=\frac{5 R_{t o t a l} \overline{\overline{v^{2}}}}{3 G_{N}}
$$

Realizando o cálculo para 2.4, o valor encontrado é $M_{\text {total }}>4.510^{13} M_{\odot}$, valor 500 vezes maior que o observado de resultados de observações da razão mass-to-light realizadas na época.

Outra forma convincente e direta da existência da matéria escura vem da observação das curvas de rotação de galáxias. Essa técnica consiste em observar a velocidade radial de estrelas e gases a partir do centro da galáxia. As primeiras observações de rotações de galáxia para detecção de matéria escura foram realizadas por Vera Rubin [15, 16], 40 anos depois dos primeiros estudos realizados por Zwicky.

Usando a dinâmica Newtoniana, a velocidade radial esperada é:

$$
v(r)=\sqrt{\frac{G M(r)}{r}}
$$

Onde v é a velocidade radial, M(r) distribuição de massa em função da distância $r$ do centro da galáxia e G a constante de gravitação. Seria esperado que a velocidade diminuísse conforme aumenta a distância do centro da galáxia, seguindo $\frac{1}{\sqrt{r}}$. A Figura 2.1] [17] mostra o que é 
observado de fato: as velocidades se mantêm constantes, indicando existência de matéria escura. Essa matéria escura se encontra distribuída em um halo ao redor da galáxia. O halo de matéria escura tem um papel fundamental na formação e evolução das galáxias [18] e se estende além da região visível da galáxia. O modelo padrão de halo galáctico assume que a matéria escura esteja em repouso com relação ao centro da galáxia e possua distribuição de velocidades de Maxwell-Boltzmann [19].

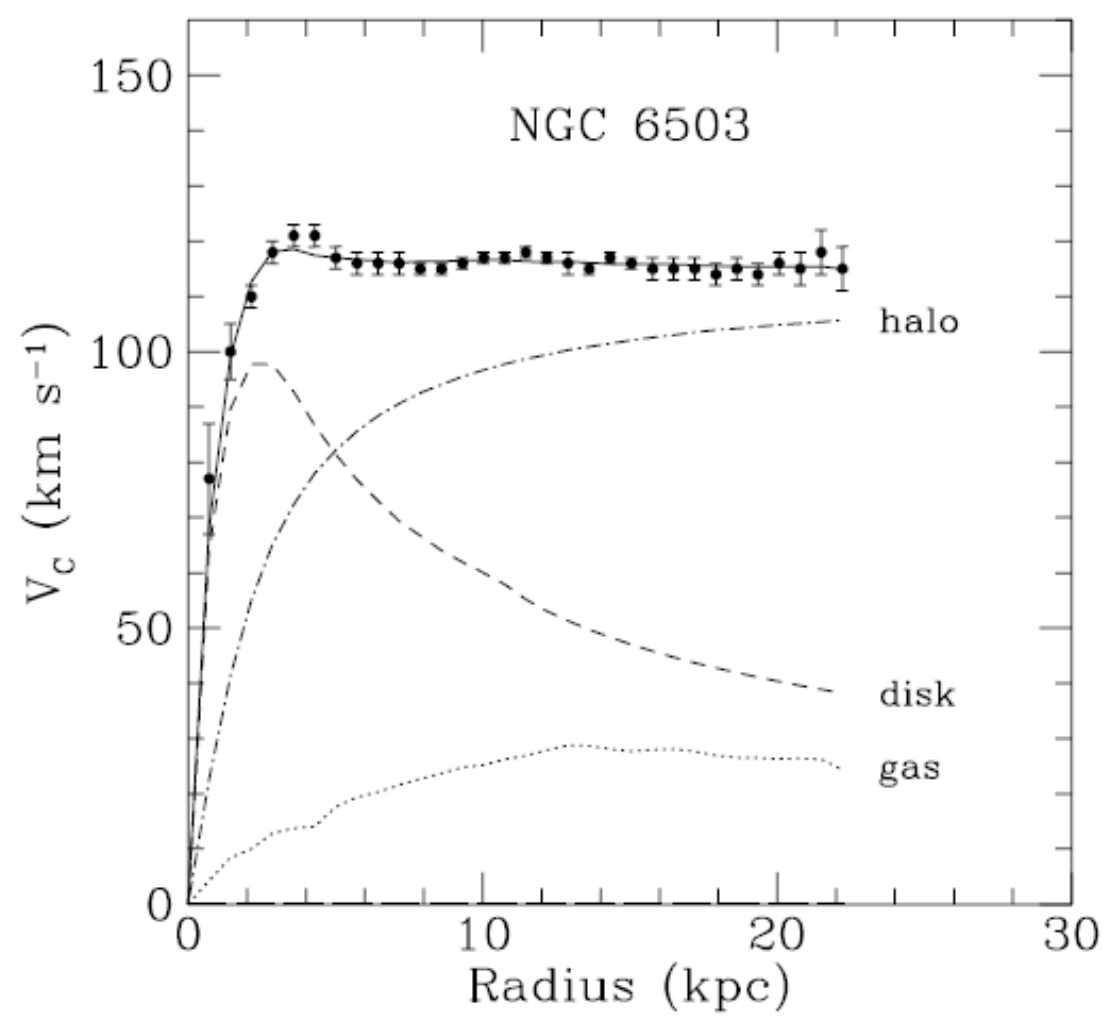

Figura 2.1: Curva de rotação da Galáxia NGC 6503. A linha tracejada indicada como gás representa a contribuição de poeira e gases no meio estelar. A linha tracejada do disco representa a contribuição dos componentes visíveis. A linha tracejada Halo apresenta a curva de velocidades atribuída à matéria faltante para obtenção da linha que melhor ajusta os dados experimentais

Outros estudos referentes a supernovas, lentes gravitacionais e o fundo cósmico de micro-ondas [20-22] confirmam a existência de matéria não luminosa, não composta por bárions ou outras partículas atualmente conhecidas. Sabe-se hoje que o universo é constituído de $4 \%$ de matéria bariônica, $23 \%$ de matéria escura e $73 \%$ de energia escura por meio do estudo da radiação cósmica de fundo, [21,23]. Sabemos também que essas quantidades variam com o tempo [24]: a expansão e resfriamento do universo alteram a fração relativa de matéria bariônica, escura e energia escura.

No início do universo, as temperaturas permitiam que a interação de partículas do mo- 
delo padrão gerassem partículas de matéria escura e vice-versa. Com a expansão do universo e as quedas de temperaturas, há um momento em que essa produção de matéria escura não ocorre mais (freeze-out). Supondo que a matéria escura é estável ou que sua meia vida seja muito grande, a abundância observada atualmente não mudou desde o processo de freeze-out.

Praticamente todas as evidências da existência de matéria escura baseiam-se em interações gravitacionais. Apenas esse aspecto não é o suficiente para se compreender a natureza da matéria escura. Sua existência é importante na astrofísica e sua compreensão é necessária para o bom entendimento da evolução do universo e da física de partículas, uma vez que pode sugerir novas partículas e interações.

O Modelo Padrão (SM, Standard Model, apresentado na Figura 2.2) é muito aceito, visto a precisão de seus resultados experimentais. Este modelo é formado por férmions: quarks (up, down, charm, strange, top, bottom), e léptons (elétrons, múons, Tau-lepton e seus respectivos neutrinos), com spin 1/2. Os férmions têm antipartículas, que possuem mesma massa e spin mas carga oposta. Quando uma partícula interage com sua antipartícula, ambas são aniquiladas e há produção de energia. As interações são mediadas por bósons de gauge que possuem spin inteiro. Os glúons são os mediadores da força forte, os fótons são mediadores da força eletromagnética e os bósons Z e W da força fraca. O bóson de Higgs é responsável pelo mecanismo que gera a massa das outras partículas. A matéria visível é constituída principalmente de bárions e léptons. Os bárions pertencem a família dos hádrons, constituídos de combinações de quarks. 


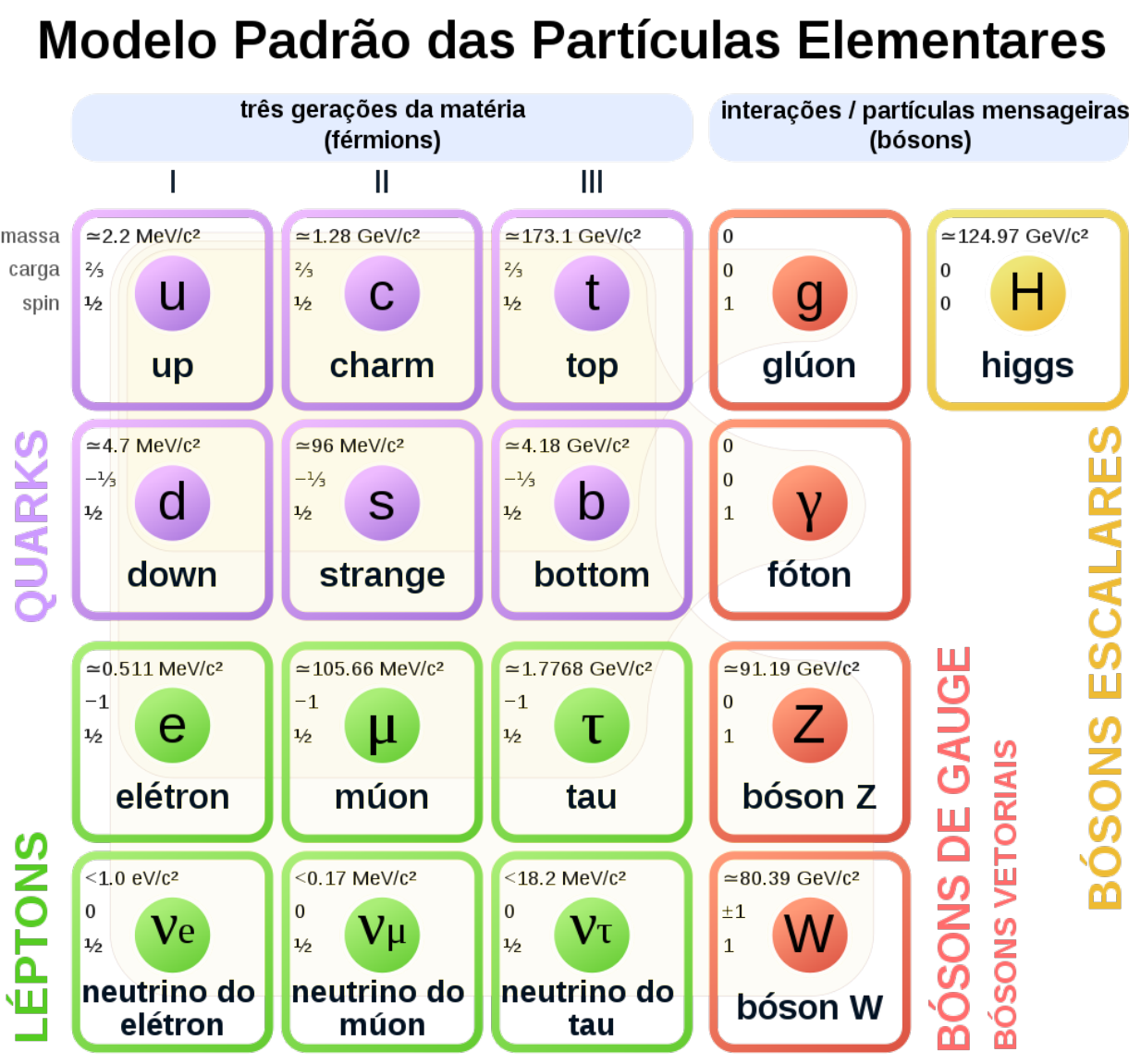

Figura 2.2: Modelo Padrão de partículas.

O Modelo Padrão ainda não é capaz de explicar algumas coisas, como matéria escura, energia escura, massa dos neutrinos e sua oscilação e assimetria na quantidade de matéria e antimatéria.

Dessa forma, os candidatos a matéria escura devem ser:

- Massivos o suficiente para explicar as anomalias gravitacionais;

- Eletromagneticamente neutros uma vez que são escuros;

- Estáveis ou com meia vida suficientemente grande para que não tenham decaído em outras partículas desde sua criaçãd] sendo compatíveis com a relíquia de densidade.

Essas condições eliminam os fótons e glúons que não possuem massa, os quarks e léptons carregados e os bósons Z, W e de Higgs, que possuem vida média curta. Os neutrinos já

\footnotetext{
${ }^{1}$ Nos momentos iniciais do universo, as altas temperaturas mantinham o equilíbrio na produção de matéria escura por interação de partículas do modelo padrão. Com a expansão e resfriamento, esse equilíbrio é quebrado impedindo a criação de mais matéria escura
} 
foram candidatos por possuírem todas características citadas, porém, eles não são abundantes o suficiente [25].

Existiram buscas por matéria escura bariônica [1]. Essa matéria bariônica poderia ser composta de objetos compactos e pouco luminosos, incluindo planetas, anãs marrons, anãs vermelhas, anãs brancas, estrelas de nêutrons, buracos negros entre outros, denominados MACHOs "Massive Astrophysical Compact Halo Objects" (Objetos massivos compactos). Há um consenso de que os MACHOs constituem uma pequena fração da matéria escura. Outros candidatos considerados foram os buracos negros primordiais [1], criados antes da nucleossíntese dos elementos. Esses objetos foram descartados como candidatos a matéria escura, pois sua taxa de formação é pequena demais para explicar a abundancia de matéria escura observada. Observações recentes realizadas pela colaboração LIGO/Virgo [26] trouxeram novamente a possibilidade da matéria escura ser constituída por buracos negros primordiais. Esses estudos ainda são inconclusivos e necessitam de mais análises.

Vários modelos teóricos que se estendem além do modelo padrão apresentam alguma partícula que possua uma ou mais características que possam ser atribuídas a matéria escura. A supersimetria (SUSY) [27] está entre os mais utilizados. Entre os candidatos mais prováveis, também se encontram os WIMPs (weakly interacting massive particles), partículas produzidas na abundância correta e passíveis de observação devido a suas interações fracas.

Mais recentemente, modelos que consideram um setor oculto (hidden sector - HS) [28] têm chamado a atenção. Os HS se caracterizam por não possuir conexão direta com o SM e interagem fracamente com o setor visível por meio de um mediador. No caso de um HS com uma simetria extra de gauge U(1), o bóson de gauge massivo, chamado de fóton oculto (HP, hidden photon) ou fóton escuro (DP, dark photon) A' , atua como mediador das interações com o SM.

Esses modelos postulam a existência de partículas com massas de $\mathrm{keV}$ a TeV. O que sempre deve ser considerado é que os parâmetros e previsões do modelo devem ser consistentes com resultados de observações astrofísicas e cosmológicas.

\subsection{Detecção da matéria escura}

Para a determinação da natureza da matéria escura, é importante considerar interações além das gravitacionais. Podemos então dividir as buscas experimentais em 3 frentes que cons- 
tituem metodologias de investigação complementares, cada uma possuindo vantagens e desvantagens:

- Detecção indireta: Sinais de aniquilação de matéria escura por neutrinos, raios $\gamma$, pósitrons ou outras partículas do SM [4]. Normalmente realizada com o uso de telescópios ou satélites. O maior problema enfrentado nesse tipo de detecção é a determinação correta da fonte emissora de sinais. Exemplo de alguns experimentos que buscam sinais indiretos de matéria escura: AMS [29] (Alpha Magnetic Spectrometer), PAMELA [30] (Payload for Matter Antimatter Exploration and Light-nuclei Astrophysics), ATIC [31] (Advanced Thin Ionization Calorimeter) e IceCube [32];

- Produção em colliders: onde a interação entre partículas do SM podem produzir matéria escura que pode ser evidenciada como energia faltante em eventos [5]. A energia faltante pode não ser observada devido aos erros sistemáticos existentes nesse tipo de experimento. Os experimentos do LHC são exemplos de busca por matéria escura em colisores.

- Detecção direta: baseada na observação de recuo de núcleos após espalhamento com partículas de matéria escura [3]. Geralmente, experimentos de detecção direta são realizados em instalações subterrâneas ou submarinas com o intuito de minimizar efeitos de fundos. A observação de sinais está diretamente ligada ao tempo de exposição dos detectores e quantidade de material do detector;

Por se tratar do método utilizado pelo COSINE-100, aqui detalharemos um pouco mais a detecção direta. Existe um esforço mundial para detecção direta de matéria escura. A Figura 2.3 mostra a localização geográfica de cada experimento citado:

- ANDES: O Laboratório ANDES [33] (Agua Negra Deep Experiment Site) será um futuro laboratório subterrâneo que abrigará experimento de detecção de matéria escura.

- ANAIS-112: O experimento ANAIS-112 [12] (Annual modulation with NaI Scintillators), consiste de $112.5 \mathrm{~kg}$ de cristais de $\mathrm{NaI}(\mathrm{Tl})$, instalado em 2017 no laboratório subterrâneo de Canfranc (LSC) na espanha.

- CDEX: Localizado no laboratório subterrâneo de Jinping, na china, o CDEX [34] (China Dark Matter Experiment) utiliza detectores de germânio encapsulados em cilindros de $\mathrm{NaI}(\mathrm{Tl})$; 
- CDMS: O experimento CDMS [35] (Cryogenic Dark Matter Search), localizado no laboratório subterrâneo de Soudan consiste em detectores de germânio. Iniciou sua tomada de dados em 2012;

- CoGenT O experimento CoGenT [8] (Coherent Germanium Neutrino Technology), localizado no laboratório subterrâneo de Soudan, Estados Unidos, iniciou operação em 2009. Consiste em um detector de cristal de Germânio;

- COSINE-100: O experimento COSINE-100 [36], localizado no laboratório subterrâneo de Yangyang, Coréia do Sul. Consiste em $106 \mathrm{~kg}$ de cristais de $\mathrm{NaI}(\mathrm{Tl})$. Iniciou sua tomada de dados em 2016;

- CRESST: O experimento CRESST [9] (Cryogenic Rare Event Search with Superconducting Thermometers), localizado no laboratório Nacional de Gran Sasso (LNGS), Itália, utiliza cristais de $\mathrm{CaWO}_{4}$ e iniciou sua tomada de dados em 2012;

- DAMIC: O experimento DAMIC [37] (Dark Matter in CCDs), localizado no SNOLAB, Canadá, utiliza CCDs de silício para detecção de matéria escura. Iniciou sua tomada de dados em 2015;

- DAMA/LIBRA: O experimento DAMA/LIBRA (DArk MAtter Large sodium Iodide Bulk for RAre processes) [38], inicialmente chamado de DAMA/NaI utiliza cristais de NaI(Tl). Localizado no Laboratório Nacional de Gran Sasso, Itália, tem observado uma modulação atribuída a detecção de matéria escura desde a década de 1990;

- DarkSide: O experimento DarkSide [39], também situado no LNGS, utiliza Argônio líquido para detecção de matéria escura. Iniciou sua operação em 2014;

- DEAP-3600: O DEAP-3600 [40] (Dark MAtter Experiment using Argon Pulse-shape discrimination), localizado no SNOLAB, Canadá, utiliza 1000 kg de Argônio líquido;

- DM-Ice: O experimento DM-Ice [41], localizado no pólo sul, consiste de 2 cristais de $\mathrm{NaI}(\mathrm{Tl})$, Iniciou sua tomada de dados em 2010. É um experimento importante, pois caso observe alguma modulação, deve observar a mesma fase que outros experimentos. Caso a fase observada se encontre defasada em $180^{\circ}$, poderíamos supor que a modulação observada ocorra devido a variações sazonais; 
- EDELWEISS: O experimento EDELWEISS [42] (Expérience pour DEtecter Les WIMPs En Site Suterrain) iniciou sua tomada de dados em 2003. Está instalado no laboratório subterrâneo de Modane, na França e utiliza detectores de germânio;

- LUX: O experimento LUX [43] (Large Underground Xenon), localizado em Lead, Dacota do Sul na instalação subterrânea de pesquisa de Sanford, utiliza 370 kg de xenônio liquido;

- NAIAD: O experimento NAIAD [44] (NaI Advanced Detector), da colaboração UK Dark Matter Collaboration, operou entre 2000 e 2003 no laboratório subterrâneo de Boulby, Reino Unido. Esse experimento utilizou um total de $46 \mathrm{~kg}$ de cristais de $\mathrm{NaI}(\mathrm{Tl})$;

- PandaX: O experimento PandaX [45] (Particle and Astrophysical Xenon Detector), também localizado no laboratório subterrâneo de Jinping, utiliza detectores de xenônio;

- SABRE: O experimento SABRE [46] (Sodium-iodide Active Background Rejection Experiment) é um experimento que englobará os esforços de detecção nos dois hemisférios do planeta: O SABRE PoP (proof-of-principle) ja está em funcionamento no LNGS enquanto que o experimento do hemisfério sul será situado no laboratório subterrâneo de Stawell em Vitoria, Austrália. Ambos detectores utilizarão $50 \mathrm{~kg}$ de cristais de $\mathrm{NaI}(\mathrm{Tl})$;

- XENON1T: O experimento XENON1T [7], localizado no laboratório nacional de Gran Sasso, Itália, consiste de um detector com 2 toneladas de Xe líquido. Iniciou sua tomada de dados em 2016;

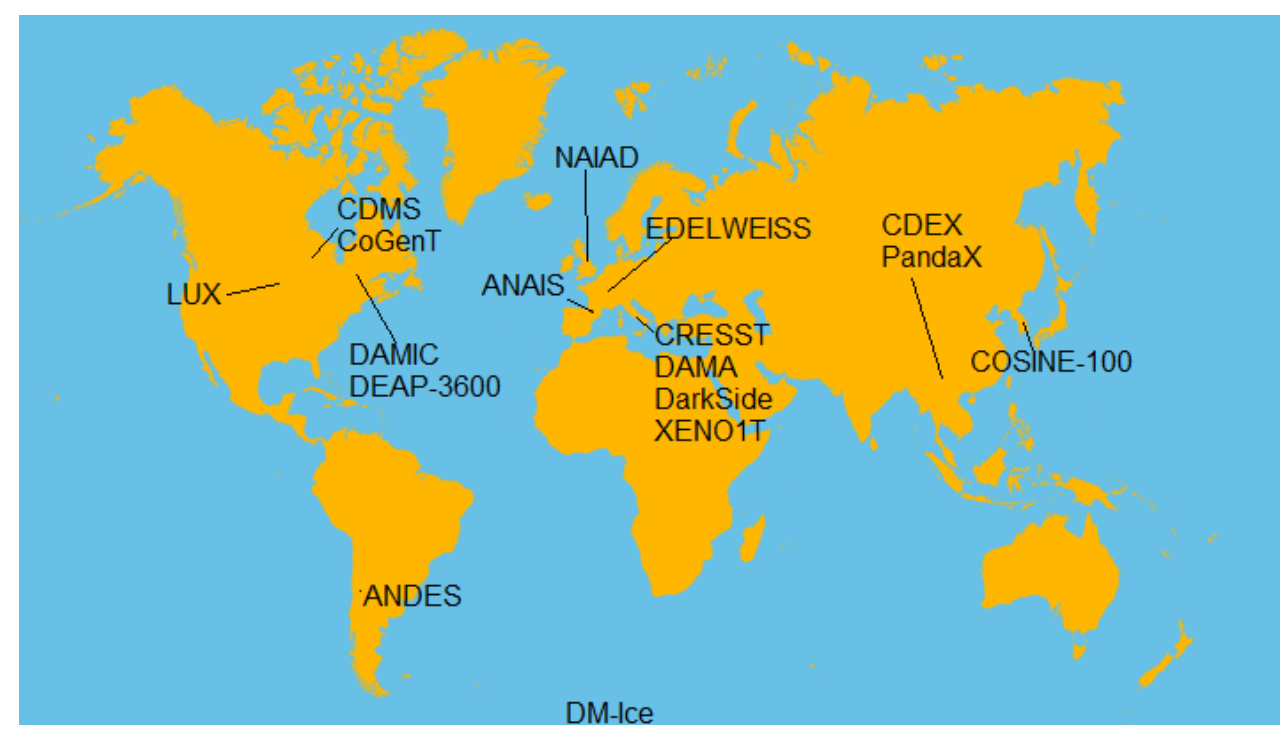

Figura 2.3: Localização aproximada dos experimentos de detecção direta de matéria escura. 


\subsubsection{Detecção direta}

O método de detecção direta consiste na observação do espalhamento de matéria escura proveniente do halo galáctico em núcleos do detector. Existem três técnicas principais de detecção direta da matéria escura utilizadas: a busca por sinais de ionização, que emprega o uso de detectores semicondutores e gases nobres, cintilação, que se utiliza de cristais inorgânicos ou gases nobres, e fônons térmicos, que se utiliza de detectores criogênicos. Experimentos modernos combinam essas técnicas para discriminar melhor os eventos selecionados.

- Detecção de fônons térmicos: Quando ocorre um recuo nuclear devido ao espalhamento de partículas, ocorre um aumento na temperatura do material alvo. Os experimentos criogênicos medem os fônons gerados desses espalhamentos, que estão relacionados a esse aumento de temperatura. Um exemplo desse tipo de detector é o experimento CDMS [47];

- Detecção de carga ionizada: A interação de partículas com materiais do detector criam pares de elétron-buraco ou elétron-íon. Campos elétricos coletam essas cargas para discriminar energia. Um exemplo de experimento que utiliza essa técnica é o CoGENT [8];

- Detecção de cintilação: A interação de partículas com o detector produz cintilação de luz. Essa luz é convertida em pulsos elétricos. É empregado, por exemplo, no experimento DAMA/LIBRA [6].

Na Figura 2.4, retirada de [48]) são mostrados os mais recentes resultados de vários experimentos em termos de limites superiores de seção de choque de interação para observação de WIMPs em função da massa do WIMP. 


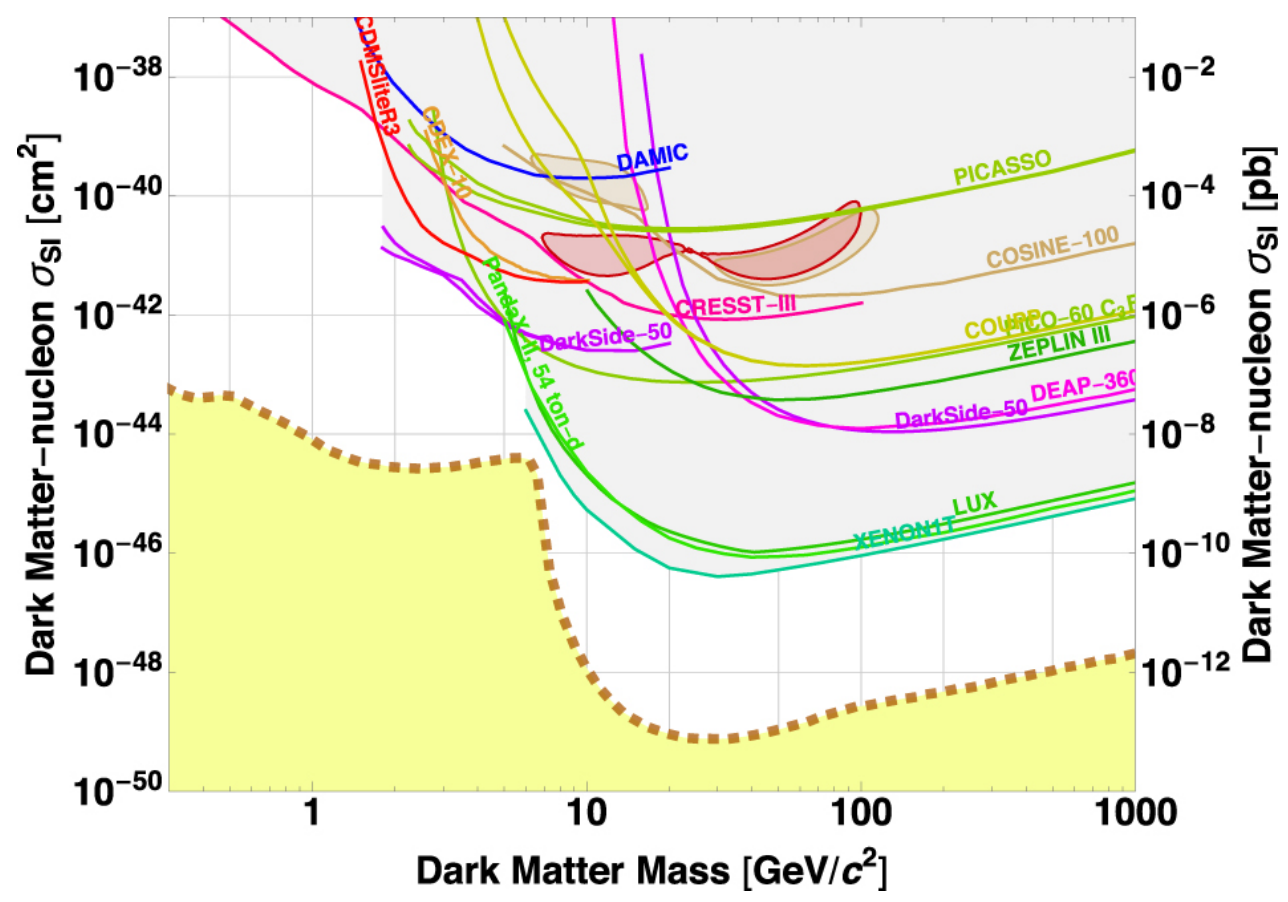

Figura 2.4: Limites superiores para a seção de choque de interação WIMP-núcleo em função da massa do WIMP para diversos experimentos. É também mostrado o limite devido ao fundo irredutível de neutrinos.

Podemos calcular a taxa diferencial do espalhamento elástico de WIMPs por núcleos usando [49]:

$$
\frac{d R}{d E_{r}}=N_{N} \frac{\rho_{0}}{m_{W}} \int_{v_{\min }}^{v_{\max }} f(v) v \frac{d \sigma}{d E_{r}}
$$

onde $N_{N}$ é o número de núcleos do alvo, $\rho_{0}$ a densidade de matéria escura no halo galático, $\mathrm{v}$ a velocidade dos WIMPs no referencial da terra, $\mathrm{f}(\mathrm{v})$ a distribuição de velocidades que segue uma distribuição de Maxwell-Boltzmann, $m_{W}$ a massa dos WIMPs e $\frac{d \sigma}{d E_{r}}$ a seção de choque diferencial por energia da interação WIMP-núcleo. Os modelos teóricos preveem que a interação entre os WIMPs pode resultar na aniquilação dos mesmos, resultando na produção de quarks. Dessa forma, podemos relacionar essa amplitude de aniquilação com a amplitude de espalhamento elástico através da crossing symmetry. Isso nos permite supor que existe uma constante de acoplamento entre a matéria escura e quarks [50], de forma que podemos calcular uma seção de choque WIMPs-núcleons. Essa seção de choque pode ser dependente ou independente da interação dos spins das partículas envolvidas, dependendo da configuração dos quarks nos núcleons que participam da interação [50-52]. A energia transferida ao núcleo em recuo é:

$$
E_{r}=\frac{P^{2}}{2 m_{N}}=\frac{m_{r}^{2} v^{2}}{m_{N}}(1-\cos \theta)
$$


onde $\theta$ é o ângulo de espalhamento no referencial do centro de massa WIMP-núcleo, P o momento transferido, $m_{N}$ a massa do núcleo e $m_{r}$ a massa reduzida do sistema WIMP-Núcleo escrita como:

$$
m_{r}=\frac{m_{N} m_{W}}{m_{N}+m_{W}}
$$

As energias de recuo dessas interações são baixas. Por exemplo, supondo WIMPs com massa igual a $100 \mathrm{GeV} / \mathrm{c}^{2}$ e velocidade média em relação ao alvo igual a $220 \mathrm{Km} / \mathrm{s}$ e usando

$$
<E_{R}>\frac{1}{2} m_{W}<v>^{2}
$$

temos uma energia transferida média da ordem de $30 \mathrm{keV}$.

A densidade local de matéria escura $\rho_{0}$ é igual a $0.3 \mathrm{GeV} / \mathrm{cm}^{2}$ de forma que seu fluxo $\phi_{0}$ na superfície da terra é de:

$$
\phi_{0}=\frac{\rho_{0}}{m_{W}}<v>=6.610^{4} \mathrm{~cm}^{-2} s^{-1}
$$

Considerando uma seção de choque de espalhamento na escala de massas eletro-fracas, $\sigma_{W N}$ da ordem de $10^{-38} \mathrm{~cm}^{2}$, podemos estimar a taxa de espalhamento elástico por:

$$
R \approx N_{N} \phi_{0} \sigma_{W N}
$$

que fornece aproximadamente 0.13 eventos $\mathrm{kg}^{-1} \mathrm{ano}^{-1}$, revelando outro desafio experimental: baixa taxa de contagem.

\subsubsection{Modulação anual}

A taxa de interação WIMP-núcleo depende da distribuição de velocidades das partículas de matéria escura em relação ao referencial do laboratório na Terra. Supondo que o halo de matéria escura tenha velocidade nula em relação ao centro da galáxia, a velocidade relativa do Sol em relação ao halo será de aproximadamente $220 \mathrm{~km} / \mathrm{s}$. Pode-se considerar que o Sol se encontra sujeito a um "vento"de WIMPs. A Terra orbita o sol com velocidade aproximada de $30 \mathrm{~km} / \mathrm{s}$, de forma que se move contra o vento de WIMPs em junho e a favor do vento em dezembro. A seção de choque de espalhamento e fluxo de partículas de matéria escura dependem da velocidade da partícula. A Figura 2.5 esquematiza como ocorre o vento de WIMPs 
[53]. Dessa forma, um detector pode observar a modulação desses valores durante o ano. Essa modulação pode ser escrita como [54]:

$$
\frac{d R}{d E_{r}}(t)=S_{0}\left(E_{R}\right)+S_{m}\left(E_{r}\right) \cos \left(\omega\left(t-t_{0}\right)\right)
$$

Onde $S_{0}$ é a taxa média de interações, $S_{m}$ a amplitude da modulação, $t_{0} \approx 152$ dias a fase, equivalendo ao dia 1 de junho, onde esperamos o máximo da modulação e $\omega=2 \pi /$ ano a frequência angular.

A modulação atribuída a WIMPS foi observada apenas pela colaboração DAMA, com os experimentos DAMA/NaI e DAMA/LIBRA.

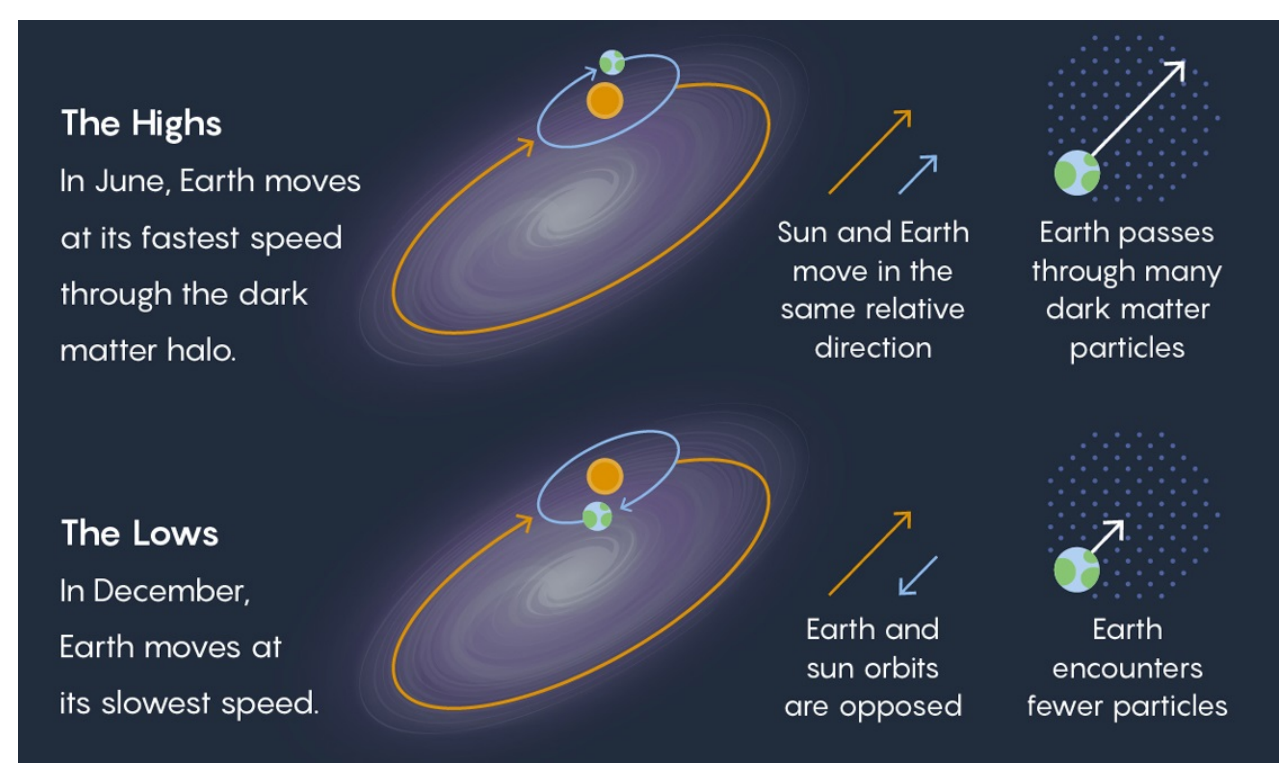

Figura 2.5: A imagem esquematiza o vento de WIMPs ao qual o Sol e a Terra estão sujeitos, bem como a diferença de velocidades observadas no referencial da Terra.

O experimento DAMA/LIBRA, continuação do DAMA/NaI fica localizado no Laboratório Nacional de Gran Sasso na Itália. A parte sensível do experimento é composta por 25 cristais de $\mathrm{NaI}(\mathrm{Tl})$, cada um com $9.7 \mathrm{~kg}$, arranjados em uma matriz de 5 colunas e 5 linhas [6]. Esse experimento sugere a existência de matéria escura pela verificação de uma modulação anual como consta na Figura 2.6[38] A amplitude é medida em $\mathrm{cpd} / \mathrm{kg} / \mathrm{keV}$ onde cpd significa contagens por dia. Essa unidade é equivalente ao dru (differential rate unit). O experimento DAMA/LIBRA já funciona há cerca de quinze anos e os resultados no momento já estão com um nível de confiança de 9,5 $\sigma$ para modulações de eventos de recuo nuclear com energia entre 1 a $6 \mathrm{keV}$ e de $12,9 \sigma$ para energia entre 2 a $6 \mathrm{keV}$ [38]. 


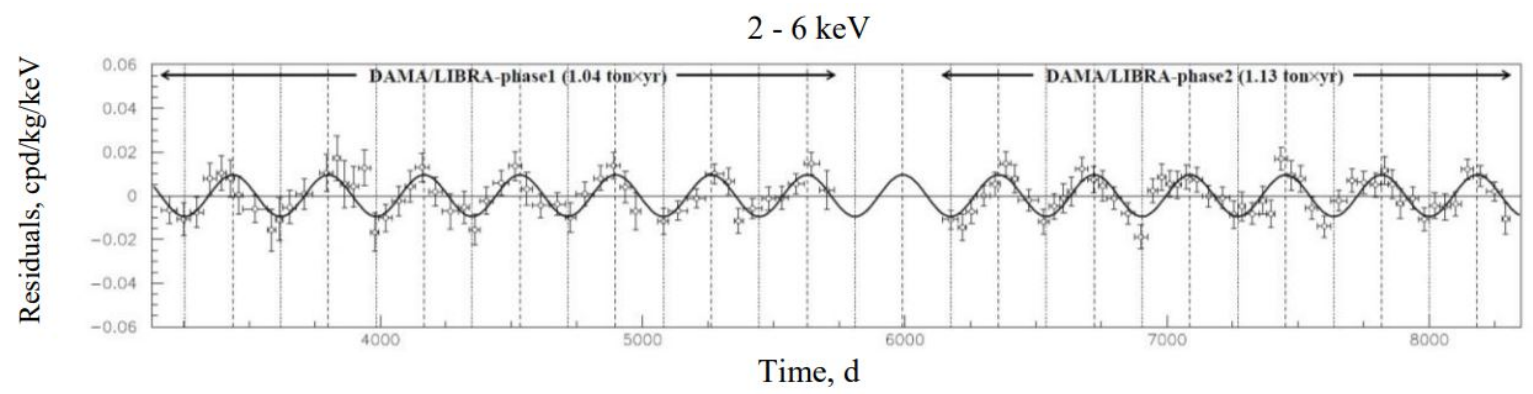

Figura 2.6: Taxa residual de eventos de cintilação únicos com energia entre 2 a $6 \mathrm{keV}$ medidos durante a fase 1 e fase 2 do experimento DAMA/LIBRA em função do tempo. A função ajustada é $A \cos \frac{2 \pi\left(t-t_{0}\right)}{T}$, onde A é a amplitude igual $0.0095(8) \mathrm{cpd} / \mathrm{kg} / \mathrm{keV}$, T o período igual 1 ano e $t_{0}$ a fase da modulação, igual a 152.5 dias ( 2 de junho).

A hipótese sobre a possibilidade dos sinais observados pelo DAMA/LIBRA serem originados por outras partículas, como múons, nêutrons e neutrinos foi testada e descartada. A Figura 2.7 exemplifica um desses resultados [13]. Dados de outros experimentos baseados em detecção por cristais de NaI, como o COSINE-100 e o ANAIS, poderiam comprovar as observações realizadas pelo experimento.

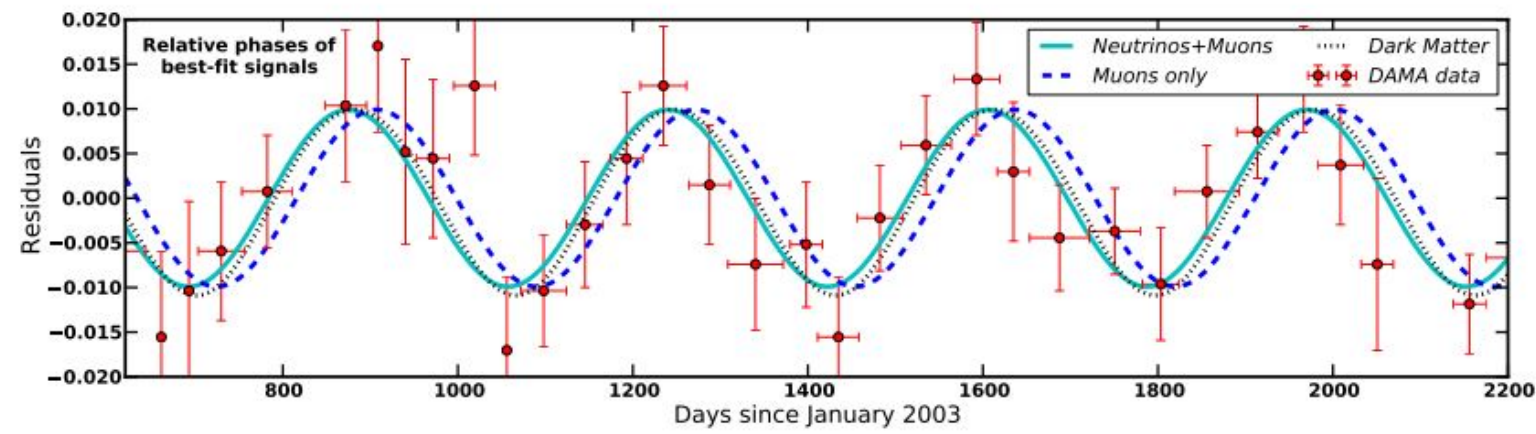

Figura 2.7: Comparação entre os dados obtidos pelo DAMA/LIBRA e um modelo que considera a modulação conjunta de nêutrons produzidos por neutrinos solares, múons atmosféricos e neutrinos. Esse modelo falha para períodos maiores que 1 ano e para análises de modulação dependentes da energia do sinal observado.

Os primeiro resultados do experimento COSINE-100 não apresentam excesso de sinais provenientes de interações com WIMPs [10]. A Figura 2.8 apresenta o gráfico de exclusão do experimento COSINE-100 em comparação ao do DAMA/LIBRA com base nos dados obtidos em 59.5 dias. Esses resultados excluem a região de sinais previstos pelo DAMA/LIBRA. Resultados mais recentes do experimento DAMA/LIBRA, COSINE-100 e ANAIS [11, 12], são apresentados nas Figuras 2.9 2 e 2.10 . O experimento ANAIS não observou modulação anual enquanto que o experimento COSINE-100 apresentou resultados compatíveis com existência de modulação anual e com a hipótese nula. Esses gráficos apresentam a amplitude da modulação 
anual observada pelos experimentos em função da energia de recuo nos detectores. A Tabela 2.1 apresenta as amplitudes obtidas pelos experimentos. As duas primeiras linhas mostram resultados com a fase da modulação como parâmetros livres. Para todos os outros resultados, a fase foi fixada em 152.5 dias. Os dados do COSINE-100 são apresentados com e sem a remoção de fundos pelo cintilador líquido (LS). Os resultados dos dois experimentos apontam para a não observação de modulação anual. O COSINE-100 está em processo de produção de mais cristais de $\mathrm{NaI}(\mathrm{Tl})$ para a segunda fase do experimento, denominada COSINE-200, e os dois experimentos continuarão a tomar dados por mais alguns anos de modo a obter exposição comparável à do experimento DAMA/LIBRA para uma conclusão definitiva sobre a existência ou não de uma modulação anual.

\begin{tabular}{|c||c|c|c|c|c|}
\hline \multicolumn{7}{|c|}{ Modulações } \\
\hline \hline Experimento & $\chi^{2}$ & N.D.F & p-valor & Amplitude (cpd/kg/kev) & Fase (dias) \\
\hline COSINE-100 & 175.3 & 174 & 0.457 & $0.0092(67)$ & $127.2(45.9)$ \\
DAMA/LIBRA (fase 1 + fase2) & - & - & - & $0.0096(8)$ & $145(5)$ \\
COSINE-100 & 175.6 & 175 & 0.473 & $0.0083(68)$ & 152.5 \\
COSINE-100 (Sem LS) & 194.7 & 175 & 0.147 & $0.0024(71)$ & 152.5 \\
ANAIS-112 & 48.0 & 53 & 0.67 & $-0.0044(58)$ & 152.5 \\
DAMA/LIBRA (fase 1 + fase 2) & 71.8 & 101 & 0.988 & $0.0095(8)$ & 152.5 \\
\hline
\end{tabular}

Tabela 2.1: Comparação de resultados de amplitudes e fase entre experimentos de cristais de NaI. As duas primeiras linhas apresentam o ajuste dos dados com a fase da modulação como parâmetro livre. Os dados do COSINE-100 (Sem LS) apresentam os parâmetros obtidos sem a remoção de eventos pelo veto do cintilador líquido (LS). 


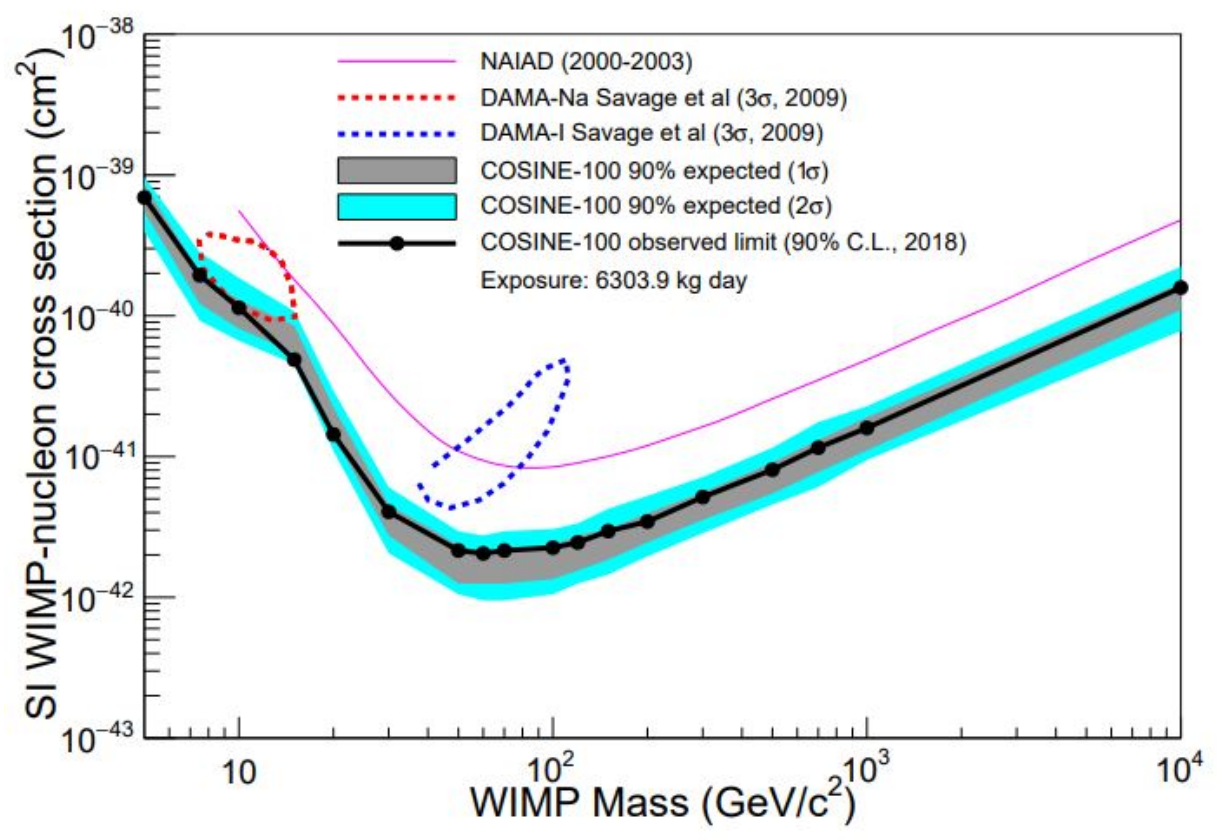

Figura 2.8: Limites de exclusão de seção de choque para interações WIMP-nucleon independentes de spin para os dados dos primeiros 59.5 dias do experimento COSINE-100. Esses limites excluem a região de sinais observados pelo DAMA/LIBRA.

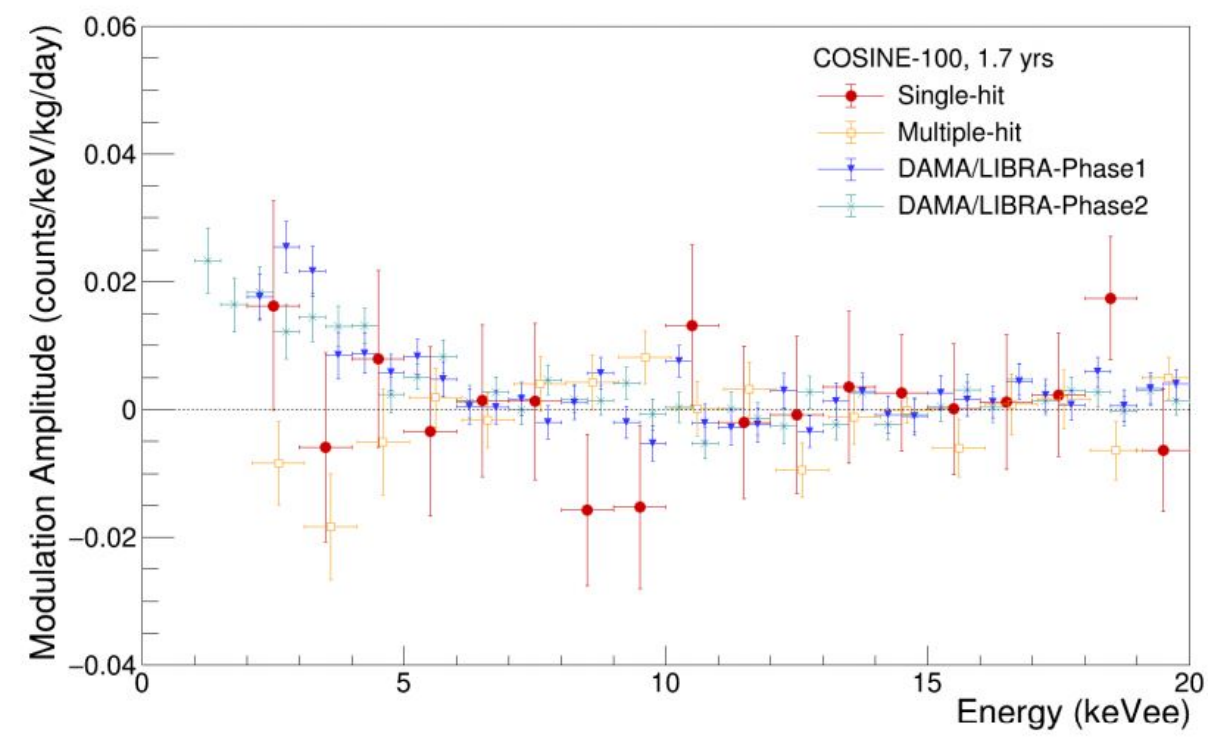

Figura 2.9: Amplitude da modulação em função da energia para dados de 1.7 anos do COSINE100. As barras de erro horizontais representam a largura do bin de energia usado na análise. Barras de erro verticais representam $1 \sigma$ da amplitude de modulação. Os pontos azuis e verdes representam as fases 1 e 2 do experimento DAMA/LIBRA. 


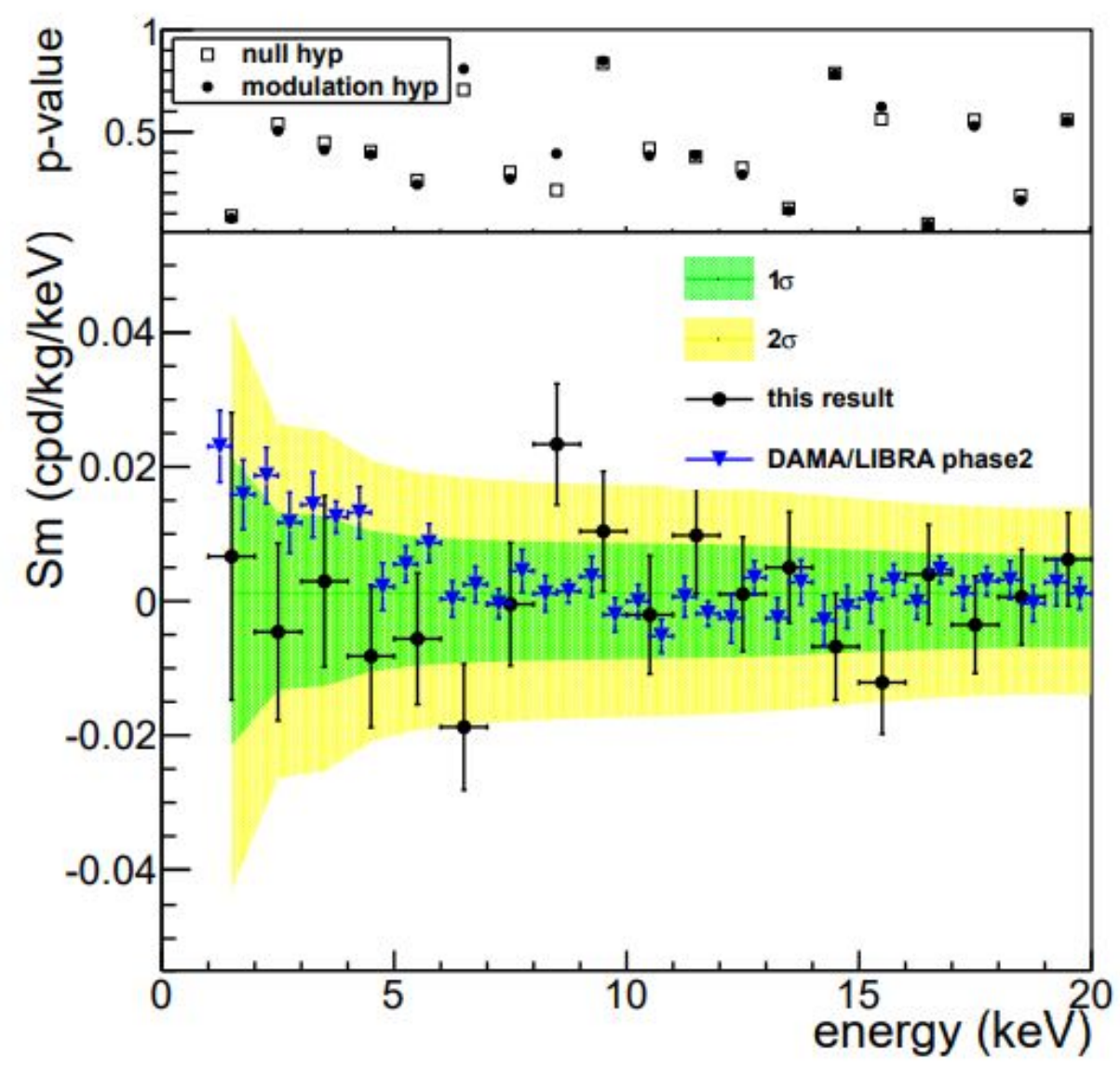

Figura 2.10: Amplitude da modulação em função da energia para dados de 1.5 anos do ANAIS112. As barras de erro horizontais representam a largura do bin de energia usado na análise. Barras de erro verticais representam $1 \sigma$ da amplitude de modulação. Os pontos em azul representam os dados da fase 2 do experimento DAMA/LIBRA.

Com maior tempo de exposição, e no caso do COSINE-200, mais material de detecção, a chance de se observar interações entre a matéria escura e os cristais de $\mathrm{NaI}(\mathrm{Tl})$ aumentam. Além disso, o aprimoramento nas técnicas utilizadas para análise dos dados já obtidos permitem um melhor entendimento dos fenômenos observados e ajudarão a elucidar se a modulação observada pelo DAMA/LIBRA se deve à matéria escura.

As análises realizadas referentes à modulação dos múons e sua correlação com a modulação da temperatura atmosférica são essenciais para garantir a qualidade dos dados da modulação anual da matéria escura. Essa análise permite compreender o comportamento dos múons e remover seus eventos correlacionados na análise dos cristais. 


\section{Capítulo 3}

\section{Experimento COSINE-100}

O arranjo experimental está montado em Y2L na Coreia do Sul, ilustrado na Figura 3.1 , localizado a $700 \mathrm{~m}$ abaixo da montanha.
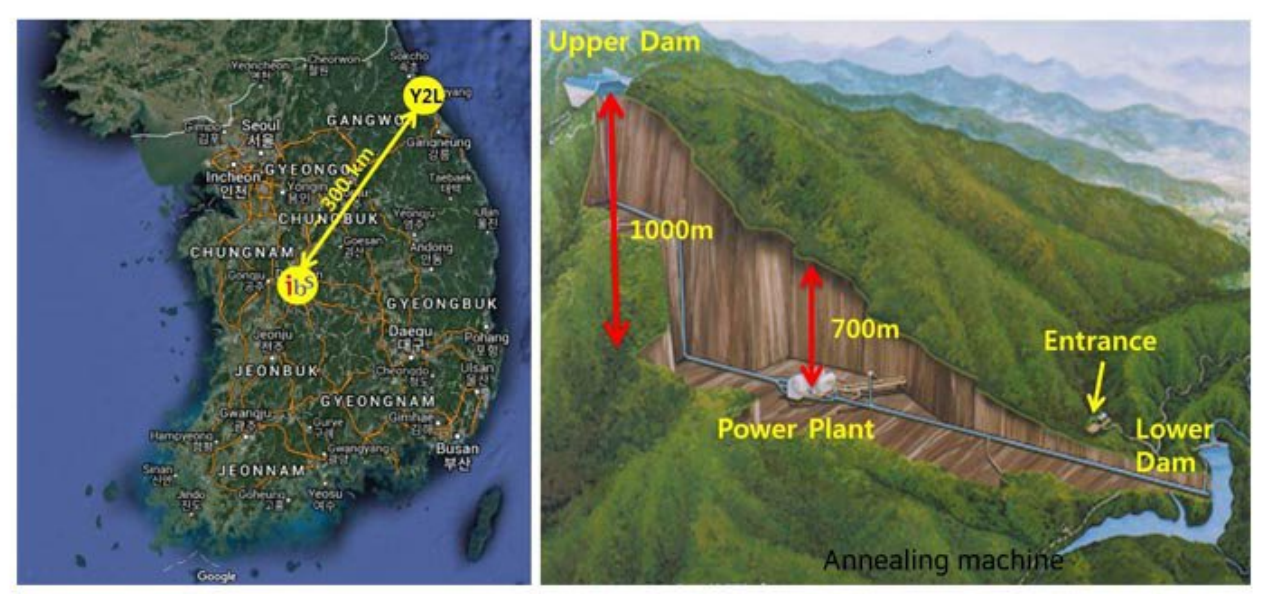

Figura 3.1: Localização do laboratório Y2L

Na primeira fase, a tomada de dados iniciou-se em setembro de 2016. O experimento consiste de 8 cristais de $\mathrm{NaI}(\mathrm{Tl})$ de elevada pureza (total de $106 \mathrm{~kg}$ ), cada um acoplado a duas fotomultiplicadoras. Os cristais estão imersos em aproximadamente $2000 \mathrm{~L}$ de cintilador líquido, com a função de reduzir o fundo de baixas energias proveniente principalmente de potássio radioativo. A estrutura de blindagem consiste de caixa de $\mathrm{Cu}$ com $3 \mathrm{~cm}$ de espessura, $20 \mathrm{~cm}$ de $\mathrm{Pb}$ e 37 cintiladores plásticos com $3 \mathrm{~cm}$ de espessura cada, para identificação de múons de raios cósmicos. Na caixa de Cu são acopladas 18 fotomultiplicadoras de 5" para detecção da luz do cintilador líquido. Os plásticos cintiladores laterais são acoplados a uma fotomultiplicadora de 2" e os painéis superiores possuem duas fotomultiplicadoras de 2" acopladas. Na Figura 3.2 é mostrado um esquema da montagem do experimento COSINE-100 em sua primeira fase. 


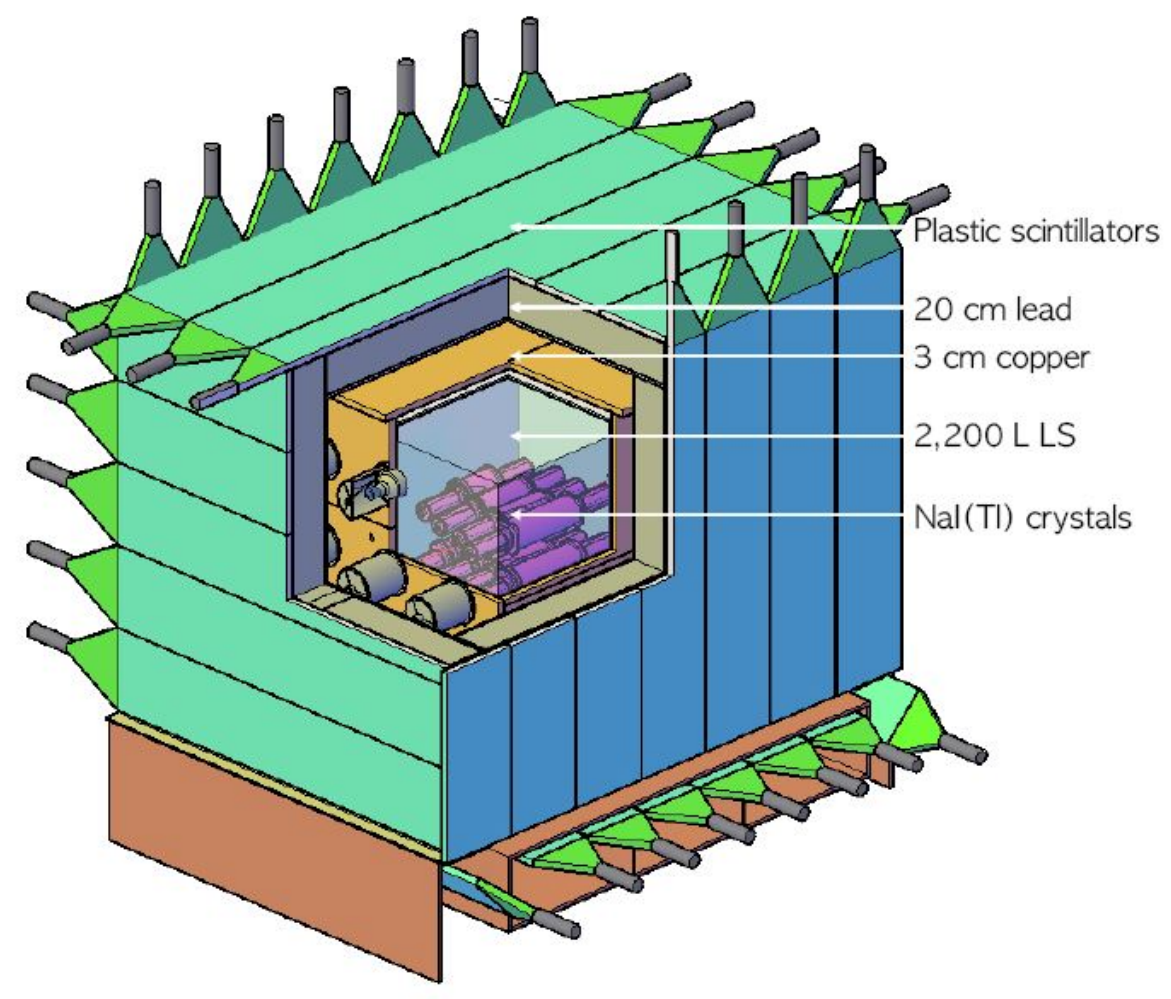

Figura 3.2: Componentes do experimento COSINE-100 montados.

O experimento COSINE-100 está localizado no túnel A5 de Y2L. Essa instalação está próxima aos geradores da usina hidroelétrica do Monte Jumbong, $150 \mathrm{~km}$ a leste de Seul na Coreia do Sul. Esse laboratório possui áreas experimentais nos túneis A5 e A6, como consta na Figura 3.3, acessíveis por carro através de um túnel horizontal de $2 \mathrm{~km}$.

\section{Y2L in the underground power plant}

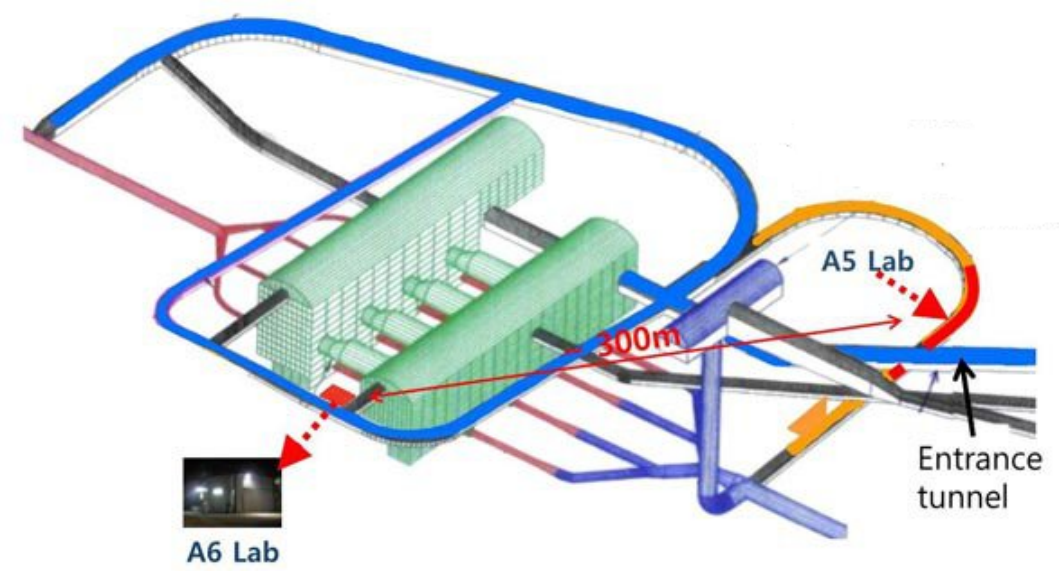

Figura 3.3: Planta de Y2L, com identificação dos túneis A5 e A6.

As salas experimentais são localizadas em cavernas no meio dos túneis. Possuem supri- 
mento ininterrupto de energia elétrica com tensões continuamente monitoradas. Durante o ano, as temperaturas de $\mathrm{A} 5$ são controladas e mantidas entre $22^{\circ} \mathrm{C}$ e $25^{\circ} \mathrm{C}$ e umidade relativa entre 60 e $70 \%$, respectivamente.

$\mathrm{O}$ experimento se encontra em uma sala com temperatura e umidade controladas, sistemas de suprimento de ar filtrado de radônio e suprimento de gases monitorados remotamente na sala de controle, na superfície. A sala do detector tem $44 \mathrm{~m}^{2}$ de área e $4 \mathrm{~m}$ de altura. O acesso a essa sala é controlado para minimizar contato com o ar do túnel, que contém $(1.20 \pm 0.49) p C i / L$ de $R n^{222}$ e outros contaminantes. $\mathrm{O}$ ar dessa sala é circulado através de um filtro HEPA e o número máximo de partículas de poeira maiores que $0.5 \mu \mathrm{m}$ controlado para menos de 1500 partículas por pé cúbico. O sistema de controle de ar mantém a temperatura e umidade relativa da sala em $(23.5 \pm 0.3)^{\circ} \mathrm{C} \mathrm{e}(40 \pm 3) \%$, respectivamente.

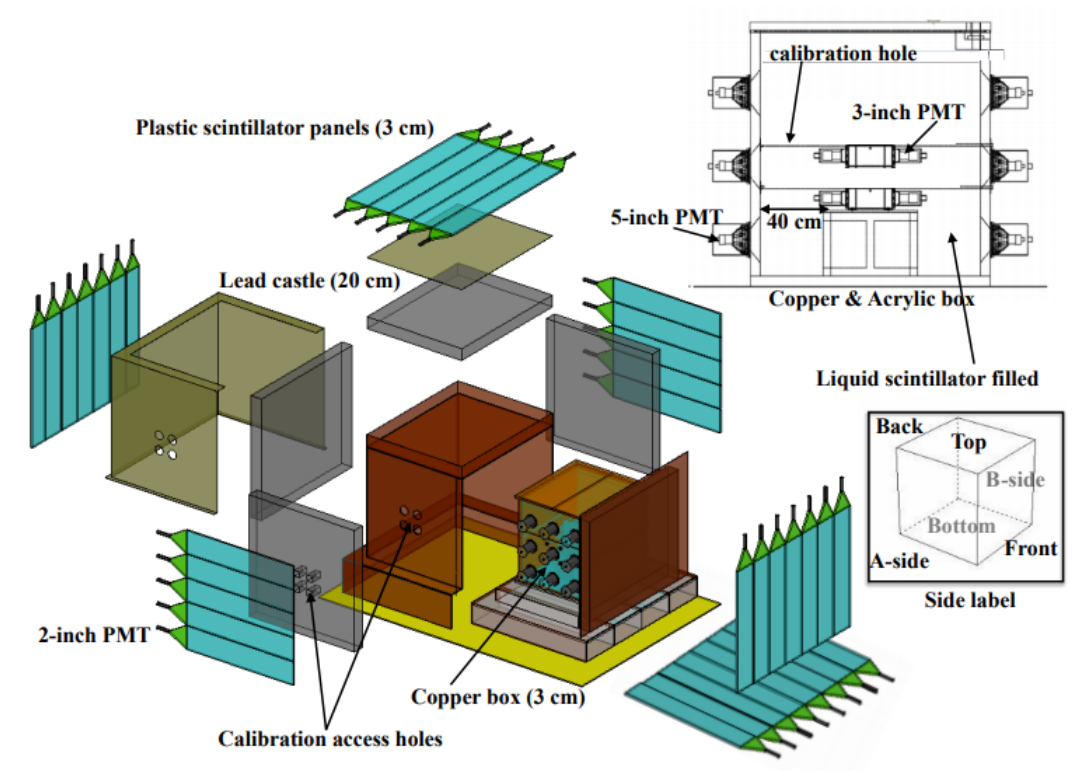

Figura 3.4: Componentes da blindagem do COSINE-100.

A blindagem do detector herdou vários recursos do KIMS, designado para atenuar a influência de fontes de radiação exteriores da forma mais eficiente possível. Uma estrutura de aço com 3 metros de comprimento, 2,2 de largura e 2.7 de altura suporta a blindagem. $\mathrm{O}$ detector está contido em uma estrutura de 4 camadas de componentes de blindagem que cobre um ângulo sólido de $4 \pi$ para radiações de várias fontes como consta na Figura 3.4. De fora para dentro, há uma camada de painéis de cintiladores plásticos, um castelo de tijolos de chumbo, uma caixa de cobre e o cintilador líquido. Os 8 cristais de Iodeto de Sódio e seus suportes se encontram imersos no cintilador líquido. A parte frontal do detector se encontra em um trilho 
móvel, que pode deslizar, conforme detalhado na Figura 3.5 .

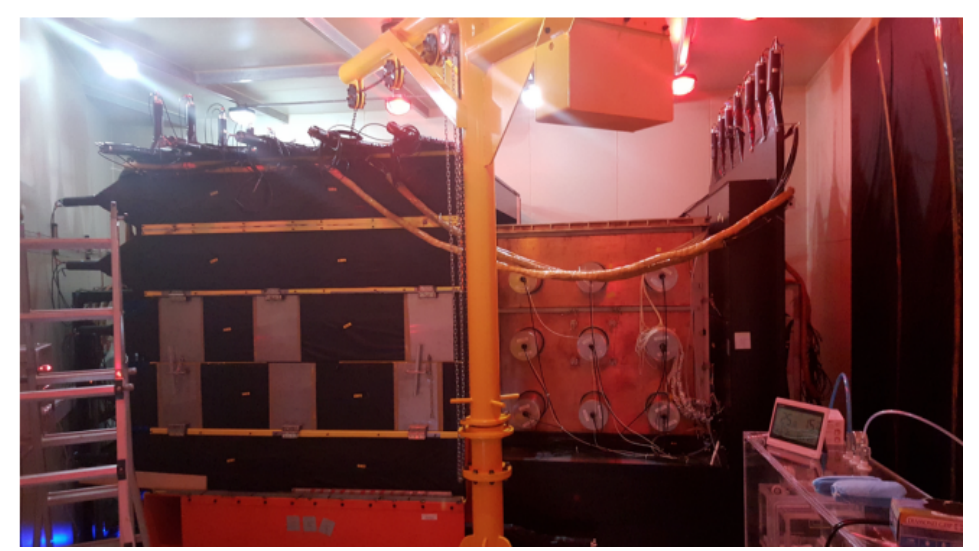

Figura 3.5: Foto do detector com a parte frontal aberta, mostrando os componentes de seu interior.

\subsection{Componentes do experimento}

\subsubsection{Painéis de cintiladores plásticos}

Um conjunto de cintiladores plásticos (PS) é usado para a detecção de múons oriundos de raios cósmicos que passam pelo detector. Esses eventos são marcados e gravados no mesmo data-stream que comporta a informação dos cristais.

\subsubsection{Armação de chumbo}

Uma armação de chumbo com $20 \mathrm{~cm}$ de espessura envolve a caixa de cobre e atenua os raios gama originados fora da blindagem. Sua parte interior é feita de chumbo de baixa contaminação, possuindo concentração de para ${ }^{238} \mathrm{U}$ de 6.9 ppt e para ${ }^{232}$ Th de 3.8 ppt. A atividade do ${ }^{210} \mathrm{~Pb}$ medida em Y2L é de $30 \pm 1 \mathrm{~Bq} / \mathrm{kg}$ [36]. A metade exterior é feita de chumbo comum, com pureza de $99.99 \%$. Essa estrutura é feita de tijolos de chumbo com dimensões 20 $\mathrm{cm}$ x $10 \mathrm{~cm}$ x $5 \mathrm{~cm}$ montados de forma que não haja ligação entre a camada exterior e interior do detector.

\subsubsection{Caixa de cobre}

Essa caixa serve como blindagem para raios gama e suporte para o cintilador líquido, que se encontra dentro de um recipiente de acrílico com espessura de $1 \mathrm{~cm}$. As medições do 
cobre usando ICP-MS mostram a existência de ${ }^{238} \mathrm{U}$ em 27 ppt e ${ }^{232} \mathrm{Th}$ em 51 ppt. Possui o tamanho de $152 \mathrm{~cm}$ x $142 \mathrm{~cm}$ x $142 \mathrm{~cm}$, com paredes com $3 \mathrm{~cm}$ de espessura e constituído de cobre livre de oxigênio (OFC).

\subsubsection{Cintilador líquido}

O cintilador líquido (LS) é composto por 2200 L de Linear Alquil Benzeno (LAB) e é utilizado para detectar uma variedade de fundos produzidos por radionuclídeos presentes nos componentes próximos aos cristais. As paredes interiores da caixa de acrílico e as superfícies dos cristais foram envolvidas com filmes especulares refletivos para aumentar a eficiência de coleção de luz. Os fótons produzidos no LS são detectados por 18 fotomultiplicadoras (PMT) Hamamatsu de 5 polegadas (R877), conectadas em lados opostos da caixa de acrílico. Sua contaminação intrínseca de ${ }^{238} \mathrm{U}$ e ${ }^{232} \mathrm{Th}$ foi determinada em 7 ppt e 4 ppt respectivamente.

Os $9 \mathrm{~cm}$ superiores da caixa de acrílico não foram preenchidos pelo LS, como forma de segurança para uma eventual expansão do volume do LS devido a temperatura. Resfriamento com a utilização de nitrogênio líquido é fornecido nesse espaço para evitar o contato com água e oxigênio. O volume do LS e sua alta capacidade térmica ajudam a manter a sua temperatura, bem como a dos cristais, estável em $(24.20 \pm 0.05)^{\circ} \mathrm{C}$.

\subsubsection{Cristais de NaI(Tl)}

O experimento COSINE-100 usa 08 cristais de $\mathrm{NaI}(\mathrm{Tl})$ com baixas contribuições de fundo, desenvolvidos pela Alpha Spectra Inc. (AS). Os cristais têm formato cilíndrico e são hermeticamente encapsulados em tubos de OFC de $1.5 \mathrm{~mm}$ de espessura. Antes do encapsulamento, são envolvidos por 10 camadas de filme reflexivo de politetrafluoretileno (PFTE) de $250 \mu \mathrm{m}$ de espessura e selados em um ambiente de nitrogênio. Suas extremidades possuem janelas de quartzo com $12 \mathrm{~mm}$ de espessura e são acoplados em optical pads de 1,5 mm de espessura que por sua vez, são acoplados a PMTs Hamamatsu R12669SEL 3 polegadas. A eficiência quântica média ${ }^{1}$ dessas PMTs é de 35\%. Os cilindros de cobre que encapsulam os cristais têm janelas de calibração de $16 \mathrm{~mm}$ de diâmetro com cobre reduzido de $0.5 \mathrm{~mm}$ de espessura ou $0.13 \mathrm{~mm}$ de Mylar para calibração com fontes de baixas energias.

Os oito cristais estão arranjados em uma matriz 4 x 2, suportada por uma mesa de acrílico de duas camadas localizada na região central do cintilador líquido. Os cristais são orientados

\footnotetext{
${ }^{1}$ razão entre fótons incidentes e elétrons convertidos
} 


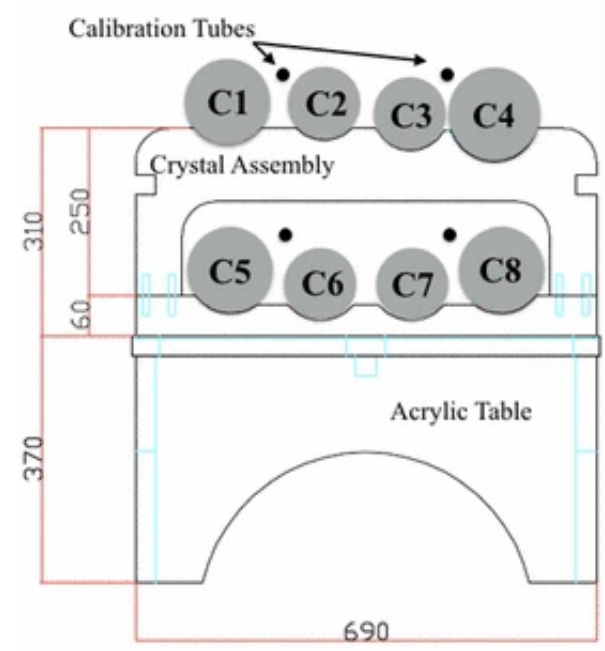

Figura 3.6: Diagrama do arranjo dos cristais. A mesa de acrílico suporta o conjunto de cristais, rotulados de $\mathrm{C} 1$ a $\mathrm{C} 8$. Os orifícios para calibração, bem como as dimensões da mesa, em mm, são indicados.

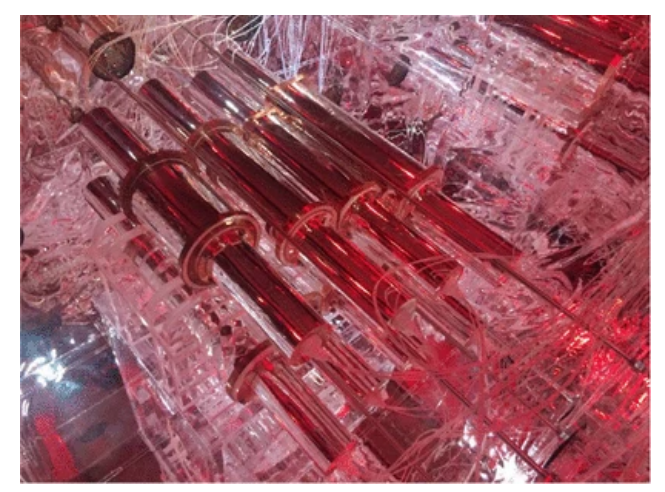

Figura 3.7: Foto mostrando os cristais. Cada cristal tem 2 PMTs acopladas em cada uma de suas extremidades. São encapsulados em cobre e por um filme reflexivo de politetrafluoretileno (PFTE).

de forma que suas janelas de calibração estão voltadas aos tubos de calibração mais próximos. $\mathrm{O}$ arranjo dos cristais bem como suas numerações se encontram nas Figuras $3.6 \mathrm{e} 3.7$.

\subsection{Sistema de veto do cintilador líquido}

O LAB-LS contém baixa porcentagem de 2,5-difeniloxazol (PPO) com quantidade residual de p-bis-(o-metilestiril)-benzeno (bis-MSB), deslocadores de comprimento de onda. Para produzir o volume final de 2200 L de LAB-LS, uma solução concentrada de 110 L de PPO e bis-MSB foi preparada. Esta solução mestre foi então misturada com LAB em uma proporção de 1:20 para fazer o LS final baseado em LAB. O LS foi produzido na superfície e movido ao túnel A5 após sua produção. Então foi transferido para o recipiente de acrílico passando por 
duas camadas de filtro com poros de $0.1 \mu \mathrm{m}$.

Uma vez que o PPO pode ter um nível relativamente alto de contaminação por radioisótopos, um método de extração de água [55] com água deionizada $17 M \Omega$ foi usado para extrair impurezas da solução. Após o tratamento, a água residual foi removida através do borbulhamento líquido de $N_{2}$ até que o gás exaurido possuísse umidade de aproximadamente 20 ppm de $\mathrm{H}_{2} \mathrm{O}$.

Medidas realizadas em um protótipo do detector de cintilador líquido mostraram que os limites superiores de contaminação do LS são fontes de fundos insignificantes para o espectro de energia dos cristais de $\mathrm{NaI}(\mathrm{Tl})$ [56]. A calibração do sistema de veto foi realizada com a utilização de fontes de raios gama através do tubo de calibração.

\subsection{Detectores de múons}

O sistema de detectores de múons consiste em 37 painéis de cintilidadores plásticos da Eljen EJ-200 de $3 \mathrm{~cm}$ de espessura. As dimensões de cada painel e sua localização conforme consta na Figura 3.4 se encontram na Tabela 3.1. Cada painel foi polido e acoplado a uma guia de luz de acrílico usando cimento óptico BC-600 da Saint-Gobain. Ao final de cada guia de luz, foi acoplada uma fotomultiplicadora (PMT) H7195 de duas polegadas da Hamamatsu Photonics. Os painéis do topo possuem duas fotomultiplicadoras cada um enquanto que os demais painéis possuem apenas uma. Nesses painéis, um filme refletor Vikuiti é fixado em sua outra extremidade. Todos painéis foram envolvidos com um refletor TYVEK para melhor coleta de luz, folhas de alumínio de $50 \mu m$ de espessura e uma camada de vinil preta para evitar vazamento de luz e danos aos painéis.

\begin{tabular}{|c||c|c|c|c|c|}
\hline Lado & Comprimento $(\mathrm{cm})$ & Largura $(\mathrm{cm})$ & Espessura $(\mathrm{cm})$ & Painéis & PMTs \\
\hline Topo & 282 & 40 & 3 & 5 & 2 \\
\hline Baixo & 207 & 33 & 3 & 6 & 1 \\
& 205 & 40 & 3 & 2 & 1 \\
\hline \multirow{2}{*}{ Frente } & 205 & 40 & 3 & 5 & 1 \\
& 207 & 33 & 3 & 2 & 1 \\
\hline Posterior & 202 & 40 & 3 & 5 & 1 \\
& 202 & 33 & 3 & 2 & 1 \\
\hline Direito & 204 & 40 & 3 & 5 & 1 \\
\hline Esquerdo & 204 & 40 & 3 & 5 & 1 \\
\hline
\end{tabular}

Tabela 3.1: Painéis plásticos do experimento COSINE-100. 


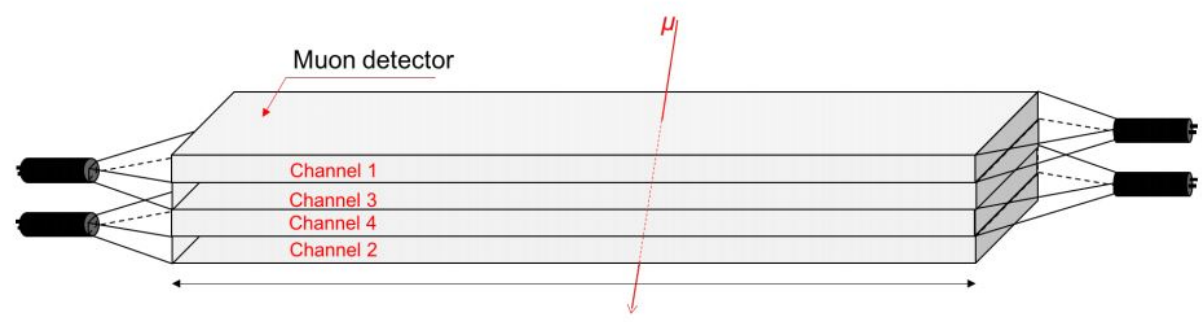

Figura 3.8: Configuração para obtenção da eficiência da detecção de múons pelos painéis plásticos utilizados.

A eficiência de detecção de múons foi estimada com o uso de 4 painéis empilhados (Figura 3.8 [57]). Nessa estimativa, um evento ocorre de forma coincidente nos canais 1 (painel do topo) e 2 (painel de baixo) e a informação de todos os canais era registrada. Se um múon passou nos dois primeiros canais, ele necessariamente passou por todos os painéis. Após aplicação dos thresholds de carga, 4800 contagens do ADC para o canal 1 e 5400 contagens do ADC para o canal 2, determinou-se que a eficiência dos painéis utilizados foi de $99.0 \pm 0.1 \%$. Medições do fluxo de múons na superfície resultaram em um fluxo de $136 \pm 7$ muons $/ \mathrm{m}^{2} / \mathrm{s}$.

\subsection{Sistema de aquisição de dados (DAQ)}

O sistema de aquisição de dados (DAQ) [58] do COSINE-100 consiste de 8 módulos flash conversores analógico-digital (FADC), 2 módulos flash conversores analógico-digital sensíveis a carga (M64ADC), uma placa de triggers e relógios (TCB), 4 pré-amplificadores, sistema de alta voltagem (HV) e processadores Linux, como consta na Figura 3.9.

M64ADC recebe sinais dos cintiladores plásticos e líquido. Os sinais do cintilador líquido são amplificados por um fator de 30 e os sinais dos cintiladores plásticos são conectados diretamente. As fotomultiplicadoras dos cristais possuem duas saídas cada uma: o anodo, com altos fatores de amplificação e o dínodo de quinto estágio, com sinal de baixo ganho, digitalizados pelo FADC. No total, são 92 canais cujos sinais são registrados pelo DAQ: 32 sinais dos cristais, 18 do cintilador líquido e 42 dos cintiladores plásticos. Os triggers globais são feitos pelo TCB, que sincroniza os relógios de todos os módulos. A informação então é armazenada no computador do DAQ no formato .ROOT. A Figura 3.9 apresenta um fluxograma dos sistemas apresentados.

O suprimento de alta voltagem das fotomultiplicadoras é realizado por módulos HV CAEN. O experimento se utiliza de 8 CAEN A1535N, 2 dos módulos com 24 canais e 6 com 
12 canais, instalados em CAEN-4527 VME. Todos os módulos fornecem até $3.5 \mathrm{kV}$ com polaridade negativa, suficiente para o funcionamento de todas fotomultiplicadoras do experimento.

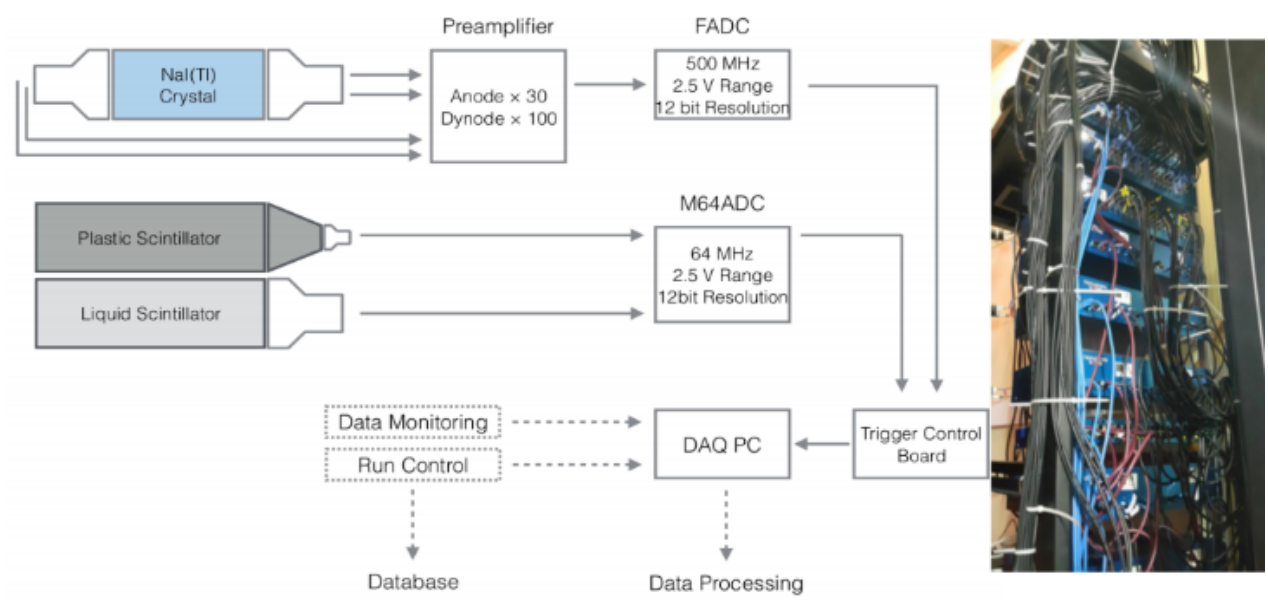

Figura 3.9: Fluxograma do COSINE-100. Os sinais das fotomultiplicadoras são enviados a dois tipos de digitizers, administrados pelo TCB. A informação digitalizada é salva no computador do DAQ. São usados 32 canais do FADC e 60 do M64ADC. A visualização e armazenamento dos dados são realizadas com o InfluxDB e Grafana.

\subsubsection{Módulos M64ADC}

Os dados dos cintiladores plásticos e líquido são coletados pelos módulos do M64ADC com taxa de amostragem de $64 \mathrm{MS} / \mathrm{s}$. Cada um dos módulos possui 32 canais com intervalo dinâmico de input de 2 Vpp e resolução de 12 bit. Os sinais das fotomultplicadoras são conectados aos módulos com conectores do tipo-BNC. As informações de trigger dos módulos são transferidas ao TCB onde ocorrem as decisões globais e depois são transferidos ao computador do DAQ através de uma porta USB3.

O M64ADC armazena os dados de carga integrados no tempo de acordo com o preset do field programmable gate array (FPGA). O sinal analógico é digitalizado a cada 16 ns e quando o FPGA recebe o trigger, o sinal é integrado nos próximos 192 ns e digitalizado.

O threshold de carga para separação de múons e gamas é de 4000 contagens do ADC e a carga integrada dos eventos da maioria dos múons é superior a 12000 contagens do ADC. Quando um múon atravessa os detectores do COSINE-100, sua energia é depositada em pelo menos 2 painéis plásticos e também no cintilador líquido. O múon que para dentro do detector deposita toda sua energia em apenas um dos painéis e no cintilador líquido. Assim, quando a carga integrada supera o threshold, uma janela de coincidência de 400 ns de largura é aberta. Se outro canal dentro dessa janela de tempo também alcançar algum trigger, M64ADC envia um 
sinal ao TCB. A Figura 3.10 mostra a sequência de triggers utilizadas pelo M64ADC. Quando o TCB envia um sinal para que o FADC e o M64ADC salvem algum evento, uma janela de gate de $4 \mu s$ é aberta pelo M64ADC, com o final do tempo do TCB no meio da janela. Nesse intervalo, são salvos os valores máximos de carga e o tempo correspondente para cada canal.

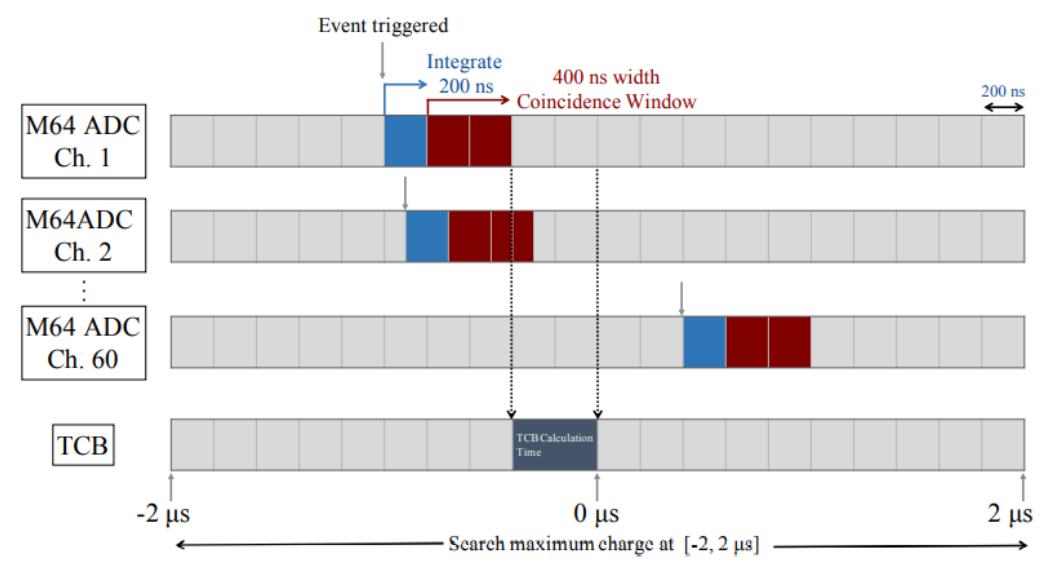

Figura 3.10: Sequência de trigger do M64ADC. Os eventos são considerados coincidentes quando o sinal de pelo menos duas fotomultiplicadoras, sejam elas dos cintiladores plásticos ou líquidos, ocorrer dentro de 400 ns. Os quadrados azuis representam o tempo de integração de carga e os quadrados vermelhos a janela de coincidência de $400 \mathrm{~ns}$. O tempo do TBC representa o tempo necessário para que o TBC receba a informação do M64ADC e gere um trigger global.

\subsubsection{Módulos FADC}

Os sinais dos cristais de $\mathrm{NaI}(\mathrm{Tl})$ são digitalizados com o uso de 8 módulos FADC de 500 MS/s. Cada FADC tem 4 canais com conectores do tipo SMA, cada um com intervalo dinâmico de 2.5 Vpp e resolução de 12 bits.

Como dito anteriormente, cada cristal possui uma fotomultiplicadora ligada em cada uma de suas extremidades. O ânodo possui sensibilidade de detecção de fotoelétrons únicos e é o canal principal nas análises de matéria escura. O sinal dos dínodos são usados para gravação de sinais de altas energias. As fotomultiplicadoras usadas apresentam não linearidades em sinais com energia superior a $1 \mathrm{MeV}$ [59] e o quinto dínodo é usado para gravação de sinais acima dessa energia.

As formas de onda de cada uma das 2 fotomultiplicadoras são gravadas quando há coincidência dos sinais dos anodos de um cristal acima do threshold, $6 \mathrm{mV}$, equivalente a 10 contagens do ADC ou 0.2 fotoelétrons, em um intervalo de tempo de 200 ns. Os sinais dos dínodos 
são gravados quando o trigger global é recebido pelo TCB. Nesse caso, o FADC salva as formas de onda de todos os canais. Esses sinais são gravados em um intervalo de $8 \mu \mathrm{s}$. As informações pré-trigger são armazenadas na memória DRAM da placa do FADC, que pode armazenar ondas de até $64 \mu s$.

\subsubsection{TCB}

Os sinais de trigger gerados pelo FACS ou M64ADC são enviados ao TCB onde um trigger global é criado. Esse trigger pode ser de dois tipos:

- Gravação passiva: quando o trigger é enviado pelo FADC, todos os canais do FADC e M64ADC são gravados. Esse trigger global serve para armazenar informação de eventos nos cristais e nos cintiladores plásticos e líquidos. a Figura 3.11 apresenta uma esquematização desse processo;

- Gravação ativa: os módulos do M64ADC armazenam informações continuamente sempre que a condição de trigger dos cintiladores plásticos é atingida.

Os trigger globais são enviados a todos canais do FADC e/ou M64ADC ao mesmo tempo, dependendo do tipo de trigger acionado. O TCB possui 40 slots do tipo RJ-45 e a comunicação entre o TCB e os módulos é feita via cabo Ethernet. O TCB também envia informações do contador do relógio do TCB para sincronização dos eventos entre os módulos. Quando múons energéticos atravessam diretamente os cristais, acionam uma grande quantidade de triggers, superior à capacidade do DAQ. Isso ocorre devido ao elevado número de eventos induzidos por múons [59,60]. Para evitar a saturação do DAQ, o tempo morto de $1 \mathrm{~ms}$ de hardware é acrescentado ao canal do FADC que gera o trigger. 


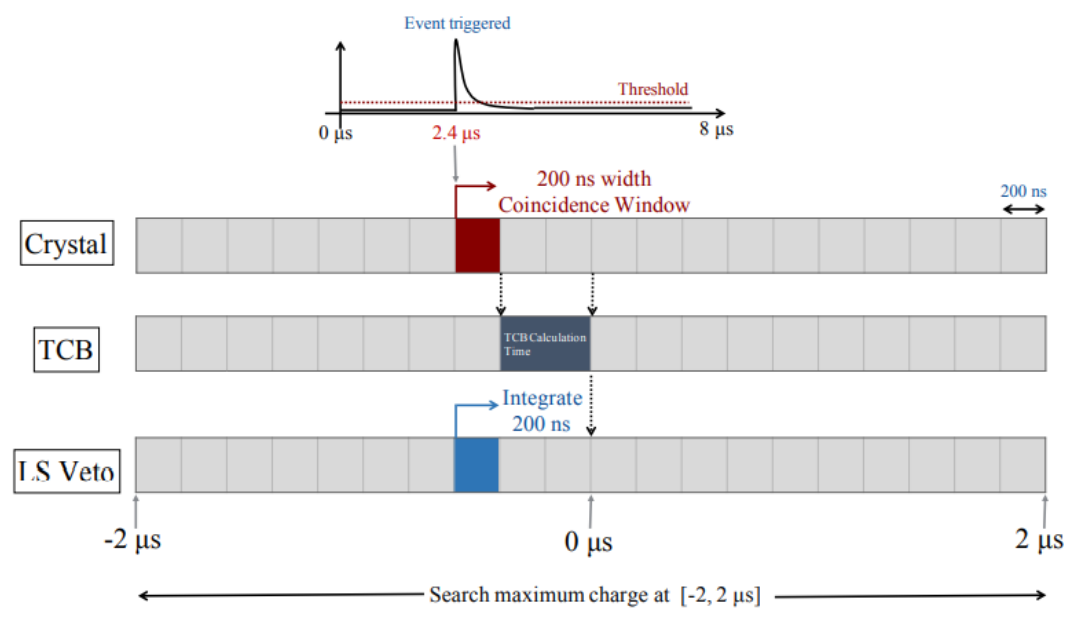

Figura 3.11: Algoritmo para gravação passiva. As caixas azuis representam o tempo de integração de carga e as caixas vermelhas a janela de coincidência de tempo de 200 ns. Em azul escuro, a representação do tempo necessário para que o TCB interprete as informações dos módulos e gere os triggers globais. Caso as condições sejam satisfeitas, todos os dados são coletados ao mesmo tempo.

\subsubsection{Monitoramento lento}

Para garantir uma tomada de dados estável e analisar variações sazonais no experimento, ocorre o monitoramento contínuo de parâmetros ambientais. Esses parâmetros são monitorados com o uso de sensores diversos conectados a um banco de dados. O InfluxDB é o software responsável pelo armazenamento das informações do monitoramento lento. O software utilizado para visualização e monitoramento desses parâmetros é o Grafana, apresentado nas Figuras 3.12 e 3.13. Os parâmetros monitorados são:

- Temperatura: a temperatura é monitorada em várias posições do experimento. Para isso, é utilizado um data-log par termoelétrico de 8 canais TC-08, da Pico Technology. 8 termopares tipo K são conectados ao data-logger. 3 desses sensores estão instalados dentro da caixa de cobre, em contato com o cintilador líquido enquanto os outros 5 monitoram as temperaturas da sala e do túnel.

- Alta tensão: Os equipamentos da CAEN HV são monitorados pelo software da própria empresa. Todas tensões, correntes e status de funcionamento das fotomultiplicadoras são monitorados a cada minuto.

- Umidade relativa: 3 sensores MM2001 analógicos, fabricados pela Maxdetec medem a umidade relativa. Esses sensores são conectados ao servidor de monitoramento via 
módulo DAQ Labjack U3, também usado para o monitoramento da baixa tensão utilizada nos pré-amplificadores.

- Nível de Oxigênio: Os níveis de oxigênio da sala do detector são monitorados com um dispositvo Lutron O2H-9903SD com uma porta RS-232 para comunicação serial. Por motivos de segurança, o nível de oxigênio é informado na entrada da sala do detector.

- Refrigeração: A empresa Korea Air Conditioning Technology fornece um protocolo de comunicação baseado no RS-485 e Modbus para monitoramento do status do equipamento de refrigeração, como temperatura e umidade.

- Eletricidade: os equipamentos de monitoramento são protegidos por um UPS ( uninterruptible power supply) on-line de $80 \mathrm{KVA}$, fabricado pela Ewah Electronics.

- Níveis de radônio: Um RAD7 da Durridge Company é utilizado para o monitoramento dos níveis de radônio na sala do detector. Essa medida é realizada a cada 30 minutos.

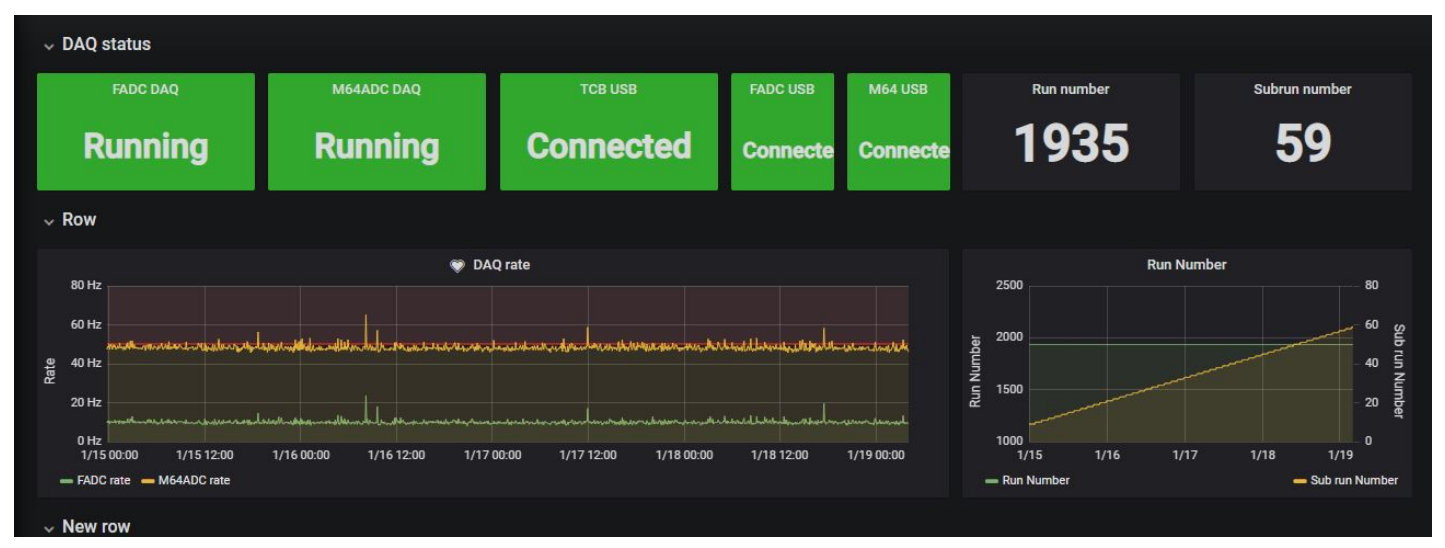

Figura 3.12: Exemplo de visualização das variáveis monitoradas pelo Grafana. Podemos ver o status dos módulos de aquisição de dados, trigger rate dos ADCs e atual run e subrun de tomada de dados. 


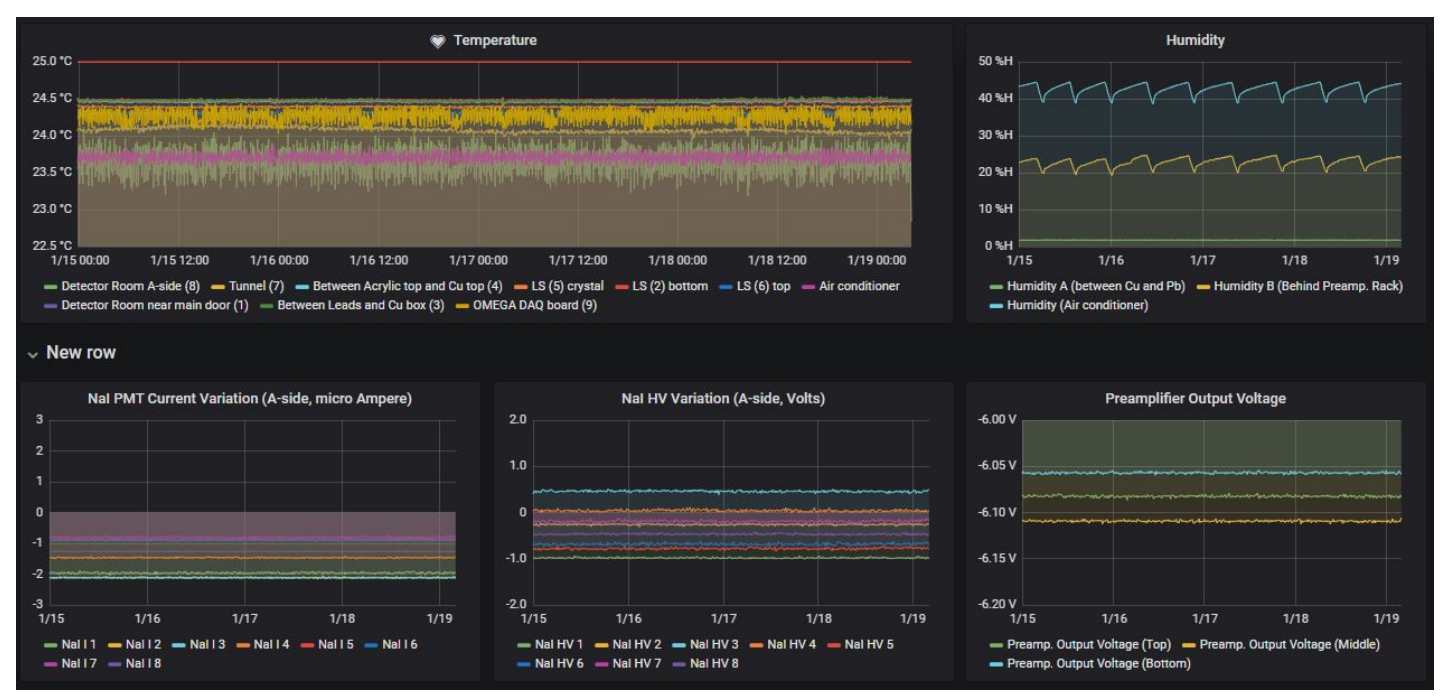

Figura 3.13: Exemplo de visualização das variáveis monitoradas pelo Grafana. A imagem mostra o status da temperatura em vários locais do detector, umidade, tensão de saída dos préamplificadores e variação da tensão e corrente das fotomultiplicadoras acoplada nos cristais.

\subsubsection{Monitoramento da qualidade dos dados}

O experimento possui um sistema de monitoramento online com um servidor dedicado ao monitoramento da qualidade dos dados. A cada 2 horas, a informação é convertida a um arquivo .ROOT e salva no computador do DAQ, onde a informação é processada para extração das variáveis monitoradas.

O sistema de monitoramento apresenta 26 variáveis do FADC: 1 para o total da taxa de trigger, 8 para variáveis dos cristais e 17 para variáveis das fotomultiplicadoras; e 6 para o M64ADC: 1 para o total da taxa de trigger, 2 para as fotomultiplicadoras dos cintiladores plásticos e 3 para as fotomultiplicadoras dos cintiladores líquidos. Essa variáveis são produzidas sobrepostas com ajustes de referência. As referências são atualizadas frequentemente. A Figura 3.14 apresenta um exemplo de variável monitorada. Os desvios entre a variável e a referência podem indicar que algo anormal ocorreu nesse período de 2 horas.

Semanalmente, são produzidos 6 gráficos automaticamente: live-time, taxa de trigger dos cristais, taxa de trigger do M64ADC, carga total do cintilador líquido, assimetria de carga do cintilador líquido e taxa de eventos por múons. Esse monitoramento é importante para identificação de tendências nos dados como mostra a Figura 3.15 e 3.16 . 

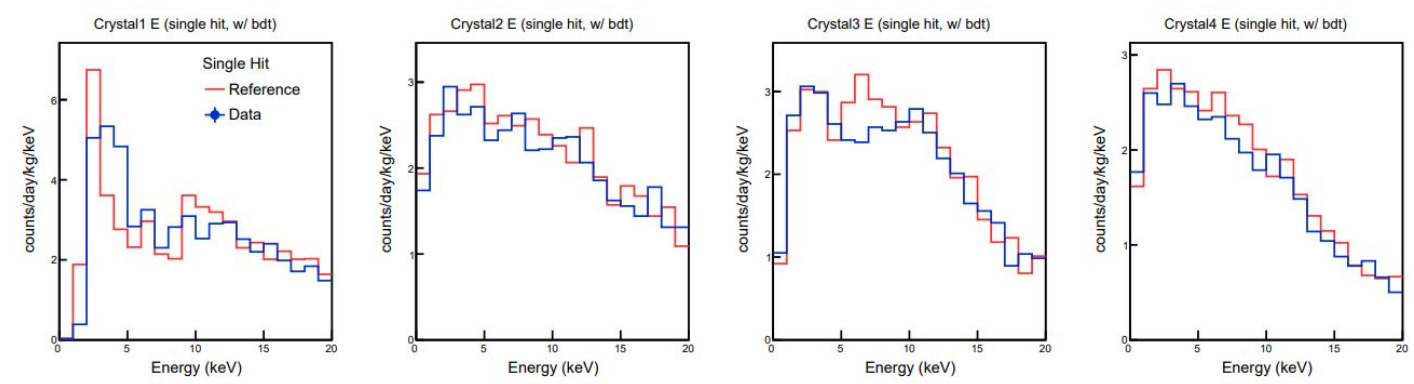

Figura 3.14: Exemplo de variáveis monitoradas. A referência, em vermelho, é retirada de dados validados. Em azul são apresentados os dados tomados em 2 horas. No exemplo, a energia de eventos únicos com seleção bdt nos cristais $1,2,3$ e 4 .
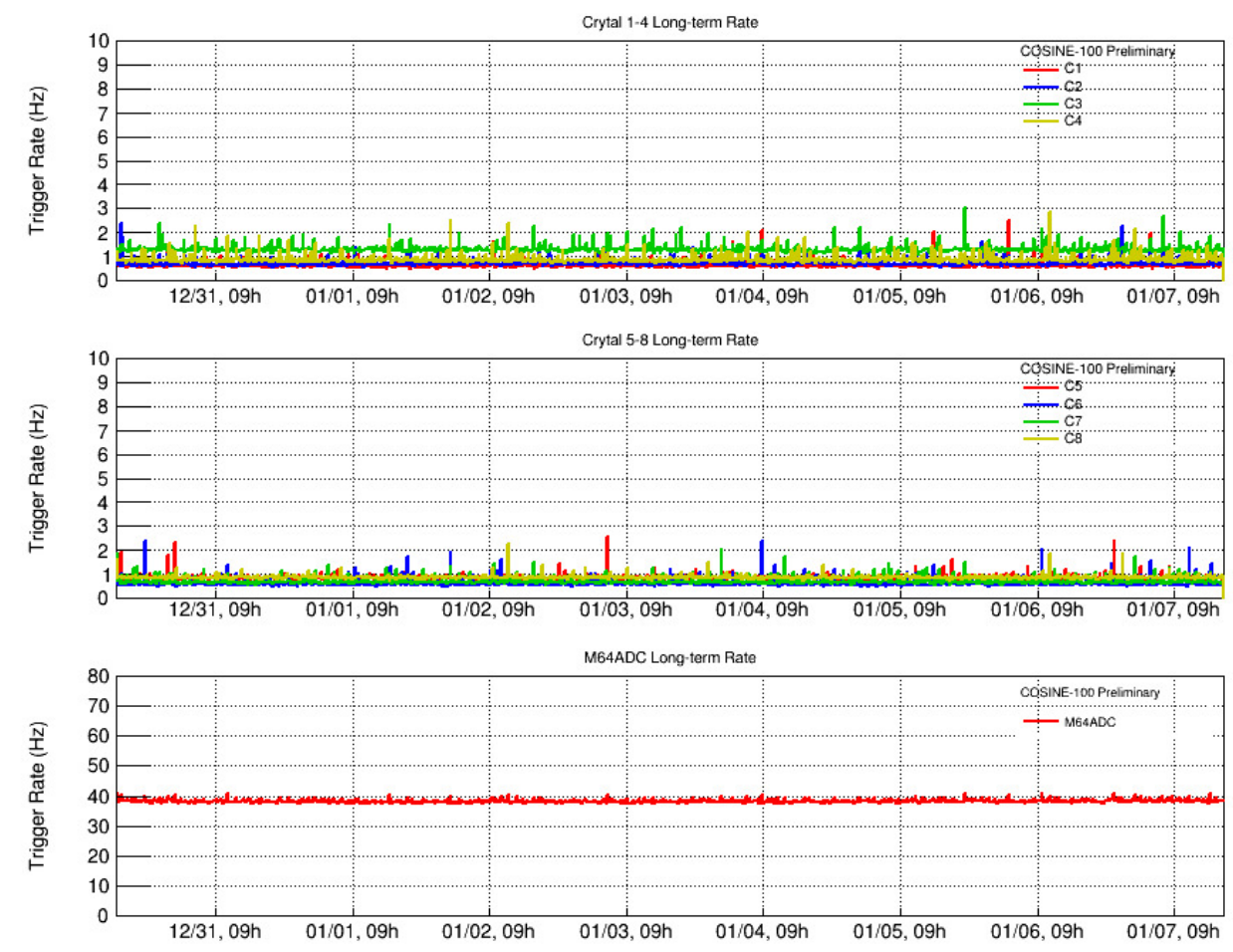

Figura 3.15: Monitoramento da taxa de eventos observada nos cristais e no sistema do M64ADC. 

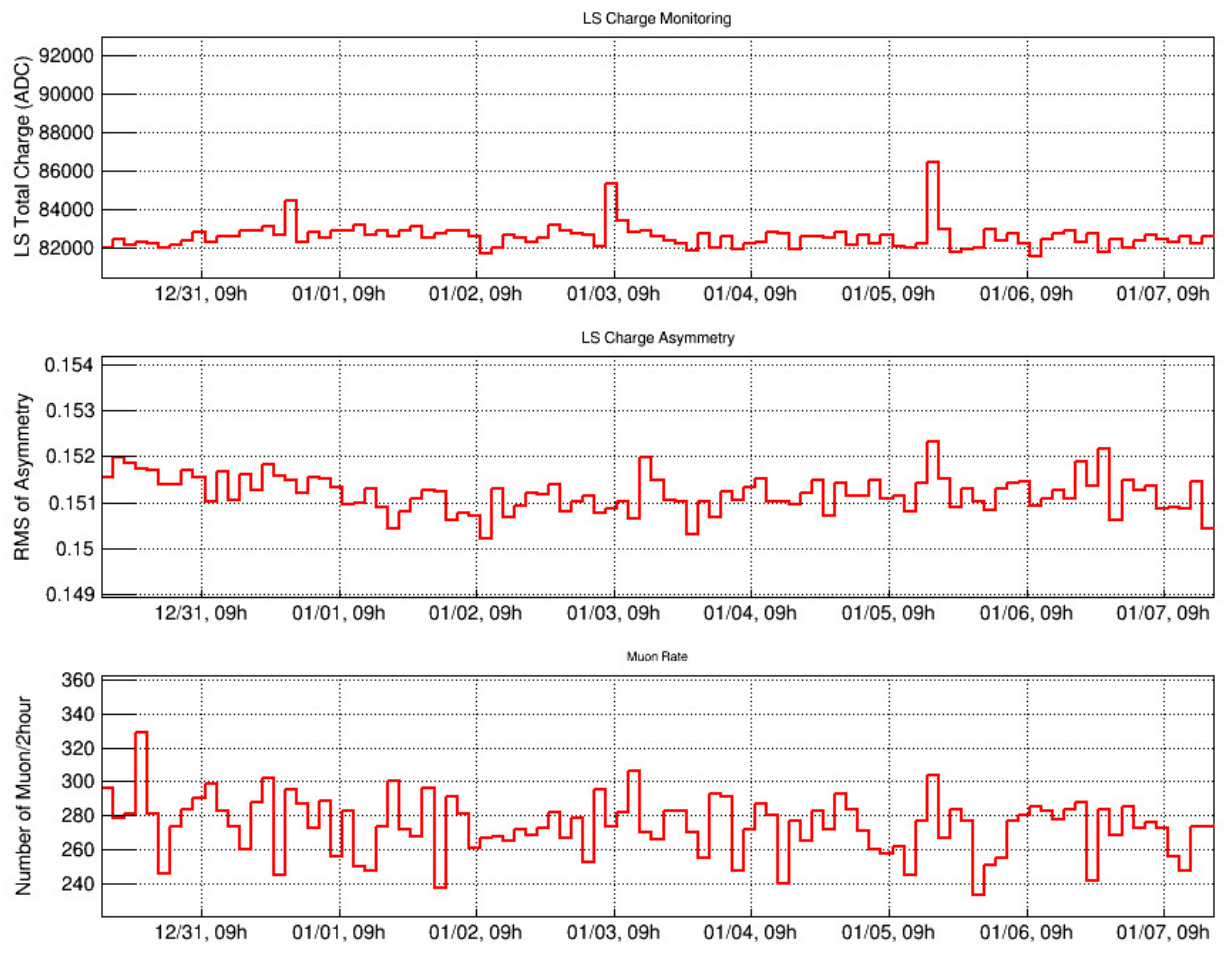

Figura 3.16: Monitoramento da carga do cintilador líquido, assimetria da carga do cintilador líquido e múons/2horas. 


\section{Capítulo 4}

\section{Análise dos eventos gerados por múons}

Quando partículas de raios cósmicos primários interagem com moléculas da atmosfera, é gerado um chuveiro de hádrons energéticos, entre eles píons $\left(\pi^{ \pm}\right)$e káons $\left(\kappa^{ \pm}\right)$. Essas partículas decaem em múons energéticos que, devido efeitos relativísticos, alcançam a superfície e laboratórios subterrâneos antes de seu decaimento [61,62]. Esses múons são fontes significativas de fundos presentes em experimentos subterrâneos.

Devido às variações na temperatura e densidade da atmosfera, a taxa de múons possui uma modulação anual [63-65]. Como mencionado anteriormente, essa modulação não explica o sinal observado pelo DAMA/LIBRA, mas representa fundos importantes ao experimento.

Este capítulo trata das análises aplicadas aos dados tomados no período de 23 de setembro de 2016 a 22 de setembro de 2020. É apresentada inicialmente uma recapitulação sobre o que é um múon e sobre as fontes que geram os múons de interesse para o experimento COSINE-100. A seguir, discutimos brevemente como é realizada a seleção de sinais dos múons. Apresentamos também o procedimento para realização da correção do ganho, importante para garantir que sinais de múons não sejam rejeitados por se encontrarem com um valor de carga abaixo do threshold estipulado devido à queda de tensão e degradação natural das fotomultiplicadoras. Apresentamos a metodologia para determinação do fluxo diário de múons detectados por todos os painéis plásticos do experimento, e determinação da modulação anual dos múons observados pelos painéis do topo e de baixo. Como mencionado anteriormente, múons induzem eventos que geram sinais na região de interesse para busca de matéria escura e o monitoramento desse fluxo e sua variação são essenciais para garantia da qualidade dos dados do experimento.

Por fim, mostramos a relação entre modulação anual dos múons e a temperatura atmosférica. Isso é importante, pois é uma forma de monitorar o caráter sazonal da modulação de múons. 


\subsection{Múons}

Os múons foram descobertos em 1937 por Carl D. Anderson e Seth Neddermeyer simultaneamente com J.C. Street e E.C. Stevenson com a utilização de câmara de nuvens no estudo de raios cósmicos. [66]. O múon é um lépton [67], ou seja, é uma partícula similar ao elétron, porém 200 vezes mais massiva e por conta disso, instável. Seu principal canal de decaimento é por meio de elétron/pósitron, dependendo de sua carga, e dois neutrinos:

$$
\mu^{ \pm} \rightarrow e^{ \pm} \nu_{e}\left(\bar{\nu}_{e}\right) \bar{\nu}_{\mu}\left(\nu_{\mu}\right)
$$

Sua vida média é de $\tau_{m}=(2.1969811 \pm 0.0000022) \mu s$ [68].

Os múons que chegam ao experimento COSINE-100 são provenientes de decaimento de raios cósmicos [61, 62]. Raios cósmicos foram descobertos em 1912 por Viktor Hess [69], são partículas oriundas do espaço que interagem com a atmosfera da Terra. Sua principal fonte é o centro de nossa galáxia. Os raios cósmicos carregados primários, aqueles que ainda não interagiram com o meio, são formados principalmente por prótons, He, núcleos pesados e elétrons. Pósitrons e antiprótons são raios cósmicos secundários originários da interação com o gás do meio estelar [70].

As interações dos raios cósmicos com a atmosfera produzem várias partículas, entre elas píons $(\pi)$ e káons $(\kappa)$. Os píons produzidos podem ser carregados ou neutros enquanto que káons sempre são carregados. Essas partículas, possuem vida média curta e quando não interagem, decaem em múons:

$$
\begin{gathered}
\pi^{ \pm} \rightarrow \mu^{ \pm} \nu_{\mu}(\bar{\nu})_{\mu} \\
\kappa^{ \pm} \rightarrow \mu^{ \pm} \nu_{\mu}(\bar{\nu})_{\mu}
\end{gathered}
$$

Devido a sua vida média relativamente alta e baixa seção de choque, múons muito energéticos são os componentes mais penetrantes dos raios cósmicos, atravessando grandes distâncias na atmosfera e até mesmo grandes porções de rocha sem decair. 


\subsection{Caracterização dos sinais de múons}

Como mencionado na seção sobre o M64ADC, pelo menos 2 fotomultiplicadoras de painéis independentes do detector de múon devem acionar os triggers, quando o sinal possui carga acima de 4000 contagens do ADC em uma janela de tempo de 400 ns. Nessa situação, as informações referentes à carga e ao tempo são integradas em um intervalo de $4 \mu s$. Nas análises físicas, a informação utilizada é a do lado em que ocorreu o sinal. A carga do lado é equivalente à soma das cargas de cada fotomultiplicadora que constitui o lado. Um exemplo se encontra na Figura 4.1. A informação de tempo do evento corresponde ao tempo da fotomultiplicadora que possui maior carga integrada.

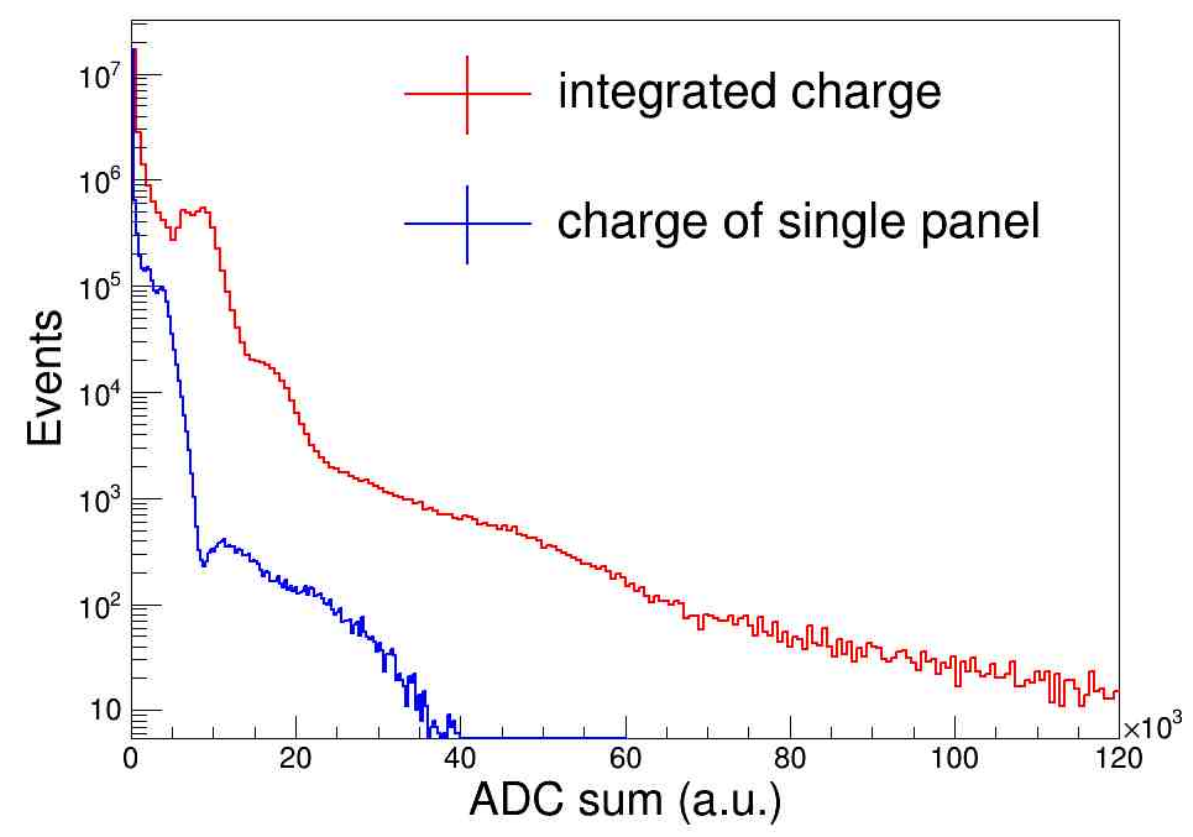

Figura 4.1: Total de carga integrada pelos painéis do topo antes da aplicação de thresholds e triggers. Em vermelho, a carga integrada por todos os painéis do topo. Em azul, a carga integrada por apenas uma das fotomultiplicadoras do topo.

O fluxo de múons em laboratórios subterrâneo é menor do que o observado na superfície [71]. Esses múons sobreviventes possuem energias elevada e depositam grandes quantidades de energia ao passar pelos materiais do detector. A Figura 4.2 exemplifica um múon energético atravessando o detector do COSINE-100. Esses múons depositam energia superior à sua energia de mínima ionização, que para cintiladores plásticos com $3 \mathrm{~cm}$ de espessura é de aproximadamente $6 \mathrm{MeV}$ [62]. Essa energia é maior que as energias esperadas para partículas beta 
e gama provenientes de decaimentos de materiais presentes no experimento. Assim, a seleção de eventos de múons é realizada combinando informações referentes a energia e coincidência entre eventos de painéis diferentes.

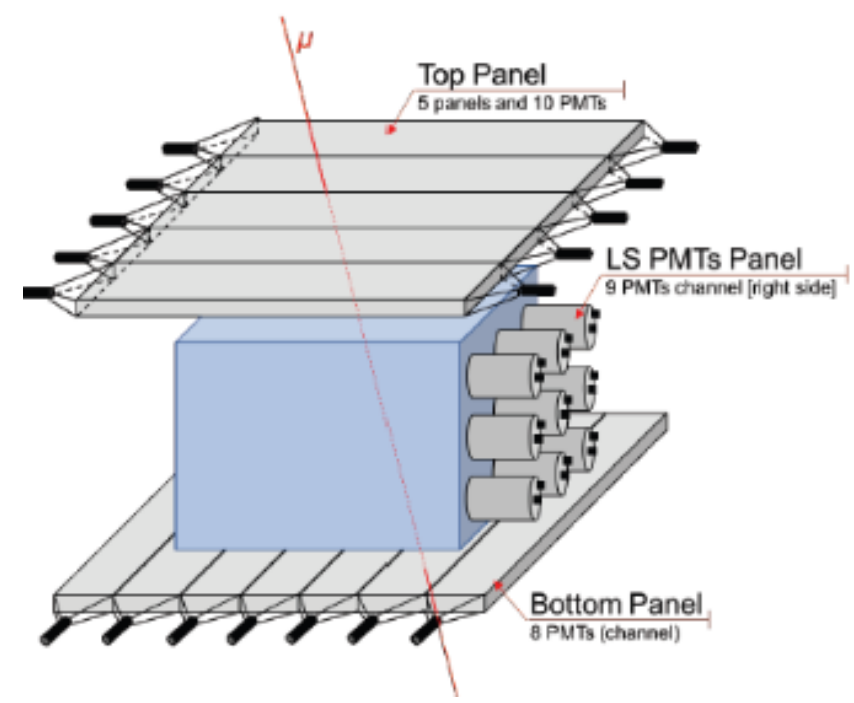

Figura 4.2: exemplo de múon atravessando os detectores.

Para determinar o threshold de carga, a distribuição de carga de eventos coincidentes em 2 lados diferentes foi analisada como consta na Figura 4.3. Nesse histograma, o eixo Y representa a carga do lado de cima e o eixo $\mathrm{X}$ a carga do lado de baixo. Observamos 2 regiões separadas por um vale.

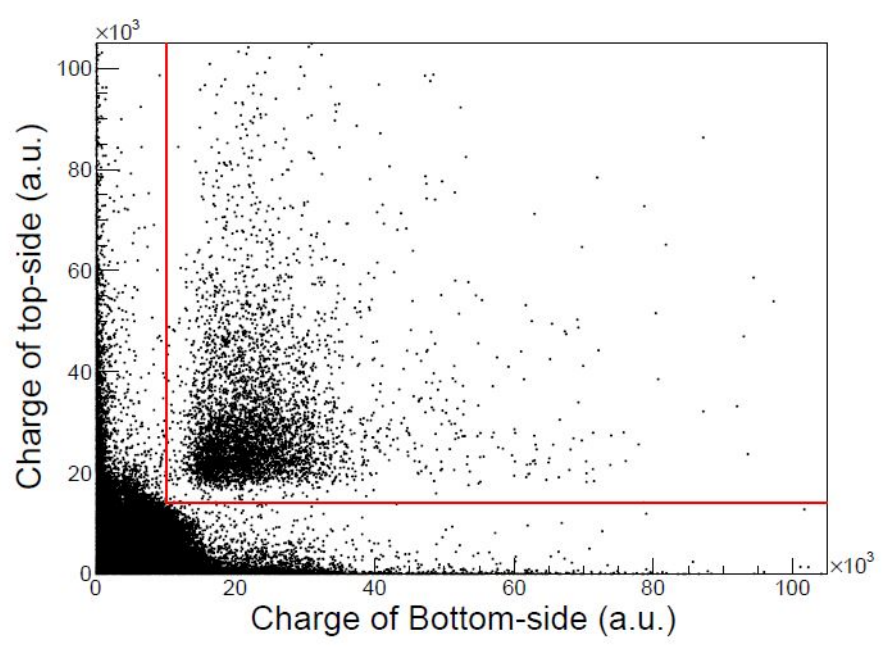

Figura 4.3: Histograma 2D dos eventos por carga no ADC para os painéis do topo (eixo Y) e painéis de baixo (eixo $\mathrm{X}$ ).

As linhas vermelhas representam os thresholds de carga, aplicados simultaneamente aos eventos de forma que sejam rejeitado o máximo de ruídos referentes à eletrônica e eventos 
de emissões beta e gama. Esses estão concentrados na região próxima à origem, abaixo dos thresholds escolhidos. Acima desse valor de carga, selecionamos eventos de múons. Os valores de threshold de carga, em contagens de ADC, para cada painel/lado encontram-se na Tabela 4.1. Um threshold de energia no cintilador líquido de $3 \mathrm{MeV}$ também é usado para selecionar múons. A Figura 4.4 mostra o espectro de carga para os painéis do topo antes e depois da aplicação do threshold de carga.

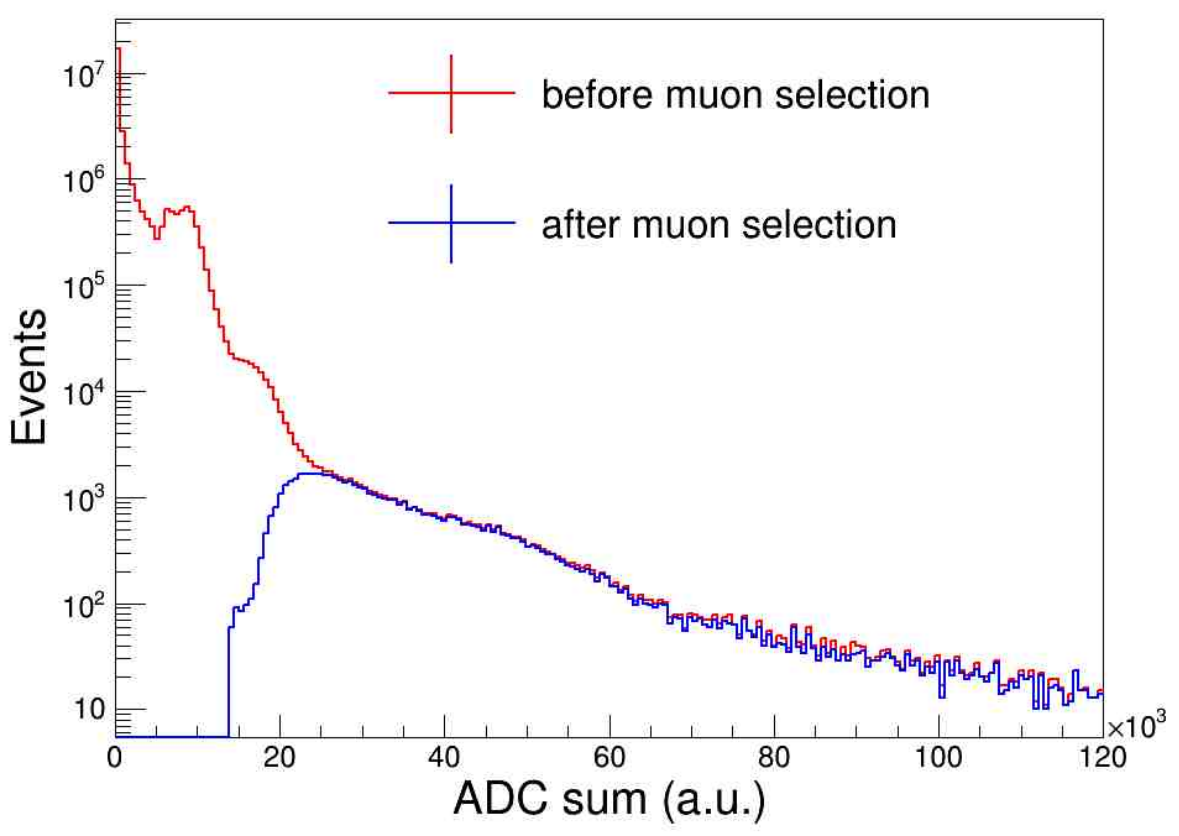

Figura 4.4: Espectro de carga dos painéis do topo. Em vermelho, toda carga coletada, em azul, carga referente aos múons.

\begin{tabular}{|c||c|}
\hline Lado & Threshold (em contagens do ADC) \\
\hline Esquerdo & 12600 \\
Direito & 12000 \\
Frente & 10000 \\
Baixo & 10000 \\
Posterior & 12000 \\
Topo & 14000 \\
Cintilador líquido & $431400(3 \mathrm{MeV})$ \\
\hline
\end{tabular}

Tabela 4.1: Valores de carga para seleção de múons para cada painel do detector de múons e cintilador líquido.

As diferenças de tempo entre os eventos da Figura 4.3 são evidenciadas nas Figuras 4.5 e 4.6. Pode-se perceber que os eventos provenientes de fundos e ruídos apresentam uma distribuição aleatória enquanto que os eventos provenientes de múons encontram-se em uma 
região bem localizada. Os eventos gerados por múons estão dentro de um intervalo de diferença de tempo $\Delta T$ com $5 \sigma$ de largura. Os eventos de múon geram sinais com intervalo de tempo entre 100 e 115 ns. Eventos fora dessa região correspondem a contaminação de fundos.

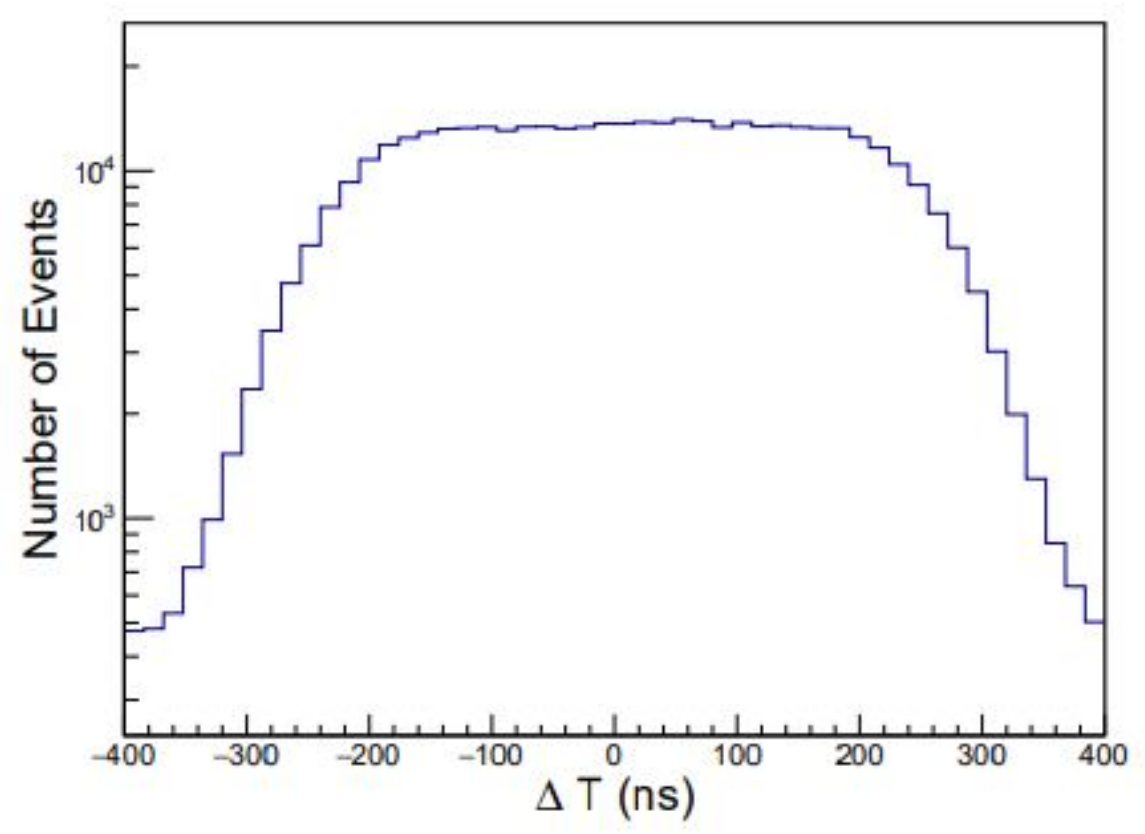

Figura 4.5: diferença de tempo de eventos simultâneos entre os painéis do topo e de baixo com carga inferior ao threshold de carga. 


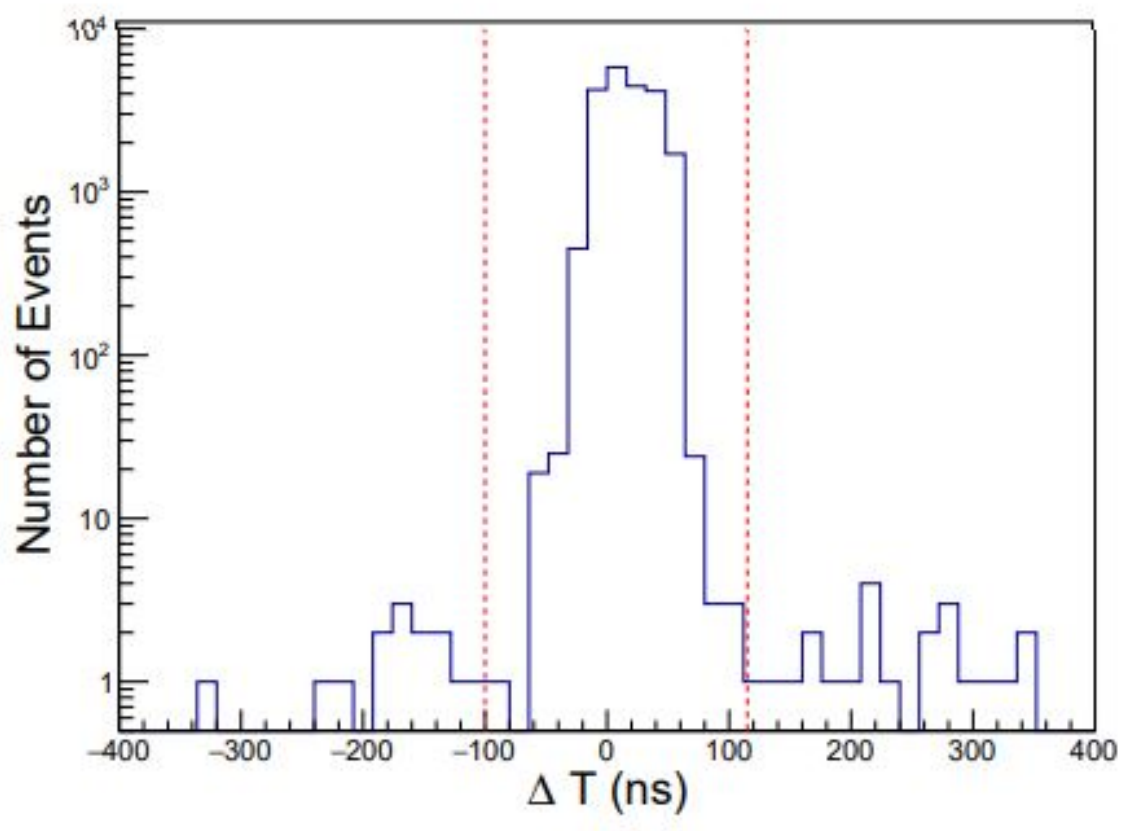

Figura 4.6: diferença de tempo de eventos simultâneos entre os painéis do topo e de baixo com carga superior ao threshold de carga. Em vermelho, região limitada em $5 \sigma$ para excluir contaminação dos fundos.

\subsubsection{Correção de ganho}

Durante o experimento, observou-se que as referências de cargas para as fotomultiplicadoras do detector de múons sofrem pequenas alterações com o tempo devido a queda das tensões de operação. A Figura 4.7 apresenta a variação do espectro de cargas proveniente dessa alteração de tensão das fotomultiplicadoras. Utilizamos como referência o espectro de carga dos primeiros 60 dias de aquisição de dados do COSINE-100. Até o momento, não houve mudança nessa referência. Isso é problemático uma vez que, para thresholds fixos de cargas, prováveis candidatos a múons podem não ser selecionados. O estudo de correção de ganho tem então como objetivo determinar qual foi o deslocamento dessa referência e assim corrigir os valores de carga coletada, permitindo que a seleção de eventos de prováveis múons seja feita de forma mais eficiente. Durante o programa de mestrado, fui responsável dentro da colaboração pela correção do ganho das fotomultiplicadoras do detector de múons. 
Panel 41 [before-gain correction]

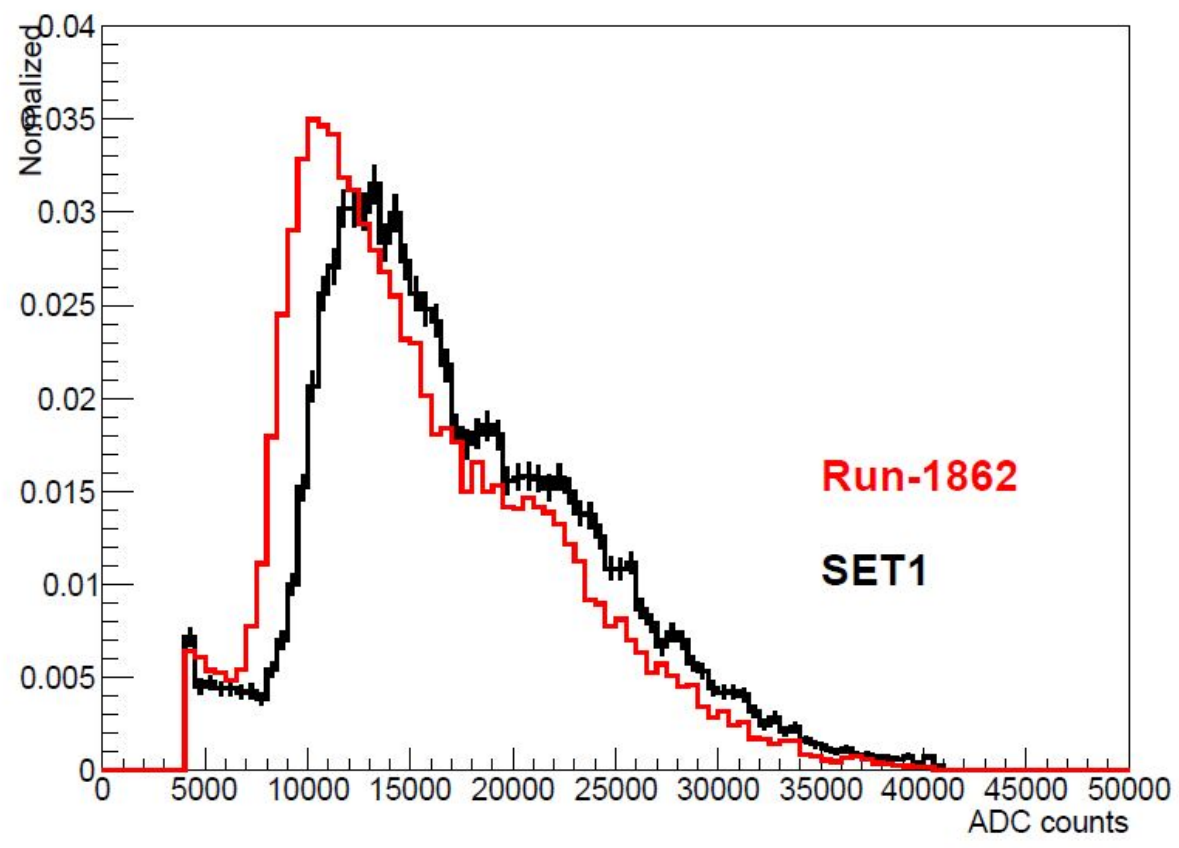

Figura 4.7: Comparação entre espectros de carga de uma das fotomultiplicados na tomada de dados de referência (em preto) e no período entre setembro e novembro de 2019 (vermelho), antes da correção do ganho.

Para a realização do estudo referente à correção de ganho, geram-se histogramas contendo a distribuição de carga coletada semanalmente com a seleção de eventos de múons sem a utilização de coincidência entre painéis. Obtém-se então o valor mais provável da carga coletada por meio do ajuste de uma função, nesse caso uma função Gaussiana para painéis com apenas uma fotomultiplicadora, como mostra a Figura 4.8, ou distribuição de Landau para fotomultiplicadoras de painéis do topo, como mostra a Figura 4.9. A distribuição de Landau é definida como $p(x)=\frac{1}{2 \pi} \int_{o}^{\infty} d t e^{-t \log (t)-x t} \sin (\pi t)$, O software ROOT permite ajustar essa função e obter o valor mais provável como sendo o valor de x para o pico da função. A distribuição de Landau é a mais adequada para representar a energia perdida por partículas em pequenas camadas de matéria [72]. A geometria dos detectores dos lados aumenta a quantidade de detector plástico que os múons atravessam: um muon que atravessa os painéis do topo ou de baixo, que se encontram paralelos ao solo, atravessa menos material em comparação aos detectores dos demais lados, que se encontram perpendiculares em relação aos painéis horizontais. Além disso, os painéis de baixo recebem múons que perderam energia por interação com diversos componentes do experimento. Por isso, uma gaussiana simples próxima ao pico do histograma é o suficiente para obter o valor média da carga. Faz-se então um ajuste linear da evolução temporal desse valor mais provável. O coeficiente angular então é usado para gerar o fator de 
correção de ganho, que aplicado nos códigos de extração de dados, corrige os valores médios garantindo que os thresholds utilizados não precisem ser alterados. A Figura 4.10 apresenta o monitoramento desse valor mais provável antes e depois da correção de ganho.

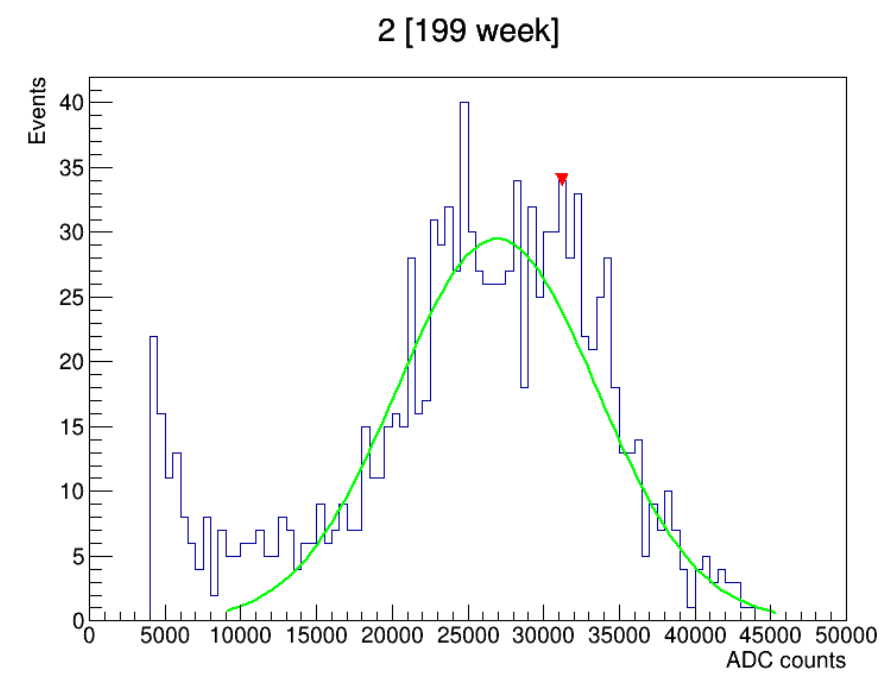

Figura 4.8: Espectro de carga de possíveis eventos de múons de uma das fotomultiplicadoras de um dos painéis do lado esquerdo com o ajuste de uma função gaussiana para obtenção do valor mais provável. O algoritmo do ROOT obtém um valor aproximado de pico, sinalizado pelo triângulo vermelho, para uso como valor inicial do ajuste da função.

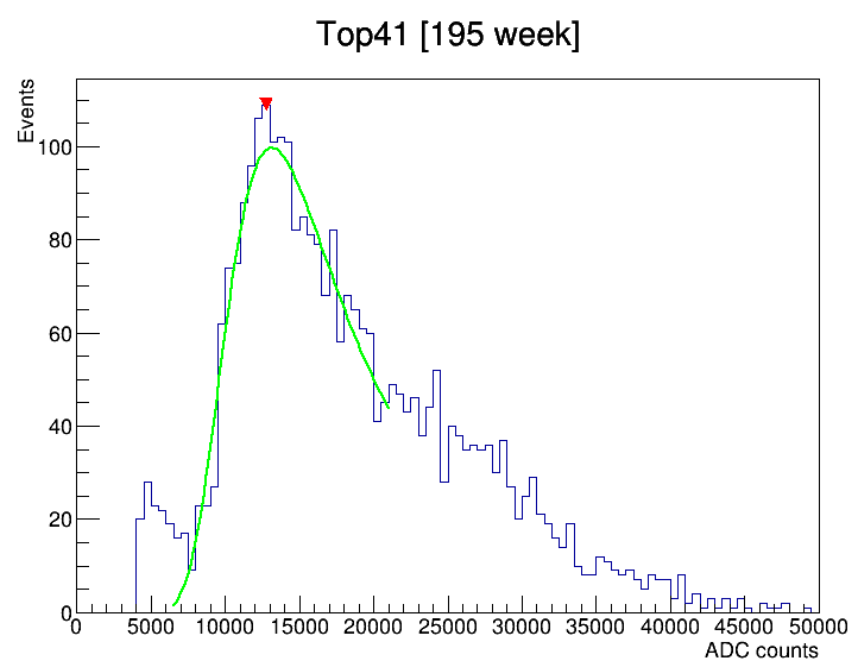

Figura 4.9: Espectro de carga de possíveis eventos de múons de uma das fotomultiplicadoras de um dos painéis do topo com o ajuste de uma função Landau para obtenção do valor mais provável. O algoritmo do ROOT obtém um valor aproximado de pico, sinalizado pelo triângulo vermelho, para uso como valor inicial do ajuste da função.

O ganho é aplicado à carga de cada evento da seguinte forma:

$$
C_{\text {corr }}=C \frac{g_{\text {ref }}}{\text { coef } f_{\text {linear }}+t \text { coef } f_{\text {angular }}}
$$


onde $C_{c o r r}$ é a carga corrigida, $C$ a carga sem correção, $g_{r e f}$ o valor mais provável de carga referência, t a informação temporal do evento, coe $f_{\text {linear }}$ e coe $f_{\text {angular }}$ os coeficientes lineares e angulares, respectivamente. Esses valores são obtidos do ajuste linear realizado. Uma comparação entre o espectro de referência e o espectro de energia depois da correção de ganho se encontra na Figura 4.11 .
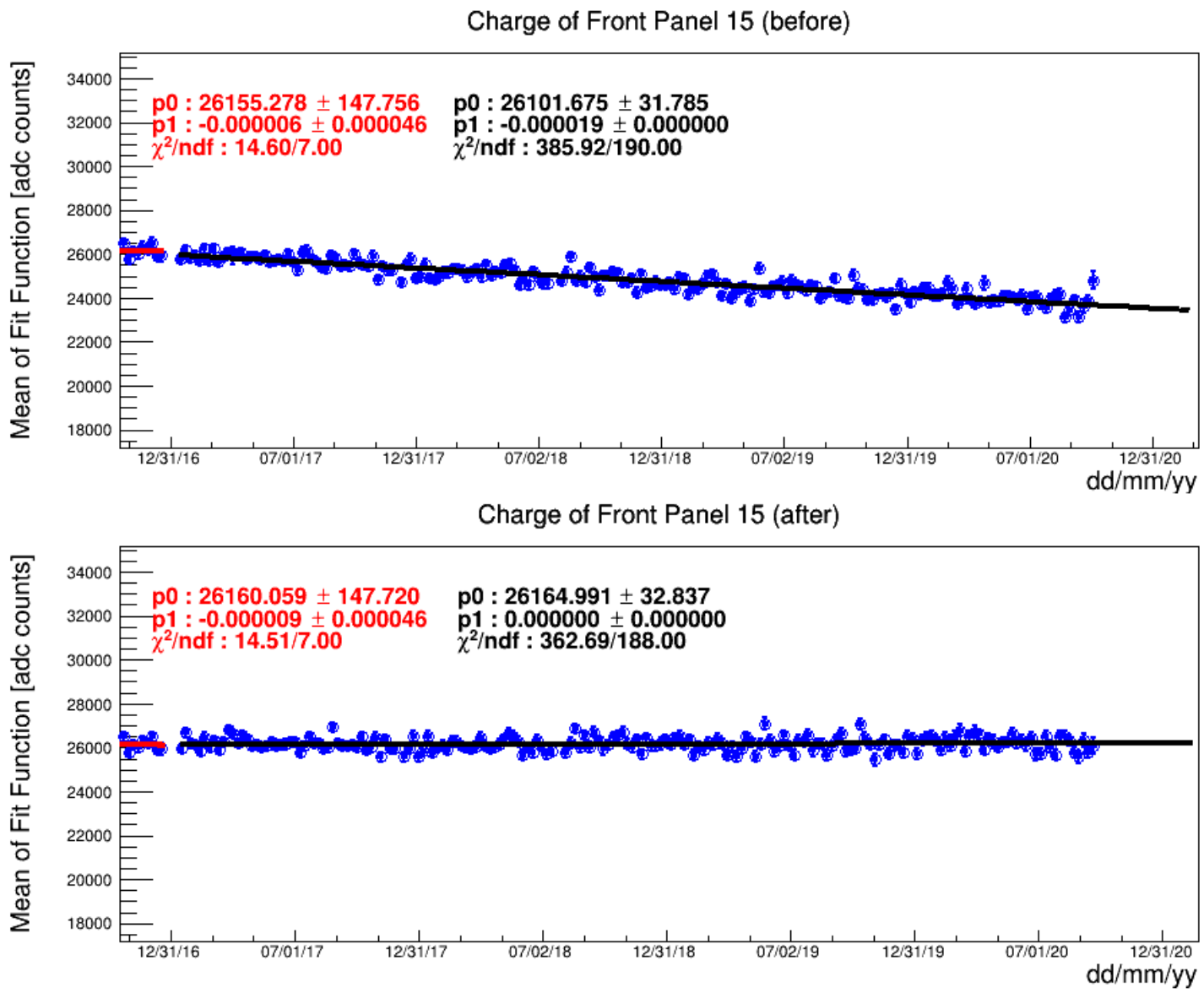

Figura 4.10: Exemplo de evolução temporal do valor mais provável da carga para uma das fotomultiplicadoras estudadas. Acima, valores sem a correção de ganho e abaixo, valores obtidos após a aplicação do fator de correção de ganho. As linhas apresentam o ajuste linear aplicado ao valor mais provável. As linhas vermelhas apresentam o valor mais provável da carga dos primeiros 60 dias de aquisição de dados do COSINE-100, utilizados como referência. 


\section{Panel 41 [after-gain correction]}

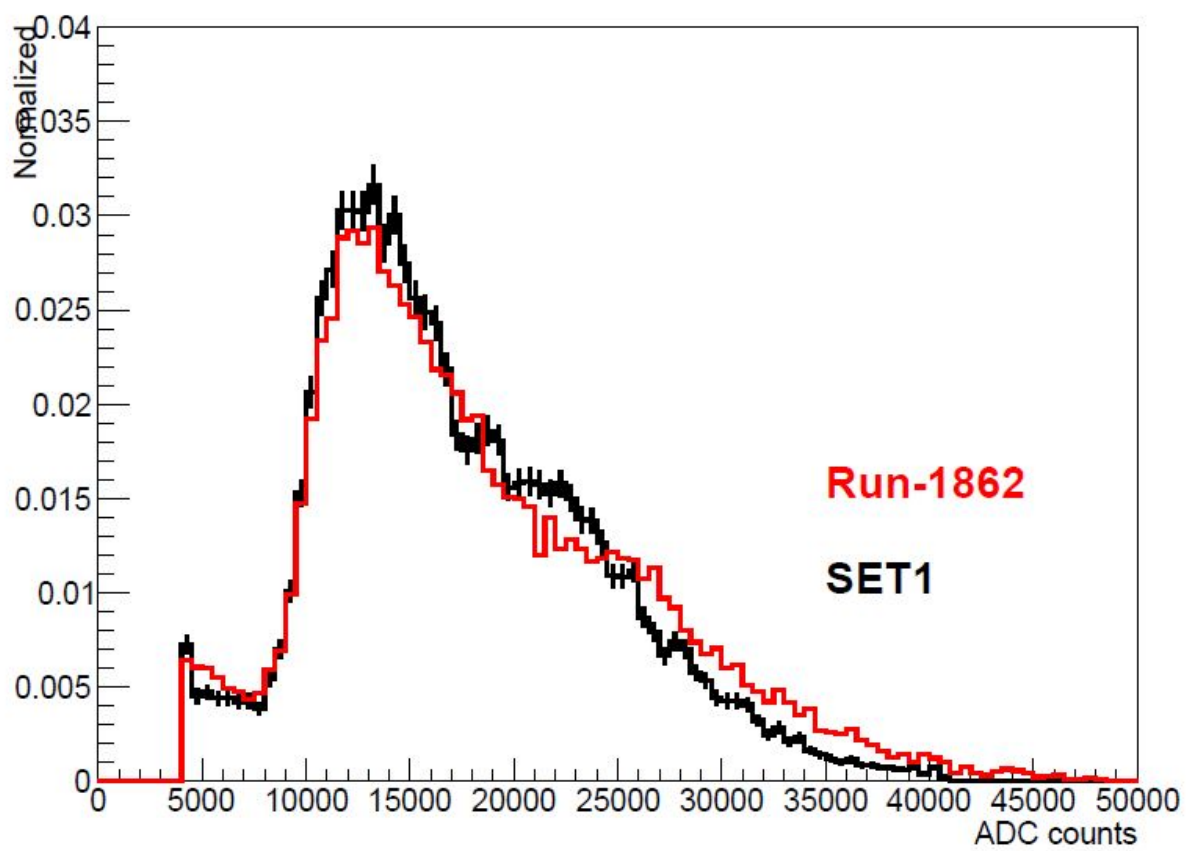

Figura 4.11: Comparação dos espectros de carga de uma das fotomultiplicados na tomada de dados de referência (em preto) e de Setembro a Novembro de 2019 (vermelho) após a correção do ganho.

Com a correção de ganho, foi possível reduzir a variação dos valores médios das fotomultiplicadoras a $0.03 \pm 0.02 \%$, como consta nas Figuras $4.12 \mathrm{e} 4.13$.

Gain dropped of 42 PMTs (Plastic Scintillator)

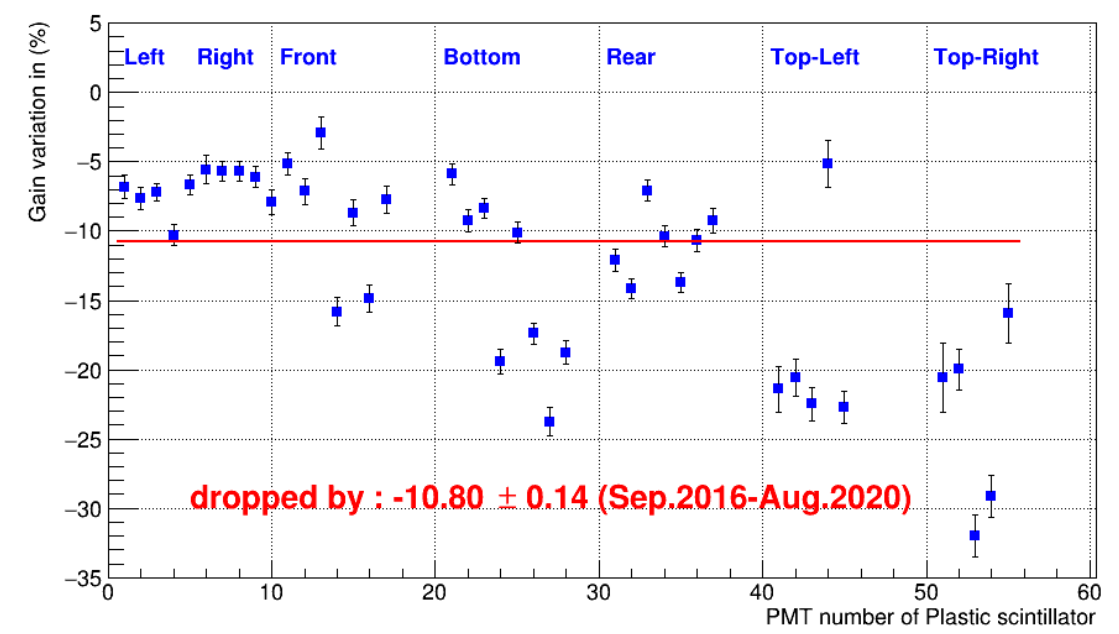

Figura 4.12: Variação do valor mais provável do ganho das fotomultiplicadoras antes da correção de ganho. 


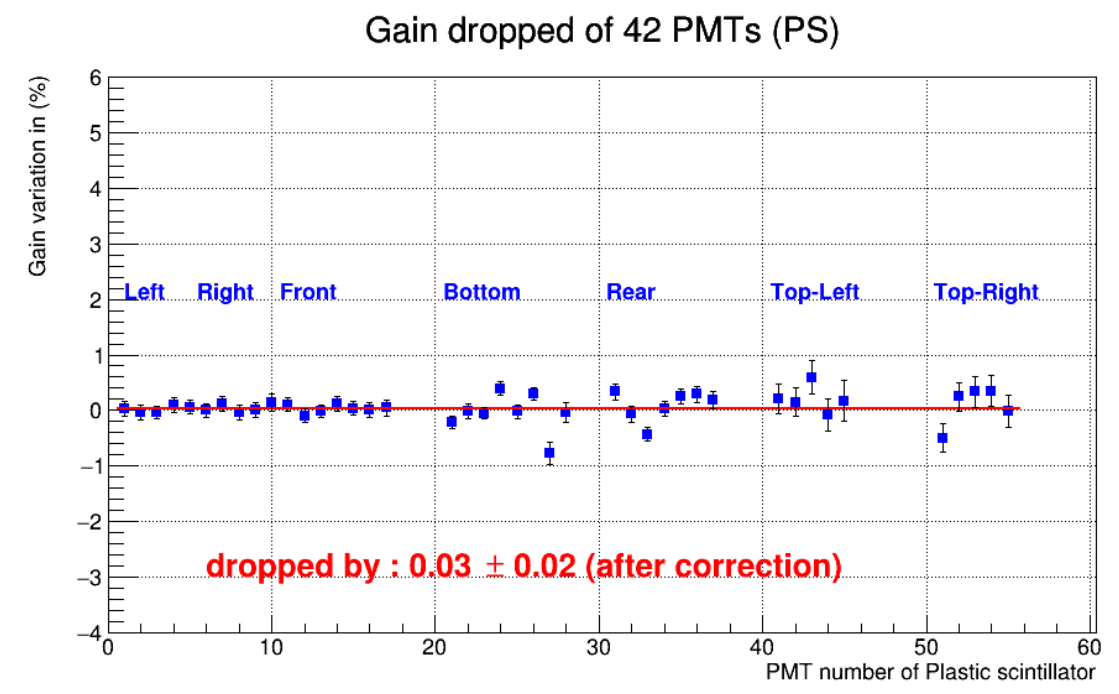

Figura 4.13: Variação do valor mais provável do ganho das fotomultiplicadoras depois da correção de ganho

A correção de ganho é atualizada a cada período de tempo de aproximadamente 2 meses. Uma comparação entre os dados corrigidos e suas referências é realizada e em casos de divergências, novos valores de ganho são obtidos e utilizados para correção dos dados a partir da data em que se observou tal divergência. Essas analises são discutidas e validadas com os outros membros da colaboração. Esses fatores são inclusos nas macros utilizadas para o processamento dos dados brutos obtidos pelo COSINE-100, aplicados na produção dos dados utilizados nas análises realizadas pela colaboração.

\subsection{Fluxo de múons}

O fluxo de múons em laboratórios subterrâneos é bem menor que o observado na superfície graças ao perfil de rocha acima do laboratório. Porém, os múons mais energéticos conseguem atravessar a rocha e os detectores do experimento, depositando energia e induzindo eventos. Dessa forma, é necessário conhecer o fluxo de múons para caracterizar seus sinais e gerar mecanismos para rejeição desses fundos para análises referentes à busca de matéria escura.

O fluxo de múons no experimento é determinado usando o detector de múons com a informação de todas as coincidências entre fotomultiplicadoras dos lados diversos com as do topo. Nessa análise, os dados são normalizados pela área efetiva dos painéis do topo, $A_{d}=$ $5.48 \pm 0.16 m^{2}$. A incerteza dessa área está relacionada com a área dos painéis do topo que se 
estendem além dos painéis dos lados. O fluxo diário é calculado por:

$$
I_{\mu}^{0}=\frac{N_{\mu}}{t_{d} A_{d} \epsilon_{\mu}}
$$

Onde $N_{\mu}$ é a quantidade de eventos de múons detectados, $\epsilon_{\mu}$ é a eficiência de seleção de múons e $t_{d}$ o tempo de de aquisição de dados. A Figura 4.14 apresenta a variação do fluxo diário de múons no experimento entre 23 de setembro de 2016 e 22 de setembro de 2020 . A linha vermelha representa um ajuste linear para obtenção do valor médio do fluxo diário de múons. A Tabela 4.2 apresenta uma comparação de valores encontrados para um período de 3 meses [57], o período entre setembro de 2016 e julho de 2019 [73] e para o período observado neste trabalho, 23 de setembro de 2016 a 22 de setembro de 2020.

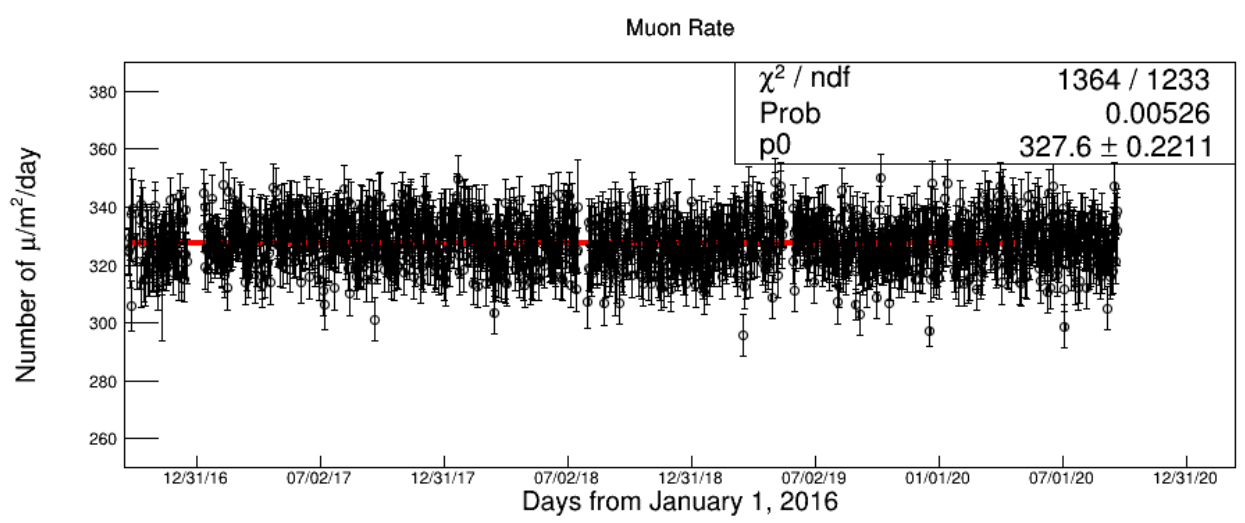

Figura 4.14: Fluxo de múons no experimento COSINE-100. Cada ponto representa um dia. A linha vermelha apresenta um ajuste linear para obtenção do fluxo médio diário de múons. Esse ajuste apresenta a qualidade de ajuste $\chi^{2} / N D F$ de $1364 / 1233 \approx 1.1$, indicando que os dados estão de acordo com o modelo proposto.

O valor médio do fluxo encontrado foi $327.8 \pm 0.2_{\text {stat }} \pm 9.6_{\text {sist }}$ múon $/ \mathrm{m}^{2} /$ dia. A incerteza sistemática se relaciona com a área dos painéis do topo que se estendem para além dos painéis do lado e a incerteza estatística provém dos ajustes dos dados ao modelo. A Tabela 4.2 também apresenta o resultado de medições realizadas no túnel A6, em 2005 [74]. Os resultados apresentam valores com ordem de grandeza semelhante. A diferença do fluxo obtido no túnel A5 e A6 leva em conta a geometria da montanha e distância horizontal de 200 m entre os túneis: uma quantidade menor de perfil rochoso acima do túnel A6 implica em um fluxo maior. Utilizando um modelo empírico para determinação do fluxo de múons em função da profundidade equivalente (equação 4.1) [75], considerando que a densidade da rocha acima do laboratório seja $2.65 \mathrm{~g} / \mathrm{cm}^{3}$ ( rocha padrão, [76]) que permite determinar a profundidade equivalente do laboratório de 1855 (mwe), temos: 


$$
I_{\mu}\left(h_{0}\right)=67.9710^{-6} \exp \left\{\frac{h_{0}}{285}\right\}+2.07110^{-6} \exp \left\{\frac{h_{0}}{698}\right\}
$$

onde $h_{0}$ é a profundidade equivalente em metros de água e $I_{\mu}\left(h_{0}\right)$ o fluxo de múons em (múon $/ \mathrm{cm}^{2} / \mathrm{s}$ ). Sabendo ainda que laboratórios abaixo de montanhas apresentam um fluxo $4 \pm 2$ vezes maior que o obtido pela equação empírica [77], uma vez que essa equação considera um perfil plano horizontal, obtemos $589 \pm 294$ múon $/ \mathrm{m}^{2} /$ dia , o que indica que os valores experimentais concordam com o valor teórico.

\begin{tabular}{|c|c|}
\hline Período & Fluxo (múon $/ \mathrm{m}^{2} /$ dia) \\
\hline 3 meses & $328 \pm 1_{\text {stat }} \pm 10_{\text {sist }}$ \\
\hline $23 / 09 / 2016-31 / 07 / 2019$ & $327.8 \pm 0.3_{\text {stat }} \pm 9.5_{\text {sist }}$ \\
\hline $23 / 09 / 2016-22 / 09 / 2020$ & $327.8 \pm 0.2_{\text {stat }} \pm 9.6_{\text {sist }}$ \\
\hline Túnel A6 & $380 \pm 20_{\text {sist }}$ \\
\hline Limites esperados & $589 \pm 294$ \\
\hline
\end{tabular}

Tabela 4.2: Fluxo diário de múons no laboratório Y2L.

Uma comparação com o fluxo médio de múons na superfície [57] $(11.8 \pm 0.6) 10^{6}$ múons $/ \mathrm{m}^{2} /$ dia nos mostra que o fluxo em Y2L é da ordem de $10^{4}$ vezes menor. Esses dados mostram a eficácia na redução de múons oriundos de raios cósmicos no experimento.

\subsection{Modulação anual de múons e temperatura atmosférica}

Os múons são produzidos no decaimento de mésons produzidos da interação de raios cósmicos com os núcleos da atmosfera. Flutuações na densidade e temperatura atmosférica contribuem para variações no fluxo de múons.

A taxa de produção de mésons é afetada pela variação sazonal da atmosfera. A variação anual ocorre principalmente pela diferença de exposição à luz solar durante o ano, mais alta no verão, que eleva a temperatura, e mais baixa no inverno. Essa diferença de temperatura modifica a densidade da atmosfera, alterando o caminho livre médio da produção de mésons. Apenas múons energéticos conseguem penetrar a montanha e chegar no laboratório Y2L e os que conseguem são produtos de decaimento de píons carregados $\pi \pm$. Uma pequena fração desses múons é proveniente de káons carregados $\kappa \pm$. O fluxo de múons medido pelo experimento deve apresentar uma modulação relacionada com a modulação atmosférica. O fluxo de múons, em uma primeira aproximação, pode ser descrito como : 


$$
I_{\mu}(t)=I_{\mu}^{0}+\Delta I_{\mu}=I_{\mu}^{0}+\delta I_{\mu} \cos \left(\frac{2 \pi}{T}\left(t-t_{0}\right)\right)
$$

Onde $I_{\mu}^{0}$ é o fluxo médio de múons, $\delta I_{\mu}$ a amplitude da variação dos múons, T o período de 1 ano e $t_{0}$ a fase da modulação.

Para garantir a correlação entre a temperatura atmosférica e o fluxo de múons, apenas eventos relacionados a múons que passaram pelos painéis do topo e de baixo do experimento foram utilizados. Isso indica que a trajetória desses múons foi praticamente vertical. A Figura 4.15 apresenta a quantidade média de múons detectados por dia observados no período de 23 de setembro de 2016 a 22 de setembro de 2020, ajustados com a equação 4.2 .

O fluxo diário apresentado na Figura 4.14 utiliza informação de todos os painéis plásticos. Para a análise da modulação anual do fluxo de múons, apenas os dados de múons que atravessaram os painéis do topo e de baixo são computados. Não há a normalização pela área dos painéis do topo, pois a amplitude da modulação do sinal e sua fração relativa em relação ao valor médio do fluxo são as variáveis de interesse.

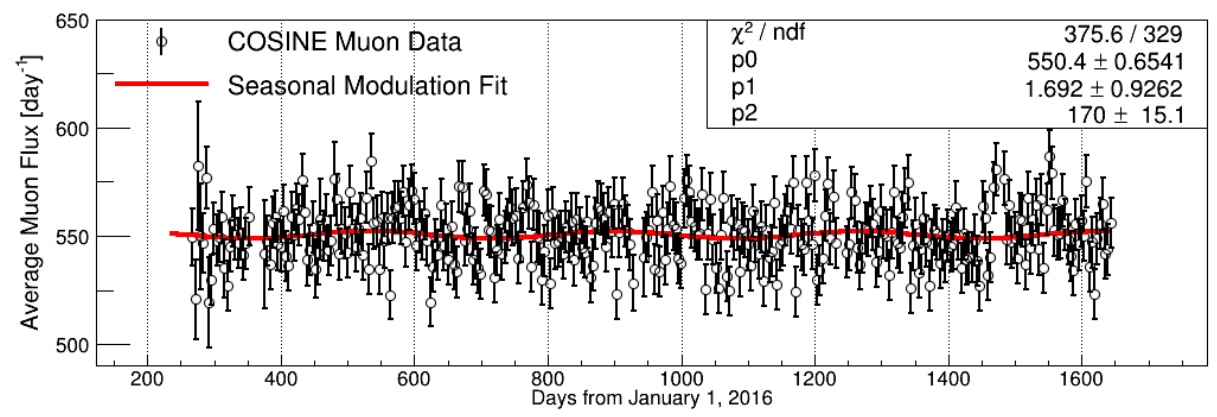

Figura 4.15: Fluxo de múons com sinais coincidentes nos painéis do topo e de baixo no experimento COSINE-100. Cada ponto representa a contagem média de múons diários para 4 dias. A linha vermelha apresenta o ajuste à modulação.

O período utilizado foi o de 1 ano (365.25 dias). Do ajuste ao modelo, obtemos a intensidade média $I_{\mu}^{0}=550.4 \pm 0.6$ múons/dia, amplitude $\delta I_{\mu}=1.6 \pm 0.9$ múons/dia e fase $=$ $170 \pm 15$ dias, que corresponde ao máximo no dia 18 de junho. A qualidade do ajuste $\chi^{2} / N D F$ foi de $376 / 329 \approx 1.1$, indicando um bom ajuste do modelo aos dados experimentais. Comparações dos valores obtidos aqui com os valores reportados na primeira medição [73] realizada pela colaboração se encontram na Tabela 4.3 . A coluna $\delta I_{\mu} / I_{\mu}^{0}(\%)$ apresenta a amplitude em relação ao fluxo médio obtido. 


\begin{tabular}{|c|c|c|c|c|c|}
\hline Período & $I_{\mu}^{0}$ (múon/dia) & $\delta I_{\mu}$ & $\delta I_{\mu} / I_{\mu}^{0}(\%)$ & $t_{0}($ Dias $)$ & $\chi^{2} / N D F$ \\
\hline $23 / 09 / 2016-31 / 072019$ & $551.43 \pm 0.78$ & $3.3 \pm 1.1$ & $0.51 \pm 0.24$ & $179 \pm 19$ & $287 / 240$ \\
\hline $23 / 09 / 2016-22 / 09 / 2020$ & $550.4 \pm 0.6$ & $1.6 \pm 0.9$ & $0.30 \pm 0.16$ & $170 \pm 15$ & $376 / 329$ \\
\hline
\end{tabular}

Tabela 4.3: modulação de múons no laboratório Y2L.

A Tabela 4.4 apresenta uma comparação entre os valores obtidos pelo COSINE-100 e outros experimentos:

\begin{tabular}{|c|c|c|c|}
\hline Experimento & COSINE-100 & BOREXINO & DM-Ice \\
\hline Data de aquisição & $2016-2020$ & $2007-2017$ & $2011-2014$ \\
\hline Amplitude (\%) & $0.30 \pm 0.16$ & $1.36 \pm 0.04$ & $12.3 \pm 1.7$ \\
\hline Fase (dias) & $170 \pm 15$ & $174.8 \pm 3.8$ & $22 \pm 9$ \\
\hline
\end{tabular}

Tabela 4.4: Variação da amplitude de modulação e fase observada em diversos experimentos.

As diferenças na amplitude da modulação estão relacionadas com as características específicas de cada experimento. É importante observar que a fase da modulação para os experimentos COSINE-100 e BOREXINO, situados no hemisfério norte, são próximas enquanto que estão defasadas em aproximadamente 5 meses da fase observada pelo DM-Ice, do hemisfério sul. Esse resultado é esperado, as estações do ano diferem em cada hemisfério, logo a variação da temperatura atmosférica também apresenta essa diferença. Esse tipo de observação é importante, pois os modelos teóricos preveem que a modulação devido à interação com matéria escura seja igual independentemente do hemisfério onde o experimento se situa. Sinais atribuídos à matéria escura com fase destoante podem indicar que o fenômeno observado é influenciado por efeitos sazonais e não são interações com a matéria escura.

A amplitude da modulação dos múons se relaciona com a variação da temperatura e pressão atmosférica em várias altitudes. A atmosfera é modelada como um gás isotérmico para produção de píons e káons e a dependência da variação de fluxo de múons com a temperatura atmosférica é expressa de forma fenomenológica com [78]:

$$
\frac{\Delta I_{\mu}}{I_{\mu}^{0}}=\int_{0}^{\infty} d X \alpha(X) \frac{\Delta T(X)}{T(X)}
$$

onde $\mathrm{T}(\mathrm{X})$ é a temperatura atmosférica na altitude $\mathrm{X}, \Delta T(X)$ a variação de temperatura na altitude $\mathrm{x}$ e $\alpha(X)$ o coeficiente de temperatura que relaciona as flutuações de temperatura atmosférica com a flutuação da intensidade de múons. A integral é realizada do nível do mar até a maior altitude onde ocorre a produção de píons. O intervalo de altitudes utilizados se encontram na Figura 4.16. A equação 4.3 pode ser reescrita como [78-80]: 


$$
\Delta I_{\mu}=\int_{0}^{\infty} d X W(X) \Delta T(X)
$$

onde $\mathrm{W}(\mathrm{X})$ são pesos que relacionam a dependência entre a temperatura e a produção de mésons e seus decaimentos observados nos detectores de Y2L. Usando as equações $4.3 \mathrm{e} 4.4$, obtemos a relação entre $\alpha(X)$ e $W(X)$ :

$$
\alpha(X)=\frac{T(X)}{I_{\mu}^{0}} W(X)
$$

A atmosfera pode ser descrita como várias camadas com uma variação contínua de temperatura e pressão. Podemos parametrizar essa variação considerando a atmosfera como um corpo de camadas isotérmicas com pressão $X_{n}$ e temperatura $T\left(X_{n}\right)$. Podemos definir uma temperatura efetiva $T_{\text {eff }}$ como uma média ponderada sobre as altitudes da atmosfera [79] :

$$
T_{e f f} \approx \frac{\sum_{n=0}^{N} X_{n} T\left(X_{n}\right)\left(W_{\pi}\left(X_{n}\right)+W_{\kappa}\left(X_{n}\right)\right)}{\sum_{n=0}^{N} X_{n}\left(W_{\pi}\left(X_{n}\right)+W_{\kappa}\left(X_{n}\right)\right)}
$$

Onde $\Delta X_{n}$ é a diferença de pressão entre duas camadas da atmosfera e $W_{\pi, \kappa}$ funções do peso da contribuição da produção de múons por káons e píons em relação à altitude em que os múons foram produzidos, definidas por [79]:

$$
W_{\pi, \kappa}(X) \approx \frac{\left(1-X / \Lambda_{\pi, \kappa}^{\varsigma}\right)^{2} e^{-X / \Lambda_{\pi, \kappa}} A_{\pi, \kappa}^{1}}{\gamma+(\gamma+1) B_{\pi, \kappa}^{1} K_{\pi, \kappa}(X)\left(\left\langle E_{t h r} \cos \theta\right\rangle / \epsilon_{\pi, \kappa}\right)^{2}}
$$

com

$$
K_{\pi, \kappa}(X)=\frac{\left(1-X / \Lambda_{\pi, \kappa}^{\prime}\right)^{2}}{\left(1-e^{-X / \Lambda_{\pi, \kappa}^{c}}\right) \Lambda_{\pi, \kappa}^{\prime} / X}
$$

Os índices $\pi e \kappa$ referem-se às funções para píons e káons, respectivamente. O parâmetro $A_{\pi, \kappa}^{1}$ descreve a contribuição relativa dos káons/píons e inclui o fluxo de da produção de mésons na região da camada atmosférica, massa dos mésons e dos múons. O parâmetro $B_{\pi, \kappa}^{1}$ referese à atenuação atmosférica dos mésons. $\gamma$ representa o índice espectral $\rrbracket^{1}$ do múon produzido. $E_{t h r}$ é a energia mínima requerida para que um múon penetre no laboratório Y2L. O parâmetro $\Lambda_{\pi, \kappa}$ é o comprimento de atenuação para káons/píons. O parâmetro utilizado na equação se relaciona com esse seguindo a relação $1 / \Lambda_{\pi, \kappa}^{\varsigma}=1 / \Lambda_{N}-1 / \Lambda_{\pi, \kappa}$, onde $\Lambda_{N}$ é o comprimento

\footnotetext{
${ }^{1} \mathrm{O}$ índice espectral mede a dependência da densidade de fluxo de uma fonte de radiação com a sua energia, supondo $\Phi(E) \propto E^{\gamma}$, sendo $\gamma$ definido como $\gamma=\frac{\partial \Phi(E)}{\partial E}$
} 
de atenuação para os raios cósmicos primários. O parâmetro $\epsilon_{\pi, \kappa}$ é a energia crítica do méson, para a qual o méson possui probabilidade igual de decair ou interagir com o meio. Na Tabela 4.5 se encontram os valores utilizados para cada parâmetro [79]. Na Tabela, o parâmetro $\tau_{\kappa / \pi}$ é a razão entre káons e píons produzidos na atmosfera.

\begin{tabular}{|c|c|c|}
\hline Parâmetro & Valor & Unidade \\
\hline$A_{\pi}^{1}$ & 1 & - \\
\hline$A_{\kappa}^{1}$ & $0.38 \tau_{\kappa / \pi}$ & - \\
\hline$\tau_{\kappa / \pi}$ & $0.149 \pm 0.060$ & - \\
\hline$B_{\pi}^{1}$ & $1.460 \pm 0.007$ & - \\
\hline$B_{\kappa}^{1}$ & $1.740 \pm 0.028$ & - \\
\hline$\epsilon_{\pi}$ & $114 \pm 3$ & $\mathrm{GeV}$ \\
\hline$\epsilon_{\kappa}$ & $851 \pm 14$ & $\mathrm{GeV}$ \\
\hline$\gamma$ & $1.7 \pm 0.1$ & - \\
\hline$\Lambda_{N}$ & 120 & $\mathrm{~g} / \mathrm{cm}^{2}$ \\
\hline$\Lambda_{\pi}$ & 180 & $\mathrm{~g} / \mathrm{cm}^{2}$ \\
\hline$\Lambda_{\kappa}$ & 160 & $\mathrm{~g} / \mathrm{cm}^{2}$ \\
\hline
\end{tabular}

Tabela 4.5: Valores dos parâmetros utilizados para determinação da temperatura efetiva $T_{\text {eff }}$.

O limite de energia $E_{t h r}$ depende do perfil da rocha pelo qual o múon passou. O valor médio do produto da energia limite e o co-seno do ângulo de zênite do múon $2\left\langle E_{t h r} \cos \theta\right\rangle=$ $795 \pm 140 \mathrm{GeV}$ foi obtido por simulações do fluxo de múons em Y2L [73].

A Figura 4.16 apresenta a variação da temperatura em diferentes altitudes/níveis de pressão obtidos pelo European Center for Medium-range Weather Forecasts (ECMWF), bem como os fatores de ponderação.

\footnotetext{
2ângulo em relação à linha normal ao laboratório
} 


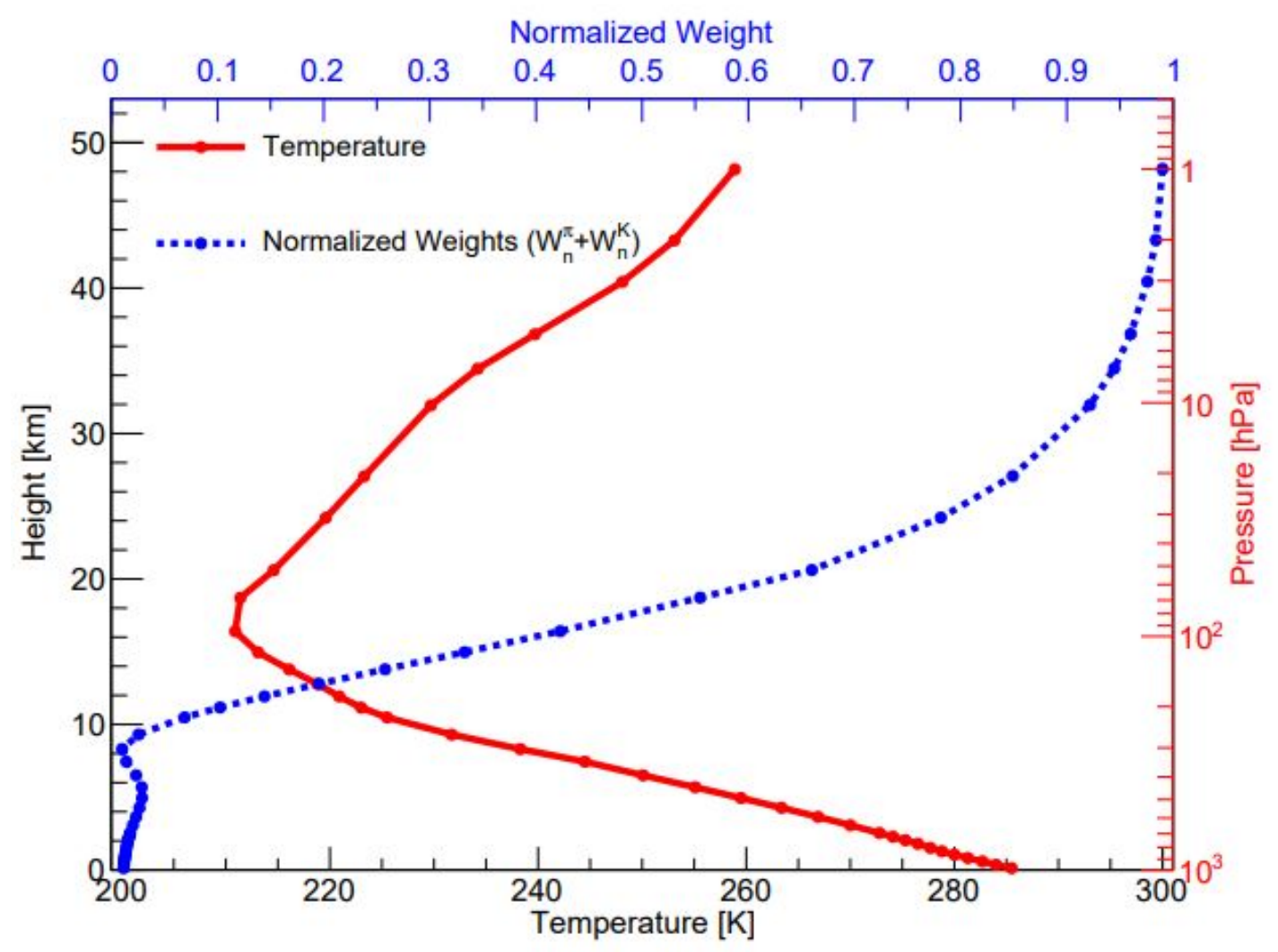

Figura 4.16: Em vermelho, o valor médio da temperatura para cada altitude/nível de pressão atmosférica. Em azul, as ponderações normalizadas $W_{\pi}+W_{\kappa}$ utilizadas para determinação da temperatura efetiva.

Os dados de temperatura do ECMWF utilizam vários tipos de observações, como medições da superfície e satélites, em várias regiões do mundo, e apresentam dados para as demais regiões através da interpolação dos dados com um modelo de atmosfera global. As temperaturas são obtidas para 37 altitudes discretas no intervalo de 0 a $50 \mathrm{~km}, 4$ vezes por dia às 00:00 h, 06:00 h, 12:00 h, e 18:00 h no horário GMT. Os dados de temperatura efetiva foram calculados e são apresentados na Figura 4.17. Em primeira ordem, a temperatura efetiva é descrita com uma função análoga à da modulação do fluxo de múons:

$$
T_{e f f}(t)=T_{e f f}^{0}+\Delta T_{e f f}=T_{e f f}^{0}+\delta T_{e f f} \cos \left(\frac{2 \pi}{T}\left(t-t_{0}\right)\right)
$$

Onde $T_{e f f}^{0}$ é a temperatura efetiva média, $\delta T_{T e f f}$ a amplitude da modulação, T o período de um ano e $t_{0}$ a fase da modulação. 


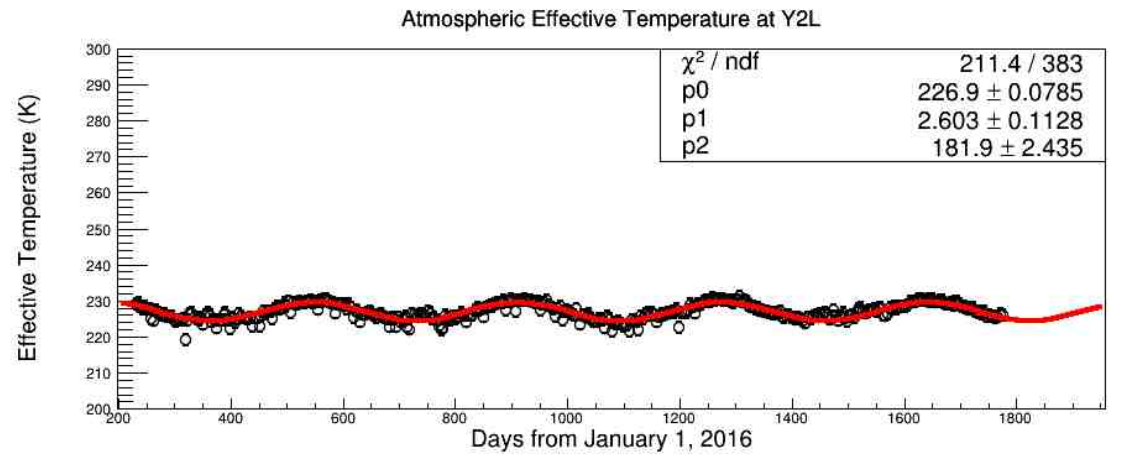

Figura 4.17: Temperatura efetiva da atmosfera acima do laboratório Y2L no período de 23 de setembro de 2016 a 22 de setembro de 2020 calculada com a equação 4.6. Cada ponto apresenta a temperatura média de 4 dias. A linha vermelha apresenta a função ajustada.

O resultado da Figura 4.17 apresenta uma temperatura efetiva média de $T_{\text {eff }}^{0}=226.9 \pm$ $0.1 \mathrm{~K}$ e fase $t_{0}=(181.2 \pm 2.4)$ dias. A qualidade do ajuste $\chi^{2} / N D F=211 / 383 \approx 0.6$ não é tão próxima de 1 . Como o modelo é uma aproximação e não leva em conta fontes de variação da temperatura atmosférica além da variação sazonal, os resultados são razoáveis. A amplitude $\delta T_{\text {eff }}=2.6 \pm 0.1 \mathrm{~K}$ corresponde a $\delta T_{\text {eff }} / T_{e f f}^{0}=1.13 \pm 0.05 \%$. De forma análoga, a Tabela 4.6 apresenta uma comparação com os primeiros valores reportados pela colaboração.

\begin{tabular}{|c|c|c|c|c|c|}
\hline Período & $T_{\text {eff }}^{0} \mathrm{~K}$ & $\delta T_{\text {eff }}$ & $\delta T_{\text {eff }} / T_{\text {eff }}^{0}(\%)$ & $t_{0}$ (Dias) & $\chi^{2} / N D F$ \\
\hline $23 / 09 / 2016-31 / 072019$ & $229.0 \pm 0.1$ & $2.43 \pm 0.13$ & $1.06 \pm 0.05$ & $183 \pm 2$ & $124 / 253$ \\
\hline $23 / 09 / 2016-22 / 09 / 2020$ & $226.9 \pm 0.1$ & $2.6 \pm 0.1$ & $1.13 \pm 0.05$ & $181 \pm 2$ & $211 / 383$ \\
\hline
\end{tabular}

Tabela 4.6: modulação da temperatura efetiva acima laboratório Y2L.

Com o uso das equações $4.4 \mathrm{e} 4.5$ pode-se relacionar a taxa de múons média e a temperatura efetiva média pelo coeficiente de correlação de temperatura $\alpha_{T}$ :

$$
\alpha_{T}=\frac{T_{e f f}^{0}}{I_{\mu}^{0}} \int_{0}^{\infty} d X W(X)
$$

Onde $W(X)=W_{\pi}(X)+W_{\kappa}(X)$. A equação 4.3 também se simplifica:

$$
\frac{\Delta I_{\mu}}{I_{\mu}^{0}}=\alpha_{T} \frac{\Delta T_{\text {eff }}}{T_{e f f}^{0}}
$$

A Figura 4.18 contém um ajuste linear de $\Delta I_{\mu} / I_{\mu}^{0}$ por $\Delta T_{\text {eff }} / T_{e f f}^{0}$. O coeficiente de correlação de temperatura obtido do ajuste linear dos dados foi $\alpha_{T}=0.73 \pm 0.10$, com coeficiente de correlação $\mathrm{R}=0.4$, indicando que os dados se correlacionam de forma positiva. 


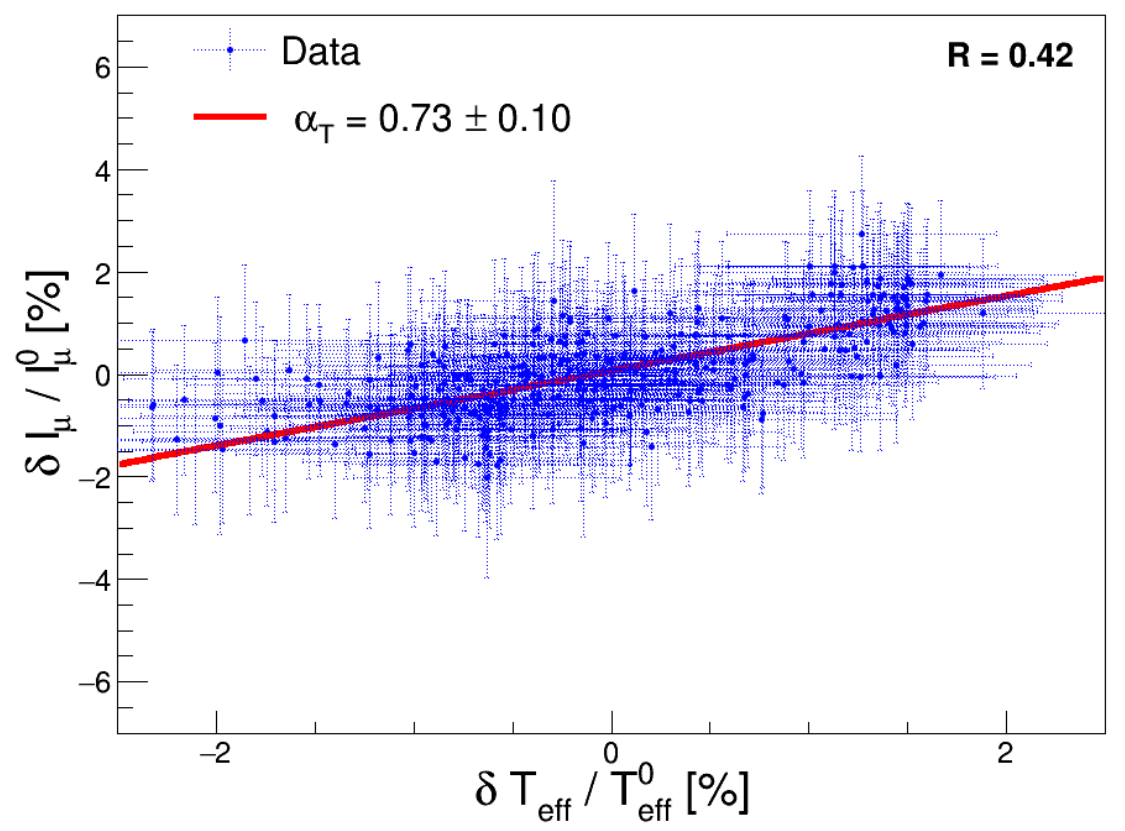

Figura 4.18: $\Delta I_{\mu} / I_{\mu}^{0}$ por $\Delta T_{e f f} / T_{e f f}^{0}$. Cada um dos pontos representa os dados médios de 4 dia.

A Figura 4.19 apresenta a comparação de parâmetros de correlação de temperatura em função da profundidade equivalente de vários experimentos. A linha vermelha apresenta a predição teórica de $\alpha_{T}$ para produção de múons por píons e káons com razão de káons/píons listada na Tabela 4.5 [79,81] utilizando a seguinte relaçã $0^{3}$.

$$
\alpha_{T}=\frac{1}{D_{\pi}} \frac{\left(1 / \epsilon_{\kappa}\right)+A_{\kappa}^{1}\left(D_{\pi} / D_{\kappa}\right)^{2} \epsilon_{\kappa}}{\left(1 / \epsilon_{\pi}\right)+A_{\kappa}^{1}\left(D_{\pi} / D_{\kappa}\right) \epsilon_{\pi}}
$$

com

$$
D_{\pi, \kappa}=\frac{\gamma}{\gamma+1} \frac{\epsilon_{\pi, \kappa}}{1.1\left\langle E_{t h r} \cos \theta\right\rangle}+1
$$

Para comparação, a linha preta apresenta o modelo onde o valor $\tau_{\pi, \kappa}$ é nulo e apenas píons são considerados para a produção de múons:

\footnotetext{
${ }^{3}$ esse modelo, bem como a determinação da temperatura efetiva são sensíveis à razão de produção de píons/káons utilizada $\left(\tau_{\pi, \kappa}\right.$ da Tabela 4.5
} 


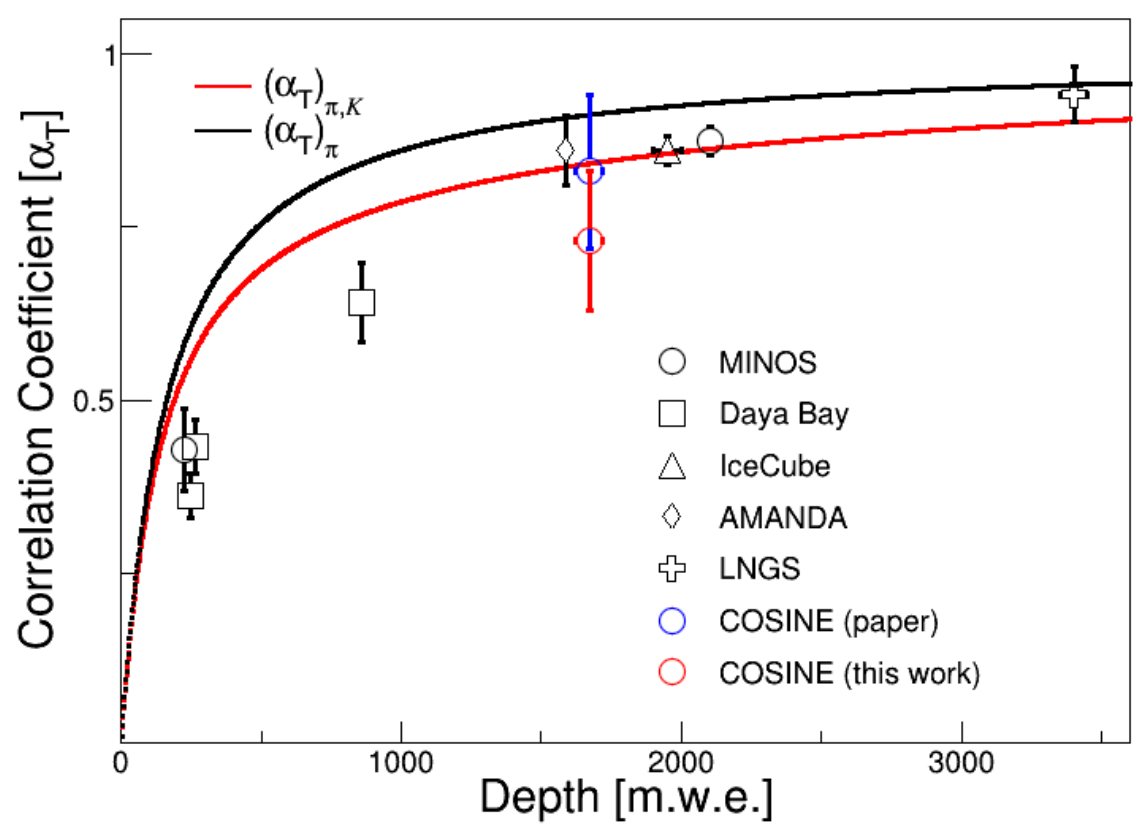

Figura 4.19: Medida de valores de $\alpha_{T}$ em função da profundidade equivalente de vários experimentos. A linha vermelha apresenta a predição teórica para produção de múons por píons e káons com razão de káons/píons listada na Tabela 4.5. A linha preta apresenta a predição teórica no caso em que ocorre apenas decaimento de múons por píons.

Podemos concluir que há uma correlação entre a temperatura efetiva e a taxa diária de múons observada no experimento COSINE-100.

De modo geral, as informações referentes ao fluxo diário, bem como sobre a modulação anual e sua correlação com a temperatura são para o uso em monitoramento de variáveis ambientais. Em um primeiro momento, a comparação com valores obtidos por outros experimentos demonstra que os resultados do COSINE-100 são coerentes. Além disso, qualquer desvio observado no monitoramento dessas variáveis pode indicar um problema em algum dos detectores ou um certo intervalo de dados que não devem ser usados em análises. Essas variações são observadas, em um primeiro momento, nos monitoramentos semanais e em análises adicionais realizadas de forma periódicas. 


\section{Capítulo 5}

\section{Considerações finais}

O experimento COSINE-100 utiliza cristais de $\mathrm{NaI}(\mathrm{Tl})$, está situado no túnel A5 do laboratório subterrâneo de Yangyang (Y2L), Coreia do Sul. Sua motivação é confirmar ou refutar a modulação anual observada por quase três décadas pelo experimento DAMA/LIBRA. A tomada de dados começou em setembro de 2016 e prossegue até o momento.

Os oito cristais, totalizando $106 \mathrm{~kg}$ de $\mathrm{NaI}(\mathrm{Tl})$ estão encapsulados e imersos em 2 toneladas de cintilador líquido, blindado por camadas de chumbo e cintiladores plásticos. Os cintiladores plásticos servem para a classificação e estudo de eventos relacionados a múons.

A sensibilidade do experimento é limitada aos fundos referentes aos decaimentos de materiais do detector, múons, eventos induzidos por múons bem como pelos fundos devido aos materiais cosmogênicos. Assim sendo, a contagem e monitoramento de múons é essencial para o bom funcionamento do experimento. Os eventos induzidos por múons podem produzir sinais na região de interesse na busca de matéria escura, afetando as análises físicas. Para evitar que isso ocorra, o DAQ irá classificar um evento como múon sempre que, em um intervalo de 192 ns, dois sinais sejam detectados em painéis plásticos diferentes. Os múons correspondem a eventos que possuem carga acima dos thresholds definidos e respeitam a diferença de tempo citada nos capítulos anteriores.

Com o passar do tempo, devido à degradação, as tensões e correntes das fotomultiplicadoras do detector de múons sofrem uma variação que a longo prazo pode interferir com a seleção de múons, rejeitando sinais proveniente de múons. Para evitar que isso aconteça, a correção de ganho é realizada no processamento dos dados dos detectores. Esse procedimento mantém a variação média do ganho das fotomultiplicadoras em $(0.03 \pm 0.02) \%$.

O fluxo diário de múons observada pelo experimento é de $327.8 \pm 0.2_{\text {stat }} \pm 9.6_{\text {sist }}$ múon $/ m^{2} /$ dia. Para o estudo da modulação sazonal dos múons, observamos uma amplitude de $(0.30 \pm 0.16) \%$ com relação à intensidade média dos múons que atravessam apenas os cintiladores plástico do topo e de baixo do experimento, com fase de $(170 \pm 15)$ dias. Usando 
informações sobre a temperatura atmosférica, a correlação entre a modulação dos múons e a temperatura foi estudada, encontrando um coeficiente efetivo $\alpha_{T}=0.73 \pm 0.10$. Esses resultados apresentados estão de acordo com resultados obtidos anteriormente e com os modelos teóricos utilizados.

O monitoramento do ganho, fluxo de múons, sua modulação anual, bem como a correlação com a variação anual da temperatura atmosférica continuaram para garantir a estabilidade do experimento. Além disso, outros estudos serão realizados. Por exemplo, podemos estudar os sinais nos cristais após a passagem de um múon no experimento em função do tempo. Os sinais que sejam coincidentes entre cristais e cintiladores plásticos podem ser usados no estudo de múons energéticos. Os eventos gerados nos cristais logo após a passagem do múon serão usados nos estudos de fosforescência induzida por múons.

Por fim, o COSINE-100 apresenta vantagens em relação a outros experimentos à base de cristais de $\mathrm{NaI}(\mathrm{Tl})$, como seu veto de cintilador líquido que permite buscas de partículas de matéria escura que se enquadrem em outros modelos, como iBDM (inelastic boosted dark matter), dark photons e áxions. A ampliação da quantidade de cristais na fase 2, COSINE-200, também será crucial no refinamento de análises futuras referentes à modulação anual. 


\section{Referências Bibliográficas}

[1] G. Bertone and D. Hooper, "History of dark matter," Reviews of Modern Physics, vol. 90, Oct 2018 .

[2] G. Bertone, D. Hooper, and J. Silk, "Particle dark matter: evidence, candidates and constraints," Physics Reports, vol. 405, p. 279-390, Jan 2005.

[3] C. MUÑOZ, "Dark matter detection in the light of recent experimental results," International Journal of Modern Physics A, vol. 19, p. 3093-3169, Jul 2004.

[4] J. Lavalle and P. Salati, "Dark matter indirect signatures," Comptes Rendus Physique, vol. 13, pp. 740-782, Jul 2012.

[5] T. Aaltonen and et. al, "Search for large extra dimensions in final states containing one photon or jet and large missing transverse energy produced in $p \bar{p}$ collisions at $\sqrt{s}=$ $1.96 \mathrm{TeV}, "$

[6] R. Bernabei et al., "New results from DAMA/LIBRA," Eur. Phys. J., vol. C67, pp. 39-49, 2010.

[7] E. Aprile, J. Aalbers, F. Agostini, M. Alfonsi, L. Althueser, F. Amaro, V. Antochi, E. Angelino, J. Angevaare, F. Arneodo, and et al., "Excess electronic recoil events in xenon1t," Physical Review D, vol. 102, Oct 2020.

[8] C. E. Aalseth, P. S. Barbeau, J. Colaresi, J. I. Collar, J. Diaz Leon, J. E. Fast, N. E. Fields, T. W. Hossbach, A. Knecht, M. S. Kos, and et al., "Cogent: A search for low-mass dark matter usingp-type point contact germanium detectors," Physical Review D, vol. 88, Jul 2013.

[9] C. collaboration, F. Petricca, G. Angloher, P. Bauer, A. Bento, C. Bucci, L. Canonica, X. Defay, A. Erb, F. v. Feilitzsch, N. F. Iachellini, P. Gorla, A. Gütlein, D. Hauff, J. Jochum, M. Kiefer, H. Kluck, H. Kraus, J. C. Lanfranchi, A. Lagenkämper, J. Loebell, M. Mancuso, E. Mondragon, A. Münster, C. Pagliarone, W. Potzel, F. Pröbst, R. Puig, 
F. Reindl, J. Rothe, K. Schäffner, J. Schieck, S. Schönert, W. Seidel, M. Stahlberg, L. Stodolsky, C. Strandhagen, R. Strauss, A. Tanzke, H. H. T. Thi, C. Türkoğlu, A. Ulrich, I. Usherov, S. Wawoczny, M. Willers, and M. Wüstrich, "First results on low-mass dark matter from the cresst-iii experiment," 2017.

[10] "An experiment to search for dark-matter interactions using sodium iodide detectors," $\mathrm{Na}$ ture, vol. 564, p. 83-86, Dec 2018.

[11] G. Adhikari, P. Adhikari, E. B. de Souza, N. Carlin, S. Choi, M. Djamal, A. Ezeribe, C. Ha, I. Hahn, E. Jeon, and et al., "Search for a dark matter-induced annual modulation signal in nai(tl) with the cosine-100 experiment," Physical Review Letters, vol. 123, Jul 2019.

[12] J. Amaré, S. Cebrián, I. Coarasa, C. Cuesta, E. García, M. Martínez, M. A. Oliván, Y. Ortigoza, A. O. de Solórzano, J. Puimedón, A. Salinas, M. L. Sarsa, P. Villar, and J. A. Villar, "First results on dark matter annual modulation from the anais-112 experiment," Phys. Rev. Lett., vol. 123, p. 031301, Jul 2019.

[13] J. H. Davis, "Fitting the annual modulation in dama with neutrons from muons and neutrinos," Physical Review Letters, vol. 113, Aug 2014.

[14] F. Zwicky, "Die Rotverschiebung von extragalaktischen Nebeln,” Helv. Phys. Acta, vol. 6, pp. 110-127, 1933.

[15] V. C. Rubin and W. K. Ford, Jr., "Rotation of the Andromeda Nebula from a Spectroscopic Survey of Emission Regions,” Astrophys. J., vol. 159, pp. 379-403, 1970.

[16] V. C. Rubin, J. Ford, W. K., and N. Thonnard, "Rotational properties of 21 SC galaxies with a large range of luminosities and radii, from NGC $4605(\mathrm{R}=4 \mathrm{kpc})$ to UGC 2885 (R=122kpc).,", vol. 238, pp. 471-487, Jun 1980.

[17] K. G. Begeman, A. H. Broeils, and R. H. Sanders, "Extended rotation curves of spiral galaxies : dark haloes and modified dynamics.,", vol. 249, p. 523, Apr. 1991.

[18] J. E. Taylor, "Dark matter halos from the inside out," Advances in Astronomy, vol. 2011, p. $1-17,2011$. 
[19] Y.-Y. Mao, L. E. Strigari, and R. H. Wechsler, "Connecting direct dark matter detection experiments to cosmologically motivated halo models," Physical Review D, vol. 89, Mar 2014.

[20] D. Clowe, M. Bradač, A. H. Gonzalez, M. Markevitch, S. W. Randall, C. Jones, and D. Zaritsky, "A direct empirical proof of the existence of dark matter," The Astrophysical Journal Letters, vol. 648, no. 2, p. L109, 2006.

[21] E. Komatsu, K. M. Smith, J. Dunkley, C. L. Bennett, B. Gold, G. Hinshaw, N. Jarosik, D. Larson, M. R. Nolta, L. Page, and et al., "Seven-yearwilkinson microwave anisotropy probe(wmap) observations: Cosmological interpretation," The Astrophysical Journal Supplement Series, vol. 192, p. 18, Jan 2011.

[22] N. Dalal and C. R. Keeton, "(Lack of) lensing constraints on cluster dark matter profiles," 122003.

[23] P. A. R. Ade, N. Aghanim, M. Arnaud, M. Ashdown, J. Aumont, C. Baccigalupi, A. J. Banday, R. B. Barreiro, J. G. Bartlett, and et al., "Planck2015 results," Astronomy Astrophysics, vol. 594, p. A13, Sep 2016.

[24] E. W. Kolb and M. S. Turner, The Early Universe, vol. 69. 1990.

[25] L. Bergström, "Non-baryonic dark matter: observational evidence and detection methods," Reports on Progress in Physics, vol. 63, p. 793-841, Apr 2000.

[26] K. Jedamzik, "Primordial black hole dark matter and the ligo/virgo observations," Journal of Cosmology and Astroparticle Physics, vol. 2020, p. 022-022, Sep 2020.

[27] D. Chung, L. Everett, G. Kane, S. King, J. Lykken, and L.-T. Wang, "The soft supersymmetry-breaking lagrangian: theory and applications," Physics Reports, vol. 407, no. 1 , pp. $1-203,2005$.

[28] P. Fayet, “Extra u(1)'s and new forces,” Nuclear Physics B, vol. 347, no. 3, pp. 743 - 768, 1990.

[29] S. Profumo, F. Queiroz, and C. Siqueira, "Has ams-02 observed two-component dark matter?," 2019. 
[30] V. Barger, W.-Y. Keung, D. Marfatia, and G. Shaughnessy, "Pamela and dark matter," Physics Letters B, vol. 672, p. 141-146, Feb 2009.

[31] "Dark matter in the ATIC," Physics World, vol. 22, pp. 4-4, jan 2009.

[32] S. Baur, "Dark matter searches with the icecube upgrade," 2019.

[33] X. Bertou, "The andes deep underground laboratory," 2013.

[34] K.-J. Kang, J.-P. Cheng, J. Li, Y.-J. Li, Q. Yue, Y. Bai, Y. Bi, J.-P. Chang, N. Chen, and et al., "Introduction to the cdex experiment," Frontiers of Physics, vol. 8, p. 412-437, Aug 2013.

[35] R. Agnese, T. Aramaki, I. Arnquist, W. Baker, D. Balakishiyeva, S. Banik, D. Barker, R. Basu Thakur, D. Bauer, T. Binder, and et al., "Results from the super cryogenic dark matter search experiment at soudan,” Physical Review Letters, vol. 120, Feb 2018.

[36] G. Adhikari, P. Adhikari, E. B. de Souza, N. Carlin, S. Choi, W. Q. Choi, M. Djamal, A. C. Ezeribe, C. Ha, I. S. Hahn, and et al., "Initial performance of the cosine-100 experiment," The European Physical Journal C, vol. 78, Feb 2018.

[37] A. Aguilar-Arevalo, D. Amidei, X. Bertou, M. Butner, G. Cancelo, A. Castañeda Vázquez, B. Cervantes Vergara, A. Chavarria, C. Chavez, J. de Mello Neto, and et al., "Search for low-mass wimps in a $0.6 \mathrm{~kg}$ day exposure of the damic experiment at snolab," Physical Review D, vol. 94, Oct 2016.

[38] R. Bernabei et al., "First model independent results from DAMA/LIBRA-phase2," Nucl. Phys. Atom. Energy, vol. 19, no. 4, pp. 307-325, 2018.

[39] P. Agnes, T. Alexander, A. Alton, K. Arisaka, H. Back, B. Baldin, K. Biery, G. Bonfini, M. Bossa, A. Brigatti, and et al., "First results from the darkside-50 dark matter experiment at laboratori nazionali del gran sasso," Physics Letters B, vol. 743, p. 456-466, Apr 2015.

[40] M. Kuźniak, P.-A. Amaudruz, M. Batygov, B. Beltran, J. Bonatt, M. Boulay, B. Broerman, J. Bueno, A. Butcher, B. Cai, and et al., "Deap-3600 dark matter search,” Nuclear and Particle Physics Proceedings, vol. 273-275, p. 340-346, Apr 2016.

[41] J. Jo, "Results from the dm-ice17 dark matter experiment at the south pole," Proceedings of 38th International Conference on High Energy Physics — PoS(ICHEP2016), Feb 2017. 
[42] V. Sanglard, A. Benoit, L. Bergé, J. Blümer, A. Broniatowski, B. Censier, L. Chabert, M. Chapellier, G. Chardin, P. Charvin, S. Collin, M. De Jésus, H. Deschamps, P. Di Stefano, Y. Dolgorouky, D. Drain, L. Dumoulin, K. Eitel, M. Fesquet, S. Fiorucci, J. Gascon, E. Gerlic, G. Gerbier, C. Goldbach, M. Goyot, M. Gros, S. Hervé, M. Horn, A. Juillard, M. Karolak, C. Kikuchi, A. de Lesquen, M. Luca, J. Mallet, S. Marnieros, L. Mosca, X.F. Navick, G. Nollez, P. Pari, L. Schoeffel, M. Stern, L. Vagneron, and V. Villar, "Final results of the edelweiss-i dark matter search with cryogenic heat-and-ionization ge detectors," Phys. Rev. D, vol. 71, p. 122002, Jun 2005.

[43] D. Akerib, S. Alsum, H. Araújo, X. Bai, A. Bailey, J. Balajthy, P. Beltrame, E. Bernard, A. Bernstein, T. Biesiadzinski, and et al., "Results from a search for dark matter in the complete lux exposure," Physical Review Letters, vol. 118, Jan 2017.

[44] B. Ahmed, "The naiad experiment for wimp searches at boulby mine and recent results," Astroparticle Physics, vol. 19, p. 691-702, Sep 2003.

[45] M. Xiao, X. Xiao, L. Zhao, X. Cao, X. Chen, Y. Chen, X. Cui, D. Fang, C. Fu, and et al., "First dark matter search results from the pandax-i experiment," Science China Physics, Mechanics Astronomy, vol. 57, p. 2024-2030, Sep 2014.

[46] M. Antonello et al., "The SABRE project and the SABRE Proof-of-Principle," Eur. Phys. J. C, vol. 79, no. 4, p. 363, 2019.

[47] Z. Ahmed, D. S. Akerib, S. Arrenberg, C. N. Bailey, D. Balakishiyeva, L. Baudis, D. A. Bauer, P. L. Brink, T. Bruch, R. Bunker, and et al., "Results from a low-energy analysis of the cdms ii germanium data," Physical Review Letters, vol. 106, Mar 2011.

[48] F. Froborg and A. R. Duffy, "Annual modulation in direct dark matter searches," Journal of Physics G: Nuclear and Particle Physics, vol. 47, p. 094002, jul 2020.

[49] C. Arina, E. Del Nobile, and P. Panci, "Dark matter with pseudoscalar-mediated interactions explains the dama signal and the galactic center excess," Phys. Rev. Lett., vol. 114, p. 011301, Jan 2015.

[50] G. Jungman, M. Kamionkowski, and K. Griest, "Supersymmetric dark matter," Physics Reports, vol. 267, no. 5, pp. 195 - 373, 1996. 
[51] L. Baudis, "Direct dark matter detection: The next decade," Physics of the Dark Universe, vol. 1, p. 94-108, Nov 2012.

[52] M. W. Goodman and E. Witten, "Detectability of certain dark-matter candidates," Phys. Rev. D, vol. 31, pp. 3059-3063, Jun 1985.

[53] N. Wolchover and s. Quanta Magazine moderates comments tonbsp;facilitate an informed, "Trouble detected in infamous dark matter signal."

[54] K. Freese, M. Lisanti, and C. Savage, "Colloquium: Annual modulation of dark matter," Rev. Mod. Phys., vol. 85, pp. 1561-1581, Nov 2013.

[55] M. Yeh, A. Garnov, and R. L. Hahn, "Gadolinium-loaded liquid scintillator for highprecision measurements of antineutrino oscillations and the mixing angle, Theta(13)," Nucl. Instrum. Meth. A, vol. 578, pp. 329-339, 2007.

[56] J. Park, P. Adhikari, G. Adhikari, S. Oh, N. Kim, Y. Kim, C. Ha, K. Park, H. Lee, and E. Jeon, "Performance of a prototype active veto system using liquid scintillator for a dark matter search experiment," Nucl. Instrum. Meth. A, vol. 851, pp. 103-107, 2017.

[57] H. Prihtiadi, G. Adhikari, P. Adhikari, E. B. de Souza, N. Carlin, S. Choi, W. Choi, M. Djamal, A. Ezeribe, C. Ha, and et al., "Muon detector for the cosine-100 experiment," Journal of Instrumentation, vol. 13, p. T02007-T02007, Feb 2018.

[58] G. Adhikari, P. Adhikari, E. B. de Souza, N. Carlin, S. Choi, W. Choi, M. Djamal, A. Ezeribe, C. Ha, I. Hahn, and et al., "The cosine-100 data acquisition system," Journal of Instrumentation, vol. 13, p. P09006-P09006, Sep 2018.

[59] K. Kim, W. Kang, S. Oh, P. Adhikari, J. So, N. Kim, H. Lee, S. Choi, I. Hahn, E. Jeon, and et al., "Tests on nai(tl) crystals for wimp search at the yangyang underground laboratory," Astroparticle Physics, vol. 62, p. 249-257, Mar 2015.

[60] J. Cherwinka, D. Grant, F. Halzen, K. Heeger, L. Hsu, A. Hubbard, A. Karle, M. Kauer, V. Kudryavtsev, K. Lim, and et al., "Measurement of muon annual modulation and muoninduced phosphorescence in nai(tl) crystals with dm-ice17," Physical Review D, vol. 93, Feb 2016.

[61] T. K. Gaisser, Cosmic rays and particle physics. 1990. 
[62] K. Olive, "Review of particle physics," Chinese Physics C, vol. 40, p. 100001, oct 2016.

[63] G. Bellini, J. Benziger, D. Bick, G. Bonfini, D. Bravo, M. B. Avanzini, B. Caccianiga, L. Cadonati, F. Calaprice, C. Carraro, and et al., "Cosmic-muon flux and annual modulation in borexino at $3800 \mathrm{~m}$ water-equivalent depth," Journal of Cosmology and Astroparticle Physics, vol. 2012, p. 015-015, May 2012.

[64] J. Cherwinka, D. Grant, F. Halzen, K. M. Heeger, L. Hsu, A. J. F. Hubbard, A. Karle, M. Kauer, V. A. Kudryavtsev, C. Macdonald, R. H. Maruyama, S. Paling, W. Pettus, Z. P. Pierpoint, B. N. Reilly, M. Robinson, P. Sandstrom, N. J. C. Spooner, S. Telfer, and L. Yang, "First data from dm-ice17," Phys. Rev. D, vol. 90, p. 092005, Nov 2014.

[65] E. Barbosa de Souza, J. Cherwinka, A. Cole, A. Ezeribe, D. Grant, F. Halzen, K. Heeger, L. Hsu, A. Hubbard, J. Jo, and et al., "First search for a dark matter annual modulation signal with nai(tl) in the southern hemisphere by dm-ice17," Physical Review D, vol. 95, Feb 2017.

[66] A. C. Fauth, A. C. Grover, and D. M. Consalter, "Medida da vida média do múon," Revista Brasileira de Ensino de Física, vol. 32, pp. 4502-1 - 4502-7, 122010.

[67] S. Ahmed, Physics and Engineering of Radiation Detection. Elsevier Science, 2007.

[68] M. Tanabashi and e. a. Hagiwara, "Review of particle physics," Phys. Rev. D, vol. 98, p. 030001, Aug 2018.

[69] V. Hess, "On the observations of the penetrating radiation during seven balloon flights," 2018.

[70] P. D. Group, P. A. Zyla, R. M. Barnett, J. Beringer, O. Dahl, D. A. Dwyer, D. E. Groom, C. J. Lin, K. S. Lugovsky, E. Pianori, D. J. Robinson, C. G. Wohl, W. M. Yao, K. Agashe, G. Aielli, B. C. Allanach, C. Amsler, M. Antonelli, E. C. Aschenauer, D. M. Asner, H. Baer, S. Banerjee, L. Baudis, C. W. Bauer, J. J. Beatty, V. I. Belousov, S. Bethke, A. Bettini, O. Biebel, K. M. Black, E. Blucher, O. Buchmuller, V. Burkert, M. A. Bychkov, R. N. Cahn, M. Carena, A. Ceccucci, A. Cerri, D. Chakraborty, R. S. Chivukula, G. Cowan, G. D’Ambrosio, T. Damour, D. de Florian, A. de Gouvêa, T. DeGrand, P. de Jong, G. Dissertori, B. A. Dobrescu, M. D’Onofrio, M. Doser, M. Drees, H. K. Dreiner, P. Eerola, U. Egede, S. Eidelman, J. Ellis, J. Erler, V. V. Ezhela, W. Fetscher, 
B. D. Fields, B. Foster, A. Freitas, H. Gallagher, L. Garren, H. J. Gerber, G. Gerbier, T. Gershon, Y. Gershtein, T. Gherghetta, A. A. Godizov, M. C. Gonzalez-Garcia, M. Goodman, C. Grab, A. V. Gritsan, C. Grojean, M. Grünewald, A. Gurtu, T. Gutsche, H. E. Haber, C. Hanhart, S. Hashimoto, Y. Hayato, A. Hebecker, S. Heinemeyer, B. Heltsley, J. J. Hernández-Rey, K. Hikasa, J. Hisano, A. Höcker, J. Holder, A. Holtkamp, J. Huston, T. Hyodo, K. F. Johnson, M. Kado, M. Karliner, U. F. Katz, M. Kenzie, V. A. Khoze, S. R. Klein, E. Klempt, R. V. Kowalewski, F. Krauss, M. Kreps, B. Krusche, Y. Kwon, O. Lahav, J. Laiho, L. P. Lellouch, J. Lesgourgues, A. R. Liddle, Z. Ligeti, C. Lippmann, T. M. Liss, L. Littenberg, C. Lourengo, S. B. Lugovsky, A. Lusiani, Y. Makida, F. Maltoni, T. Mannel, A. V. Manohar, W. J. Marciano, A. Masoni, J. Matthews, U. G. Meißner, M. Mikhasenko, D. J. Miller, D. Milstead, R. E. Mitchell, K. Mönig, P. Molaro, F. Moortgat, M. Moskovic, K. Nakamura, M. Narain, P. Nason, S. Navas, M. Neubert, P. Nevski, Y. Nir, K. A. Olive, C. Patrignani, J. A. Peacock, S. T. Petcov, V. A. Petrov, A. Pich, A. Piepke, A. Pomarol, S. Profumo, A. Quadt, K. Rabbertz, J. Rademacker, G. Raffelt, H. Ramani, M. RamseyMusolf, B. N. Ratcliff, P. Richardson, A. Ringwald, S. Roesler, S. Rolli, A. Romaniouk, L. J. Rosenberg, J. L. Rosner, G. Rybka, M. Ryskin, R. A. Ryutin, Y. Sakai, G. P. Salam, S. Sarkar, F. Sauli, O. Schneider, K. Scholberg, A. J. Schwartz, J. Schwiening, D. Scott, V. Sharma, S. R. Sharpe, T. Shutt, M. Silari, T. Sjöstrand, P. Skands, T. Skwarnicki, G. F. Smoot, A. Soffer, M. S. Sozzi, S. Spanier, C. Spiering, A. Stahl, S. L. Stone, Y. Sumino, T. Sumiyoshi, M. J. Syphers, F. Takahashi, M. Tanabashi, J. Tanaka, M. Taševský, K. Terashi, J. Terning, U. Thoma, R. S. Thorne, L. Tiator, M. Titov, N. P. Tkachenko, D. R. Tovey, K. Trabelsi, P. Urquijo, G. Valencia, R. Van de Water, N. Varelas, G. Venanzoni, L. Verde, M. G. Vincter, P. Vogel, W. Vogelsang, A. Vogt, V. Vorobyev, S. P. Wakely, W. Walkowiak, C. W. Walter, D. Wands, M. O. Wascko, D. H. Weinberg, E. J. Weinberg, M. White, L. R. Wiencke, S. Willocq, C. L. Woody, R. L. Workman, M. Yokoyama, R. Yoshida, G. Zanderighi, G. P. Zeller, O. V. Zenin, R. Y. Zhu, S. L. Zhu, F. Zimmermann, J. Anderson, T. Basaglia, V. S. Lugovsky, P. Schaffner, and W. Zheng, "Review of Particle Physics," Progress of Theoretical and Experimental Physics, vol. 2020, 08 2020. 083C01.

[71] E. V. Bugaev, A. Misaki, V. A. Naumov, T. S. Sinegovskaya, S. I. Sinegovsky, and N. Takahashi, "Atmospheric muon flux at sea level, underground, and underwater," Physical Review D, vol. 58, Jul 1998.

[72] M. MARUCHO, C. A. GARCIA CANAL, and H. FANCHIOTTI, “The landau distribution 
for charged particles traversing thin films," International Journal of Modern Physics C, vol. 17, p. 1461-1476, Oct 2006.

[73] H. Prihtiadi, G. Adhikari, E. B. de Souza, N. Carlin, J. J. Choi, S. Choi, M. Djamal, A. C. Ezeribe, L. E. França, C. Ha, I. S. Hahn, E. J. Jeon, J. H. Jo, W. G. Kang, M. Kauer, H. Kim, H. J. Kim, K. W. Kim, S. K. Kim, Y. D. Kim, Y. H. Kim, Y. J. Ko, E. K. Lee, H. S. Lee, J. Lee, J. Y. Lee, M. H. Lee, S. H. Lee, D. S. Leonard, B. B. Manzato, R. H. Maruyama, R. J. Neal, S. L. Olsen, B. J. Park, H. K. Park, H. S. Park, K. S. Park, R. L. C. Pitta, S. J. Ra, C. Rott, K. A. Shin, A. Scraff, N. J. C. Spooner, W. G. Thompson, L. Yang, and G. H. Yu, "Measurement of the cosmic muon annual and diurnal flux variation with the cosine-100 detector," 2020.

[74] L. Y.-J. "ZHU Jing-Jun", "KANG Ke-Jun", "Study on the muon background in the underground laboratory of kims," High Energy Physics and Nuclear Physics, vol. 29, no. 8, pp. 721-726, 2005.

[75] D.-M. Mei and A. Hime, "Muon-induced background study for underground laboratories," Physical Review D, vol. 73, Mar 2006.

[76] K. Olive, "Review of particle physics," Chinese Physics C, vol. 38, p. 090001, aug 2014.

[77] Z. uo, S. hen, z. wang, M. Yeh, L. Wan, Y. Liang, B. Xu, W. LUO, L. Zhao, W. Dou, and et al., "Muon flux measurement at china jinping underground laboratory," Chinese Physics C, Nov 2020.

[78] P. H. Barrett, L. M. Bollinger, G. Cocconi, Y. Eisenberg, and K. Greisen, "Interpretation of cosmic-ray measurements far underground," Rev. Mod. Phys., vol. 24, pp. 133-178, Jul 1952.

[79] P. Adamson, C. Andreopoulos, K. E. Arms, R. Armstrong, D. J. Auty, D. S. Ayres, C. Backhouse, J. Barnett, G. Barr, W. L. Barrett, B. R. Becker, M. Bishai, A. Blake, B. Bock, G. J. Bock, D. J. Boehnlein, D. Bogert, C. Bower, S. Cavanaugh, J. D. Chapman, D. Cherdack, S. Childress, B. C. Choudhary, J. H. Cobb, S. J. Coleman, D. CroninHennessy, A. J. Culling, I. Z. Danko, J. K. de Jong, N. E. Devenish, M. V. Diwan, M. Dorman, C. O. Escobar, J. J. Evans, E. Falk, G. J. Feldman, T. H. Fields, M. V. Frohne, H. R. Gallagher, A. Godley, M. C. Goodman, P. Gouffon, R. Gran, E. W. Grashorn, K. Grzelak, 
A. Habig, D. Harris, P. G. Harris, J. Hartnell, R. Hatcher, K. Heller, A. Himmel, A. Holin, J. Hylen, G. M. Irwin, Z. Isvan, D. E. Jaffe, C. James, D. Jensen, T. Kafka, S. M. S. Kasahara, G. Koizumi, S. Kopp, M. Kordosky, K. Korman, D. J. Koskinen, Z. Krahn, A. Kreymer, K. Lang, J. Ling, P. J. Litchfield, L. Loiacono, P. Lucas, J. Ma, W. A. Mann, M. L. Marshak, J. S. Marshall, N. Mayer, A. M. McGowan, R. Mehdiyev, J. R. Meier, M. D. Messier, C. J. Metelko, D. G. Michael, W. H. Miller, S. R. Mishra, J. Mitchell, C. D. Moore, J. Morfín, L. Mualem, S. Mufson, J. Musser, D. Naples, J. K. Nelson, H. B. Newman, R. J. Nichol, T. C. Nicholls, J. P. Ochoa-Ricoux, W. P. Oliver, T. Osiecki, R. Ospanov, S. Osprey, J. Paley, R. B. Patterson, T. Patzak, G. Pawloski, G. F. Pearce, E. A. Peterson, R. Pittam, R. K. Plunkett, A. Rahaman, R. A. Rameika, T. M. Raufer, B. Rebel, J. Reichenbacher, P. A. Rodrigues, C. Rosenfeld, H. A. Rubin, V. A. Ryabov, M. C. Sanchez, N. Saoulidou, J. Schneps, P. Schreiner, P. Shanahan, W. Smart, C. Smith, A. Sousa, B. Speakman, P. Stamoulis, M. Strait, N. Tagg, R. L. Talaga, J. Thomas, M. A. Thomson, J. L. Thron, G. Tinti, R. Toner, V. A. Tsarev, G. Tzanakos, J. Urheim, P. Vahle, B. Viren, M. Watabe, A. Weber, R. C. Webb, N. West, C. White, L. Whitehead, S. G. Wojcicki, D. M. Wright, T. Yang, M. Zois, K. Zhang, and R. Zwaska, “Observation of muon intensity variations by season with the minos far detector," Phys. Rev. D, vol. 81, p. 012001, Jan 2010.

[80] M. Ambrosio, R. Antolini, G. Auriemma, R. Baker, A. Baldini, G. Barbarino, B. Barish, G. Battistoni, R. Bellotti, C. Bemporad, P. Bernardini, H. Bilokon, V. Bisi, C. Bloise, T. Bosio, C. Bower, S. Bussino, F. Cafagna, M. Calicchio, D. Campana, M. Carboni, M. Castellano, S. Cecchini, F. Cei, V. Chiarella, A. Corona, S. Coutu, L. De Benedictis, G. De Cataldo, H. Dekhissi, C. De Marzo, I. De Mitri, M. De Vincenzi, A. Di Credico, O. Erriquez, R. Fantini, C. Favuzzi, C. Forti, P. Fusco, G. Giacomelli, G. Giannini, N. Giglietto, M. Goretti, M. Grassi, P. Green, A. Grillo, F. Guarino, P. Guarnaccia, C. Gustavino, A. Habig, K. Hanson, A. Hawthorne, R. Heinz, J. Hong, E. Iarocci, E. Katsavounidis, E. Kearns, S. Kyriazopoulou, E. Lamanna, C. Lane, D. Levin, P. Lipari, G. Liu, R. Liu, N. Longley, M. Longo, G. Ludlam, F. Maaroufi, G. Mancarella, G. Mandrioli, A. Margiotta-Neri, A. Marini, D. Martello, A. Marzari-Chiesa, M. Mazziotta, D. Michael, S. Mikheyev, L. Miller, P. Monacelli, T. Montaruli, M. Monteno, S. Mufson, J. Musser, D. Nicoló, R. Nolty, C. Okada, C. Orth, G. Osteria, S. Paganini, O. Palamara, S. Parlati, V. Patera, L. Patrizii, R. Pazzi, C. Peck, S. Petrera, N. Pignatano, P. Pistilli, V. Popa, 
A. Rainó, J. Reynoldson, F. Ronga, U. Rubizzo, A. Sanzgiri, F. Sartogo, C. Satriano, L. Satta, E. Scapparone, K. Scholberg, A. Sciubba, P. Serra-Lugaresi, M. Severi, M. Sitta, P. Spinelli, M. Spinetti, M. Spurio, R. Steinberg, J. Stone, L. Sulak, A. Surdo, G. Tarlé, V. Togo, V. Valente, C. Walter, and R. Webb, "Seasonal variations in the underground muon intensity as seen by macro," Astroparticle Physics, vol. 7, no. 1, pp. $109-124$, 1997.

[81] M. Agostini, K. Altenmüller, S. Appel, V. Atroshchenko, Z. Bagdasarian, D. Basilico, G. Bellini, J. Benziger, D. Bick, I. Bolognino, and et al., "Modulations of the cosmic muon signal in ten years of borexino data," Journal of Cosmology and Astroparticle Physics, vol. 2019, p. 046-046, Feb 2019. 